\title{
Taxonomy of Micronectidae (Heteroptera: Nepomorpha) from Vietnam, with descriptions of 11 new species
}

\author{
Tuyet Ngan HA ${ }^{1}$ \& Anh Duc TRAN ${ }^{\text {2,** }}$ \\ ${ }^{1,2}$ Faculty of Biology, VNU University of Science, Vietnam National University, Hanoi, \\ 334 Nguyen Trai, Thanh Xuan, Hanoi, Vietnam. \\ *Corresponding author: tran.anhduc@hus.edu.vn \\ 1Email: hatuyetngan95@gmail.com \\ ${ }^{1}$ urn:1sid:zoobank.org:author:568A022B-D36D-4147-8B0D-FB35B2A4D197 \\ ${ }^{2}$ urn:lsid:zoobank.org:author:3CB36F17-D917-4600-B888-C33B1C04259F
}

\begin{abstract}
The taxonomy of Micronectidae in Vietnam is reviewed. Based on our cumulative collections during 2001-2020, 11 new species of Micronecta Kirkaldy, 1897 are documented and described in this study: M. acuminata sp. nov., M. arcuata sp. nov., M. caperata sp. nov., M. clavata sp. nov., M. cultellata sp. nov., M. fulvopicta sp. nov., M. nieseri sp. nov., M. pingae sp. nov., M. sinuata sp. nov., M. undulata sp. nov., and M. vietnamica sp. nov. Nine species are recorded from Vietnam for the first time: M. decorata Lundblad, 1933, M. drepani Nieser, 2000, M. erythra Nieser, Chen \& Yang, 2005, M. fugitans Breddin, 1905, M. johorensis Fernando, 1964, M. melanochroa Nieser, Chen \& Yang, 2005, M. ornitheia Nieser, Chen \& Yang, 2005, M. sahlbergi (Jakovlev, 1881), and M. tuwanoni Nieser, Chen, Leksawasdi, Thanyakam \& Duangsupa, 2004. Thus, in this study, two genera and 37 species of Micronectidae are now reported from Vietnam: Synaptonecta Lundblad, 1933 with only one species, S. issa (Distant, 1910), and Micronecta with 36 species. A key to all species occurring in Vietnam, subgeneric diagnoses, and a key to all current subgenera of Micronecta are provided.
\end{abstract}

Keywords. Nepomorpha, Micronecta, taxonomy, new species, Vietnam.

Ha T.N. \& Tran A.D. 2021. Taxonomy of Micronectidae (Heteroptera: Nepomorpha) from Vietnam, with descriptions of 11 new species. European Journal of Taxonomy 756: 1-82. https://doi.org/10.5852/ejt.2021.756.1407

\section{Introduction}

Species of Micronectidae Jaczewski, 1924 (Heteroptera Latreille, 1810: Nepomorpha Popov, 1968) are water bugs, with small body sizes (length $0.8-5.0 \mathrm{~mm}$ ) and oar-like hind legs; thus, they are commonly referred to as pygmy water boatmen. Most species inhabit standing waters, especially at the bottoms of shallow ponds and lakes, or in vegetation bordering flowing water bodies. They are chiefly freshwater, although some common species, such as Micronecta quadristrigata Breddin, 1905 and M. lundibunda Breddin, 1905, are also found in brackish waters (Cheng 1976; pers. obs.). They are strong fliers, thus they can inhabit temporary water bodies, e.g., paddy fields, drains, and outdoor aquaria. 
Micronectidae belongs to the superfamily Corixoidea Leach, 1815, which consists of three families, Corixidae Leach, 1815, Micronectidae, and Diaprepocoridae Lundblad, 1928. The Diaprepocoridae occurs only in Australia and New Zealand, whereas the Corixidae is widely distributed in temperate regions, and the Micronectidae occurs commonly throughout tropical regions (Chen et al. 2005). In Southeast Asia, species of Micronectidae are more common than those of Corixidae. Due to many structural similarities with Corixidae, Micronectidae was originally established as a subfamily of Corixidae by Jaczewski (1924). This subfamily status was accepted by most subsequent entomologists, although some already considered this taxon as a separate family (see Nieser \& Chen 1999; Nieser $2002 b$ ). Nieser (2002b) pointed out key characters to support the distinction between Corixidae and Micronectidae, and this classification has been largely adopted in subsequent studies (e.g., Tinerella 2008, 2013; Chen et al. 2015). Popov (2014), based on fossil evidence, argued that Micronectidae and Diaprepocoridae should be treated as subfamilies of Corixidae. However, his assessment lacked a morphological cladistic analysis that includes both fossil and extant taxa. On the other hand, recent molecular phylogenetic analyses of Nepomorpha, which included several ingroup taxa of Corixidae, Micronectidae and Diaprepocoridae, support that each family forms a distinct clade, and the superfamily Corixoidea is monophyletic (see Ye et al. 2019; Wang et al. 2020). Considering these phylogenetic analyses and distinct morphological characteristics, we adopt the idea to classify Corixidae, Micronectidae, and Diaprepocoridae at family level.

Currently, Micronectidae is classified into two subfamilies, Micronectinae Jaczewski, 1924 and Synaptogobiinae Nieser \& Chen, 2006. Micronectinae contains six genera. Among these, Micronecta Kirkaldy, 1897 is the most widespread genus, occurring in the Eastern Hemisphere. Synaptonecta Lundblad, 1933 is probably less common, but is also widely distributed in Asia. The four remaining genera of Micronectinae have a more restricted distribution, namely Austronecta Tinerella, 2013 (endemic to Australia), Monogobia Nieser \& Chen, 2006 (South America), Papuanecta Tinerella, 2008 (endemic to New Guinea), and Tenagobia Bergroth, 1899 (Central and South America). Nieser \& Chen (2006) established the new subfamily Synaptogobiinae from South America, which contains only one genus, Synaptogobia Nieser \& Chen, 2006 with two species.

The taxonomy of the micronectid fauna of Asia has been based on the initial works by Lundblad (1933b) and Hutchinson (1940). Wróblewski, in the period from 1962 to 1972, provided significant additional contributions to the classification of Asian Micronecta. Recent regional taxonomic reviews include the works by Nieser $(2000,2002 b)$ on the fauna of Thailand and Southeast Asia, Nieser et al. (2005) on the fauna of Yunnan (China), Tinerella $(2008,2013)$ on the fauna of New Guinea, Oceania, and Australia, and Chen et al. (2015) on the fauna of Borneo.

The micronectid fauna of Vietnam was initially studied by Wróblewski during 1962-1972, and his works are still the most complete research on this family up to now. He reported and described 16 species from Vietnam (mostly from the northern area), including M. altera Wróblewski, 1972, M. anatolica Lindberg, 1922, M. desertana Distant, 1920, M. guttatostriata Lundblad, 1933, M. jaczewskii Wróblewski, 1962, M. khasiensis Hutchinson, 1940, M. ludibunda Breddin, 1905, M. pocsi Wróblewski, 1967, M. punctata (Fieber, 1844) [= M. haliploides Horváth, 1904], M. quadristrigata, M. scutellaris Stål, 1858, M. sedula Horváth, 1905, M. siva (Kirkaldy, 1897), M. tarsalis Chen, 1960, M. thyesta Distant, 1911 [= M. grisea (Fieber, 1844)], and Synaptonecta issa (Distant, 1910). Nieser (2000) described one more new species for Vietnam, M. polhemusi Nieser, 2000. Thus, prior to the present study, Wróblewski $(1962,1967$, 1972a) and Nieser (2000) recorded a total of 17 micronectid species from Vietnam. Our current study, based on samples collected throughout Vietnam in the period from 2001 to 2020, revealed that the micronectid fauna of Vietnam was still inadequately explored, as a large number of new species and first country records were discovered. 
The present paper reports our synthetic taxonomic results of the Vietnamese fauna of the Micronectidae. It includes diagnoses of taxa occurring in the country, a key to species, and descriptions of 11 new species. It also reports nine species as first records for Vietnam. Thus, the total number of micronetid species found in Vietnam is now 37, more than doubling the previous total.

\title{
Material and methods
}

Specimens examined in the present study are mostly of the macropterous morph. Specimens of the brachypterous morph, when present, are specified in the respective samples in the Material examined sections. Measurements of body length, body width, and head width were based on 10 intact specimens of each sex (in cases where there were fewer than 10 specimens of each sex, all intact specimens were measured). Body length refers to the maximum size on the longitudinal axis of the body and was measured from the anterior point of the head to the posterior point of the hemelytra in dorsal view. Body width refers to the maximum size on the vertical axis of the body. Head width is the maxiumum width of the head across eyes in dorsal view. The synthlipsis is the smallest distance between the eyes in dorsal view. Leg segments were measured in ventral view. All measurements are given in millimetres. When measurements are not given as a range, they refer to the holotype (in descriptions of males for new species) or a randomly selected specimen. Morphological terminology is chiefly based on Chen et al. (2015) and Tinerella (2013).

Specimens and their structures were examined under an Olympus SZX7 stereo microscope, and an Axiostar Plus compound microscope. Microscopic slides of male genitalia were fixed using Canada balsam. Habitus photos of each specimen were taken at different focus distances with a Nikon D300 DSLR camera, with a $180 \mathrm{~mm}$ lens attached to a reversed $50 \mathrm{~mm}$ lens via a coupling ring. Photos were then stacked using Zerene Stacker and processed using Adobe Photoshop CS3.

\section{Specimens are deposited in the following collections:}

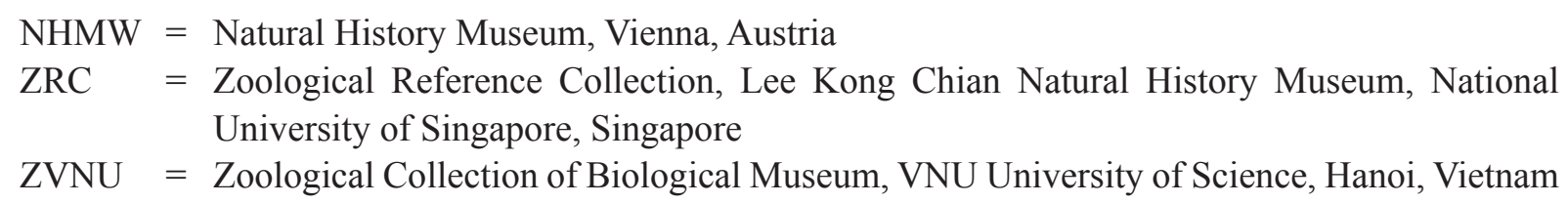

\section{Abbreviations used in Material examined sections:}

a.s.l. = above sea level

N.P. $=$ National Park

Prov. $=$ Province

\section{Results}

\author{
Class Insecta Linnaeus, 1758 \\ Order Hemiptera Linnaeus, 1758 \\ Suborder Heteroptera Latreille, 1810 \\ Infraorder Nepomorpha Popov, 1968 \\ Superfamily Corixoidea Leach, 1815 \\ Family Micronectidae Jaczewski, 1924
}

Genus Micronecta Kirkaldy, 1897

Micronecta Kirkaldy, 1897b: 260 (type species: Notonecta minutissima Linnaeus, 1758). 


\section{Comparative notes}

In Southeast Asia, only two genera of Micronectidae occur: Micronecta Kirkaldy, 1897 and Synaptonecta Lundblad, 1933. They are closely related, but there are significant structural differences between the two genera, as summarised by Wróblewski (1972a), Nieser (2002b), and Chen et al. (2005).

The genus Micronecta can be recgonised by the following characterstics: the vertex is usually convex and rarely flattened; the pronotum is usually well-developed and convex; fore tibia and pala of the male are separated; the strigil on abdominal tergite VI is usually present; the apex of the membrane in the brachypterous morph is truncate or broadly rounded. The body of species of Micronecta is ovate or subparallel sided, with length between 1.0 and $4.4 \mathrm{~mm}$.

In contrast, Synaptonecta can easily be separated from the abundant Micronecta by the fusion of the fore tibia and pala in both sexes, the concave vertex, and the pointed apex of the membrane in the brachypterous morph (also see Wróblewski 1972a; Chen et al. 2005). The body of species of Synaptonecta is ovate, with length between 1.8 and $2.6 \mathrm{~mm}$.

\section{Remarks on the current subgeneric classification of Micronecta Kirkaldy, 1897}

Several subgenera of Micronecta were established by Hutchinson (1940) and Wróblewski (1962, 1967). Hutchinson (1940) also introduced several species groups of Micronecta, recognised below the subgeneric rank, but this species group classification was hardly used by subsequent entomologists. However, many species were not formally assigned to any subgenera because they did not fit the definition of any subgenus (Štys \& Jansson 1988; Nieser 2000; Tinerella 2008, 2013). In many cases, those species which do not fit any subgenus were just placed, although tentatively, into the nominate subgenus Micronecta (see Jansson 1995). This classification scheme was questioned by Tinerella (2008, $2013)$, but no resolution was made. Tinerella $(2008,2013)$ only attempted to reconstruct phylogenetic relationships between micronectid genera occurring in New Guinea and Oceania. Nieser $(2000,2002 b)$, and Nieser \& Chen (1999) refrained from using a subgeneric classification for the same reason, but subsquently Nieser et al. (2005) and Chen et al. (2015) used a subgeneric classification again, without clear explanation about the switch in their opinions. Nieser et al. (2005) even described a new subgenus, Unguinecta Nieser, Chen \& Yang, 2005, to include several species.

It is notable that several subgenera, e.g., Ctenonecta Wróblewski, 1962, Indonectella Hutchison, 1940, Lundbladella Wróblewski, 1967, and Pardanecta Wróblewski, 1962, were defined just based on only a few aberrant morphological features, which are potentially homoplasious (e.g., the shape of the palar claw of the male, the absence of a strigil in some subgenera, the shape of the free lobe of tergite VIII, or even the general morphology of the left paramere). On the other hand, the diversity of Micronecta is still poorly known; thus, the current taxonomy of Micronecta does not yet satisfactorily reflect natural relationships among subgeneric taxa. Our present paper illustrates this situation, with a high number of previously unknown species showing an aberrant morphology. A comprehensive phylogenetic analysis is certainly needed for resolving the systematics of the genus Micronecta. However, this type of work requires extensive taxon sampling across the very large distribution range of Micronecta as a whole, together with sampling of relevant DNA sequence data. This is beyond the scope of our present study, but we hope it can be achieved in the future.

While pending such comprehensive phylogenetic analyses, we perceive that the current subgeneric classification is still useful for the identification and comparative morphology of species of Micronecta, and to some extent it reflects the great diversification of the genus. Therefore, we indicate the subgeneric position of all species treated in the present paper, largely according to definitions of subgenera by Wróblewski (1962, 1967) and Nieser et al. (2005). Among the 11 recognised subgenera, Mesonecta Poisson, 1938 and Micronectella Lundblad, 1933 do not occur in Vietnam. We note that some species in this paper do 
not fit any currently defined subgenus, and are thus still not formally assigned, i.e., M. caperata sp. nov., M. tarsalis, and M. fugitans Breddin, 1905; and we treat them under the Incertae sedis section.

To assist in the quick identification of Micronecta for readers who are not familiar with the subject, we collate and re-assess diagnostic features of all current subgenera and provide a key to them, as follows.

\section{Key to current subgenera of Micronecta Kirkaldy, 1897 (applicable to male specimens only)}

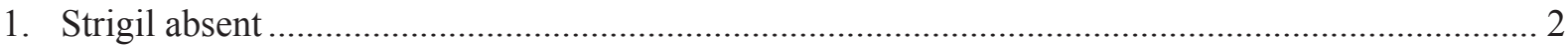

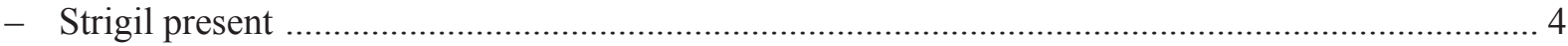

2. Palar claw broad, apically rounded................................... subgenus Micronectella Lundblad, 1933

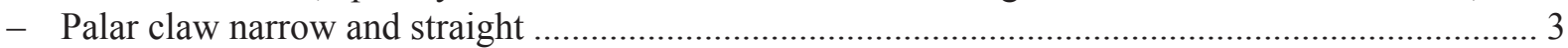

3. Median lobe of sternite VII with four long setae, apex angular; free lobe of tergite VIII subparallel sided, posterior margin concave (Fig. 6B) . subgenus Indonectella Hutchison, 1940

- Median lobe of sternite VII without long setae, nearly obtuse, both sides convex; free lobe of tergite VIII distally narrow with mesial angle produced (Fig. 6F)..... subgenus Lundbladella Wróblewski, 1967

4. Palar claw subovate with deep lateral incision (Fig. 2H); middle tibia with combs of 25 or 29 short and thick, erect setae subgenus Ctenonecta Wróblewski, 1962

- Palar claw not as above; middle tibia without combs of short setae 5

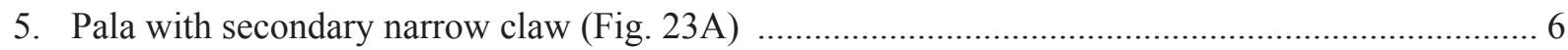

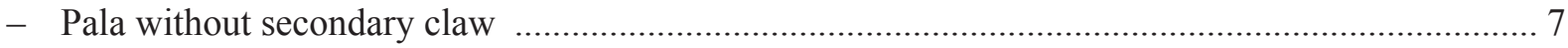

6. Free lobe of tergite VIII apically rounded; shaft of left paramere broad, slightly sinuate, with wide truncate apex subgenus Mesonecta Poisson, 1938

- Free lobe of tergite VIII with produced lateral angle (Fig. 23B, E); shaft of left paramere long and narrow, tapering apically (Fig. 23D, G) subgenus Unguinecta Nieser, Chen \& Yang, 2005

7. Palar claw slender with hooked apex or with a notch before apex (Figs 24A, 25A, E) ...... [incertae sedis, e.g., M. fugitans Breddin, 1905, M. tarsalis Chen, 1960, M. caperata sp. nov.]

- Palar claw not modified as above

8. Palar claw narrow and nearly straight (Fig. 2A) subgenus Basileonecta Hutchinson, 1940

- Palar claw broader and usually widened apically

9. Palar claw usually large, strongly widened apically (e.g., Figs 8A, 9F); shaft of left paramere platelike with subparallel sides (e.g., Figs 7C, 8F, 9E) ....................subgenus Micronecta Kirkaldy, 1897

- Palar claw not or moderately widened apically (Figs 3G, 22D); shaft of left paramere thicker, not plate-like

10. Median lobe of sternite VII elongate, tongue-shaped, with a rounded tip; free lobe of tergite VIII sigmoid (Fig. 22A, E); left paramere with a sickle-shaped apex (Fig. 22C, G)

subgenus Sigmonecta Wróblewski, 1962

- Median lobe of sternite VII less developed; free lobe of tergite VIII with expanded, truncate apex (Figs 3A, D, 4A, D, 20B); left paramere not as above

11. Body length at most $2.4 \mathrm{~mm}$; median lobe of sternite VII with one or two long setae subgenus Dichaetonecta Hutchison, 1940

- Body length 2.4-3.3 mm; median lobe of sternite VII usually with four long setae. subgenus Pardanecta Wróblewski, 1962 


\section{Diagnoses of current subgenera of Micronecta Kirkaldy, 1897}

Subgenus Basileonecta Hutchinson, 1940

Basileonecta Hutchinson, 1940: 355 (type species: Sigara scutellaris Stål, 1858, by original designation).

\section{Diagnosis}

Males: palar claw narrow, usually nearly straight; strigil present; median lobe of sternite VII narrow, with angular apex; free lobe of tergite VIII with mesial angle obtusely rounded or obsolete; left paramere styliform; right paramere: shaft slender and distally curved (adapted from Hutchinson 1940).

\section{Remarks}

Species of this subgenus occur in Africa, Madagascar, and Asia (Hutchinson 1940). There is still no formal checklist of species of Basileonecta as of yet. In Asia, there are three species, M. scutellaris (Stål, 1858), M. sedula Horváth, 1905, and M. siva (Kirkaldy, 1897); all are present in Vietnam.

\section{Subgenus Ctenonecta Wróblewski, 1962}

Ctenonecta Wróblewski, 1962: 178 (type species: Micronecta jaczewskii Wróblewski, 1962, by monotypy).

\section{Diagnosis}

Males: palar claw subovate, with deep lateral incision; middle tibia with combs of 25 or 29 short and thick, erect spines besides 10-11 longer setae; prestrigilar flap on segment V rounded, indistinct; strigil present; median lobe of sternite VII short, not extending beyond tergite VII, with two long setae; free lobe of tergite VIII sub-rectangular, posterior margin slightly concave, both angles obtuse; left paramere simple, styliform; right paramere strongly constricted apically (adapted from Wróblewski 1962).

\section{Remarks}

This subgenus is monotypic.

Subgenus Dichaetonecta Hutchison, 1940

Dichaetonecta Hutchison, 1940: 354 (type species: Sigara scholtzi Fieber, 1860, by original designation).

\section{Diagnosis}

Males: palar claw not strongly widened apically; prestrigilar flap on segment $V$ with an obtuse tip; strigil present; median lobe of sternite VII developed, with angular apex and one or two long setae; free lobe of tergite VIII widened distally, lateral angle produced; shaft of left paramere variable but not plate-like; right paramere: shaft slender and curved (adapted from Chen et al. 2015).

\section{Remarks}

Species of Dichaetonecta occur in Africa, Madagascar, and Asia (Hutchinson 1940). There is still no formal checklist of species for this subgenus as yet. In Vietnam, there are five species: M. sahlbergi (Jakovlev, 1881), M. ludibunda Breddin, 1905, M. johorensis Fernando, 1964, M. decorata Lundblad, 1933, and M. desertana Distant, 1920.

Subgenus Indonectella Hutchison, 1940

Indonectella Hutchison, 1940: 354 (type species: Micronecta thyesta Distant, 1910, by original designation). 


\section{Diagnosis}

Males: palar claw narrow, straight, and slightly constricted before apex; prestrigilar flap on segment $\mathrm{V}$ broadly rounded; strigil absent; median lobe of sternite VII with angular apex, four long setae (see Hutchinson 1940: pl. V fig. 69); free lobe of tergite VIII subparallel sided, lateral angle acute, posterior margin concave; left paramere styliform, subapical part serrated; right paramere: shaft slender and distally curved (adapted from Hutchinson 1940).

\section{Remarks}

Indonectella is a monotypic subgenus. The type species, Micronecta thyesta Distant, 1910, is a junior synonym of M. grisea (Fieber, 1844).

Subgenus Lundbladella Wróblewski, 1967

Lundbladella Wróblewski, 1967: 240-243 (type species: Micronecta guttatostriata Lundblad, 1933, by monotypy).

\section{Diagnosis}

Males: palar claw narrow and straight, apex rounded; prestrigilar flap on segment $\mathrm{V}$ trapezium-shaped, mesial corner pointed; strigil absent; median lobe of sternite VII nearly obtuse, both sides convex, without long setae (see Wróblewski 1967: fig. 13); free lobe of tergite VIII distally narrow, with lateral angle strongly produced; left paramere styliform, bent apically; right paramere distally enlarged with a membranous lobe (based on description by Wróblewski 1967).

\section{Remarks}

Hitherto, Lundbladella is a monotypic subgenus.

Subgenus Mesonecta Poisson, 1938

Mesonecta Poisson, 1938: 354 (type species: Mesonecta pilosa Poisson, 1938, by monotypy); originally as a separate genus, downgraded to subgenus by Hutchinson (1940).

\section{Diagnosis}

Males: pala with a secondary narrow claw, primary claw apically widened; strigil present; median lobe of sternite VII with two long and thick setae; free lobe of tergite VIII rounded apically; shaft of left paramere broad, slightly sinuate, with wide truncate apex; right paramere narrow, straight, with sharply pointed apex (adapted from Hutchinson 1940; Nieser et al. 2005).

\section{Remarks}

Hutchinson (1940) described two Asiatic species, M. khasiensis and M. waltoniana, and included both in Mesonecta. Nieser et al. (2005), when establishing the subgenus Unguinecta, transferred those two species to Unguinecta and also provided a detailed comparison between these two subgenera. At the moment, Mesonecta contains only one species, Mesonecta pilosa Poisson, 1938, with its distribution restricted to Madagascar (Nieser et al. 2005).

\section{Subgenus Micronecta Kirkaldy, 1897}

Micronecta Kirkaldy, 1897b: 260 (type species: Notonecta minutissima Linnaeus, 1758, by original designation). 


\section{Diagnosis}

Males: palar claw relatively large and usually distally widened; prestrigilar flap on segment V with mesial corner pointed; strigil present; median lobe of sternite VII with three to six (usually four) long setae; free lobe of tergite VIII variable, usually sub-rectangular; shaft of left paramere usually plate-like, with subparallel margins; right paramere: shaft distally curved or bent (adapted from Chen et al. 2015).

\section{Remarks}

The nominate subgenus contains the majority of species of Micronecta, most of them only share the distally widened palar claw of the male, and the plate-like shaft of the left paramere. Several taxonomic studies on Micronecta, if applying subgeneric classification, tend to 'dump' new species into the nominate subgenus, if they do not fit other subgenera. However, if a subgeneric classification is suitable, the definition of the nominate subgenus needs to be revised (Tinerella 2008, 2013), as do the definitions of the other subgenera.

\section{Subgenus Micronectella Lundblad, 1933}

Micronectella Lundblad, 1933b: 111-113 (type species: Micronectella acuta Lundblad, 1933, by monotypy); originally as a separate genus, downgraded to subgenus by Hutchinson (1940: 353).

\section{Diagnosis}

Males: palar claw broad, with rounded apex; prestrigilar flap on segment V with mesial corner produced, narrowly rounded [based on M. aleksanderi Nieser \& Chen, 1999]; strigil absent; median lobe of sternite VII short and pointed [based on M. aleksanderi]; free lobe of tergite VIII with mesial angle obsolete; shaft of right paramere moderately broad, with narrowly rounded apex (adapted from Lundblad 1933b; Hutchinson 1940).

\section{Remarks}

Currently, this subgenus contains two species, M. acuta (Lundblad, 1933) and M. aleksanderi. We have assigned the latter to the subgenus Micronectella based on the absence of a strigil, the shape of the palar claw of the male, and the shape of the right paramere (see Nieser \& Chen 1999: figs 31, 38-39).

Subgenus Pardanecta Wróblewski, 1962

Pardanecta Wróblewski, 1962: 177-178 (type species: Micronecta punctata (Fieber, 1844), by monotypy).

\section{Diagnosis}

Males: palar claw not strongly widened apically; prestrigilar flap on segment V crescent-shaped, indistinct; strigil present; median lobe of sternite VII with four long and thick setae; free lobe of tergite VIII with widened, truncate apex; left paramere with knob-like apex; right paramere distally curved (adapted from Wróblewski 1962).

\section{Remarks}

This is a monotypic subgenus. The type species, Micronecta punctata (Fieber, 1844), proved to be a junior homonym of Sigara punctata Illiger, 1807. The valid name of the species is thus Micronecta haliploides Horváth, 1904 (see Buzzetti et al. 2006). 
Subgenus Sigmonecta Wróblewski, 1962

Sigmonecta Wróblewski, 1962: 176 (type species: Micronecta quadristrigata Breddin, 1905, by monotypy).

\section{Diagnosis}

Males: palar claw moderately widened apically; prestrigilar flap on segment $\mathrm{V}$ with mesial corner acute; strigil present; median lobe of sternite VII elongate, tongue-shaped, with a rounded tip, and without long and thick setae (see Tinerella 2013: fig. 58e); strigil present; free lobe of tergite VIII sigmoid; left paramere with sickle-shaped apex; right paramere slender, distally curved (adapted from Wróblewski 1962; Chen et al. 2015).

\section{Remarks}

The subgenus Sigmonecta was established by Wróblewski (1962) for Micronecta quadristrigata Breddin, 1905. Subsequently, two more species have been placed in this subgenus: M. altera Wróblewski, 1972 and M. kymatista Nieser \& Chen, 1999 (see Chen et al. 2015).

Subgenus Unguinecta Nieser, Chen \& Yang, 2005

Unguinecta Nieser, Chen \& Yang, 2005: 200-202 (type species: Micronecta polhemusi Nieser, 2000, by original designation).

\section{Diagnosis}

Males: pala with a secondary narrow claw, primary claw apically widened; prestrigilar flap on segment V with broadly rounded medial apex; strigil present; median lobe of sternite VII with angular or rounded apex, with two long and thick setae; free lobe of tergite VIII with a slightly produced lateral angle; shaft of left paramere long and narrow, tapering apically; right paramere slightly curved over most of its length, with narrowly rounded apex (adapted from Chen et al. 2015).

\section{Remarks}

Nieser et al. (2005) established the subgenus Unguinecta, and placed five species in it: M. polhemusi Nieser, 2000, M. khasiensis Hutchinson, 1940, M. matsumurai Miyamoto, 1965, M. melanochroa Nieser, Chen \& Yang, 2005, and M. waltoniana Hutchinson, 1940. Among these, M. khasiensis and M. waltoniana were transferred from the subgenus Mesonecta.

\section{Taxonomy of Vietnamese Micronectidae}

\section{Key to species of Micronecta occurring in Vietnam (applicable to male specimens only)}

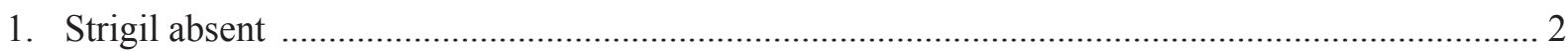

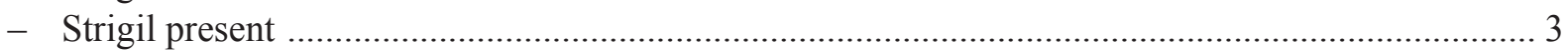

2. Body length 3.0-3.1 mm; hemelytron translucent or greyish brown, usually with two broken longitudinal dark stripes (Fig. 5A); right paramere slender, distally curved, tapering from distal half towards narrowly rounded apex (Fig. 6C) M. grisea (Fieber, 1844)

- Body length 2.0-2.4 mm; hemelytron brown with yellowish longitudinal stripes usually fragmented into small dots (Fig. 5B); distal half of right paramere strongly broadened (Fig. 6G)

3. Palar claw subovate with deep lateral incision (Fig. 2H); middle tibia with combs of 25 to 29 short and thick, erect spines besides 10-11 longer setae. M. jaczewskii Wróblewski, 1962

- Palar claw and middle tibia not as above 


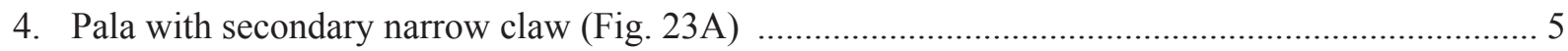

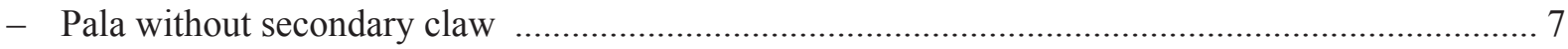

5. Primary palar claw narrow, parallel sided; left paramere swollen before apex

M. khasiensis Hutchinson, 1940

- Primary palar claw widened apically (Fig. 23A); left paramere slightly constricted and slightly twisted before apex (Fig. 23D, G)

6. Right paramere with a large swelling at the base of shaft (Fig. 23F) ......... polhemusi Nieser, 2000

- Right paramere with an indistinct swelling at the base of shaft (Fig. 23C)...

M. melanochroa Nieser, Chen \& Yang, 2005

7. Free lobe absent; prestrigilar flap absent

M. caperata sp. nov.

- Free lobe present; prestrigilar flap present

8. Palar claw slender with hooked apex or notch before apex (Fig. 25A, E)

- Palar claw not modified as above

9. Palar claw with hooked apex and pointed pre-apical tooth (Fig. 25E).

M. tarsalis Chen, 1960

- Palar claw broadly curved, with notch before apex (Fig. 25A)

M. fugitans Breddin, 1905

10. Palar claw narrow and nearly straight (Fig. 2A)

- Palar claw broader and usually widened apically

11. Body length 3.6-4.4 mm; apex of left paramere slightly bent and twisted (Fig. 2D); right paramere slightly expanded before apex (Fig. 2C)

M. scutellaris (Stål, 1858)

- Body length 2.7-3.4 mm; apex of left paramere blunt and not twisted; right paramere slender throughout

12. Pronotum with three distinct transverse dark stripes (Fig. 1C); longitudinal stripes on hemelytra distinct and dark (Fig. 1C); shaft of right paramere curved at distal third ...M. siva (Kirkaldy, 1897)

- Pronotum without distinct transverse dark stripes; longitudinal stripes on hemelytra lighter or indistinct (Fig. 1B); shaft of right paramere slightly curved at distal fourth (Fig. 2F).....

M. sedula Horváth, 1905

13. Palar claw not or moderately widened apically (Fig. 22D); shaft of left paramere thicker, not platelike

- Palar claw usually large, strongly widened apically (Figs 8A, 9F); shaft of left paramere flat, platelike with subparallel sides (Figs 7C, 8F, 9E)

14. Median lobe of sternite VII elongate, tongue-shaped, with rounded tip; free lobe of tergite VIII sigmoid (Fig. 22A, E); left paramere with sickle-shaped apex (Fig. 22C, G)

- Median lobe of sternite VII less developed; free lobe of tergite VIII with expanded, truncate apex; left paramere not as above

15. Shaft of right paramere longer, clearly thicker in basal half, then gradually tapering in apical half (Fig. 22F); curvature between base and shaft of left paramere, opposite basal lobe about $90^{\circ}$ (Fig. 22G)

M. altera Wróblewski, 1972

- Shaft of right paramere mostly parallel sided and only tapering on apical fifth towards narrowly rounded apex (Fig. 22B); curvature between base and shaft of left paramere, opposite basal lobe clearly greater than $90^{\circ}$ (Fig. 22C)

M. quadristrigata Breddin, 1905 
16. Median lobe of sternite VII usually with four long setae; shaft of left paramere stout, with knob-like apex

M. haliploides Horváth, 1904

- Median lobe of sternite VII with one or two long setae; apex of left paramere not knob-like ....... 17

17. Pronotum shorter than head; hemelytron with reticulate pattern; left paramere with a large triangular tooth near the middle section of shaft (Fig. 3I); right paramere with longitudinal striations on stout shaft (Fig. 3H)

M. johorensis Fernando, 1964

- Pronotum length at least equal to median head length; hemelytron with linear pattern or pale pattern; left and right paramere not as above

18. Pronotum usually with pair of dark oval rings, which are sometimes fragmented, reduced to streaks or spots, or absent; hemelytron usually with four longitudinal brown stripes; left paramere with broad, flat, and subovate apex

M. ludibunda Breddin, 1905

- Pronotum without dark oval marks; dark marks on hemelytra usually indistinct; apex of left paramere not modified as above

19. Apical part of left paramere sinuate and covered with small scales (Fig. 4G)

M. sahlbergi (Jakovlev, 1881)

- Shaft of left paramere not sinuate apically, without small scales (Fig. 3C, F)

20. Free lobe strongly widened distally, posterior margin produced into an obtuse angle (Fig. 3A); apical part of left paramere slightly twisted (Fig. 3C)

M. decorata Lundblad, 1933

- Free lobe sub-rectangular, only slightly widened at distal part, posterior margin nearly straight (Fig. 3D); apical part of left paramere not twisted (Fig. 3F) M. desertana Distant, 1920

21. Shaft of right paramere evenly curved, apex rounded (Figs 7B, E, 8E) 22

- Shaft of right paramere strongly curved or bent on distal half to distal fourth (Figs 9D, J, 10E, 11E)

22. Hemelytra with distinct marks (Fig. 5D); palar claw broadened distally, apex rounded; shaft of left paramere with a distinct triangular projection on lateral margin (Fig. 7F)....

M. erythra Nieser, Chen \& Yang, 2005

- Markings on hemelytra indistinct or absent; palar claw large, sub-triangular with straight apical margin; shaft of left paramere without distinct projection

23. Hemelytron with patchy, indistinct brown markings (Fig. 5C); left paramere with a short ridge running to lateral margin of shaft, apex broad (Fig. 7C) ...

M. drepani Nieser, 2000

- Hemelytron generally light orangish, without dark marking (Fig. 5E); left paramere simple, without modification on shaft, apex narrow (Fig. 8F) M. cultellata sp. nov.

24. Free lobe simple, sub-rectangular or moderately widened distally, posterior margin nearly straight or slightly concave; right paramere with simple, narrowly rounded apex

- Free lobe distinctly widened distally, posterior margin usually modified; right paramere with strongly modified apex

25. Shaft of left paramere without projection on lateral margin ....................................................... 26

- Shaft of left paramere with distinct triangular projection on lateral margin .................................. 30

26. Left paramere with shaft straight, basal lobe trapezoid (Fig. 12F); shaft of right paramere slenderer and curved at distal third (Fig. 12E)

M. vietnamica sp. nov.

- Left paramere with lateral margin of shaft sinuate, basal lobe subovate or sub-rectangular; shaft of right paramere bent or curved at distal fourth 
27. Distal part of right paramere strongly bent, forming angle of nearly $90^{\circ}$ (Figs 9D, 10E) ............ 28

- Distal part of right paramere more gently curved, forming angle of ca $45^{\circ}$ (Figs 9J, 11E) .......... 29

28. Base of right paramere with a distinct hump on mesial margin near the beginning of the shaft (Fig. 9D); basal lobe of left paramere long, tongue-shaped (Fig. 9E)...M. anatolica Lindberg, 1922

- Base of right paramere without hump on mesial margin near beginning of shaft (Fig. 10E); basal lobe of left paramere sub-rectangular (Fig. 10F).

M. fulvopicta sp. nov.

29. Left paramere shaft evenly curved outwards, apex narrowly rounded (Fig. 9K)

M. arcuata sp. nov.

- Left paramere shaft strongly constricted before an acute apex (Fig. 11F) ....... M. acuminata sp. nov.

30. Shaft of left paramere with notch on lateral margin, set basally to triangular projection (Fig. 14D); right paramere strongly bent before club-shaped apex, forming angle of nearly $90^{\circ}$ on lateral margin (Fig. 14C) M. ornitheia Nieser, Chen \& Yang, 2005

- Shaft of left paramere without a notch on lateral margin; pre-apical curve of right paramere forming an obtuse angle (Figs 14F, 15E) 31

31. Right paramere with small notch on upper margin before flap-like apical part

M. pocsi Wróblewski, 1967

- Apex of right paramere not modified as above

32. Pre-apical part of right paramere widened before truncate apex (Fig. 15E).....

M. clavata sp. nov.

- Pre-apical part of right paramere tapering towards rounded apex (Fig. 14F).

M. tuwanoni Nieser, Chen, Leksawasdi, Thanyakam \& Duangsupa, 2004

33. Free lobe widened distally, posterior margin convex (Fig. 16D); shaft of left paramere tapering towards slightly swollen apex, sub-apically with small process (Fig. 16F); shaft of right paramere widened at distal part and folded into gutter-like structure, with lobe on mesial side (Fig. 16E)

M. sinuata sp. nov.

- Free lobe strongly modified (Figs 17D, 18D, 19D); shaft of left paramere with one or two triangular projections on lateral margin (Figs 17F, 18F, 19F); shaft of right paramere modified differently (Figs 17E, 18E, 19E) 34

34. Free lobe short, distally widened, and wavy, both angles nearly square, without long setae; left paramere with two triangular projections on lateral margin, apex of paramere truncate; apical part of right paramere modified as in Fig. 17E

M. undulata sp. nov.

- Free lobe short, distally strongly widened, posterior margin convex, lateral angle notched, with long setae (Figs 18D, 19D); left paramere with one triangular projection on lateral margin 35

35. Left paramere with triangular projection on lateral margin, near to base of shaft (Fig. 18F); right paramere strongly modified, as in Fig. 18E M. nieseri sp. nov.

- Left paramere with triangular projection on lateral margin, near to apex of shaft (Fig. 19F); right paramere strongly modified, as in Fig. 19E M. pingae sp. nov.

Micronecta (Basileonecta) scutellaris (Stål, 1858)

Figs 1A, 2A-D

Sigara scutellaris Stål, 1858: 319 (type locality: Namibia).

(For extensive synonymy list, see Jansson 1995.) 


\section{Diagnosis}

Body length 3.6-4.4; only macropterous form known. Pronotum distinctly longer than median head length. Hemelytron (Fig. 1A): corium with three longitudinal brown stripes, sometimes in broken pattern or indistinct; embolium with a set of four short brown stripes, sometimes confluent into a long unbroken stripe.

Males: fore femur with three spines on proximal third ventrally, one spine on middle third and three spines on distal margin; fore tibia with two spines on distal third; palar claw slender, slightly sinuate (Fig. 2A). Free lobe sub-rectangular, posterior margin concave, lateral angle produced, with ca 30 long setae (Fig. 2B). Left paramere: shaft stout, tapering distally, apical part slightly bent and twisted (Fig. 2D). Right paramere: shaft bent and slightly enlarged at distal third, then tapering towards narrowly rounded apex; basal lobe sub-rectangular (Fig. 2C).

\section{Material examined}

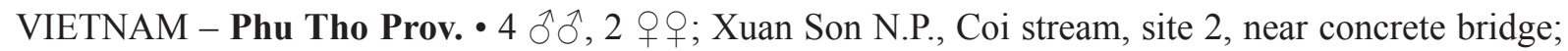

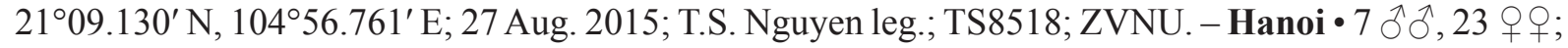
Thanh Xuan District, Me Tri area, Anh Duong Lake (used for recreational fishing); 20 Apr. 2010; T.M. Pham leg.; HN06; ZVNU • 1 क; Nhue River, in Lien Mac area; 19 Jun. 2019; T.N. Ha leg.; NHHN19.01; ZVNU. - Dong Nai Prov. 6 ổ, 9 우; Bien Hoa City, Bien Hung Lake; 9 May 2003; A.D. Tran leg.; TAD0314; ZRC.

\section{Distribution}

Vietnam: Hanoi and Ha Tinh (Wróblewski 1962, 1967); Phu Tho, Dong Nai (first records). Other countries: from Africa through Arabia, Palestine, southern Asia to Southeast Asia and southern China (Wróblewski 1968; Nieser 2002b; Zettel et al. 2017).

\section{Remarks}

This is the largest species of Micronecta occurring in Vietnam. It has some similarities with M. sedula Horváth, 1905 and M. siva (Kirkaldy, 1897) in the structures of the male genitalia, but can easily be recognised by its larger body (also see Remarks under $M$. siva).

\section{Micronecta (Basileonecta) sedula Horváth, 1905}

Figs 1B, 2E-G

Micronecta sedula Horváth, 1905: 423 (type locality: Akashi, Japan).

Micronecta quadrivittata Matsumura, 1905: 62 (type locality: Hokkaido and Honshu, Japan).

Micronecta quadriseta Lundblad, 1933a: 460-461, pl. XIII fig. 7, text fig. 6 (type locality: Soochow (Suzhou), China).

Micronecta sedula - Wróblewski 1960: 309-313, pl. XVI (redescription); 1967: 237 (descriptive notes); 1968: 776 (checklist, synonymy list). — Jansson 1995: 28-29 (catalogue).

Micronecta quadrivittata - Matsumura 1915: 114 (synonymised with Micronecta sedula).

Micronecta quadriseta - Wróblewski 1960: 309-313 (synonymised with Micronecta sedula).

\section{Diagnosis}

Body length 2.7-3.4. Pronotum distinctly longer than median head length, without dark transverse stripe. Hemelytron (Fig. 1B) pale yellowish, corium with four brown stripes. 


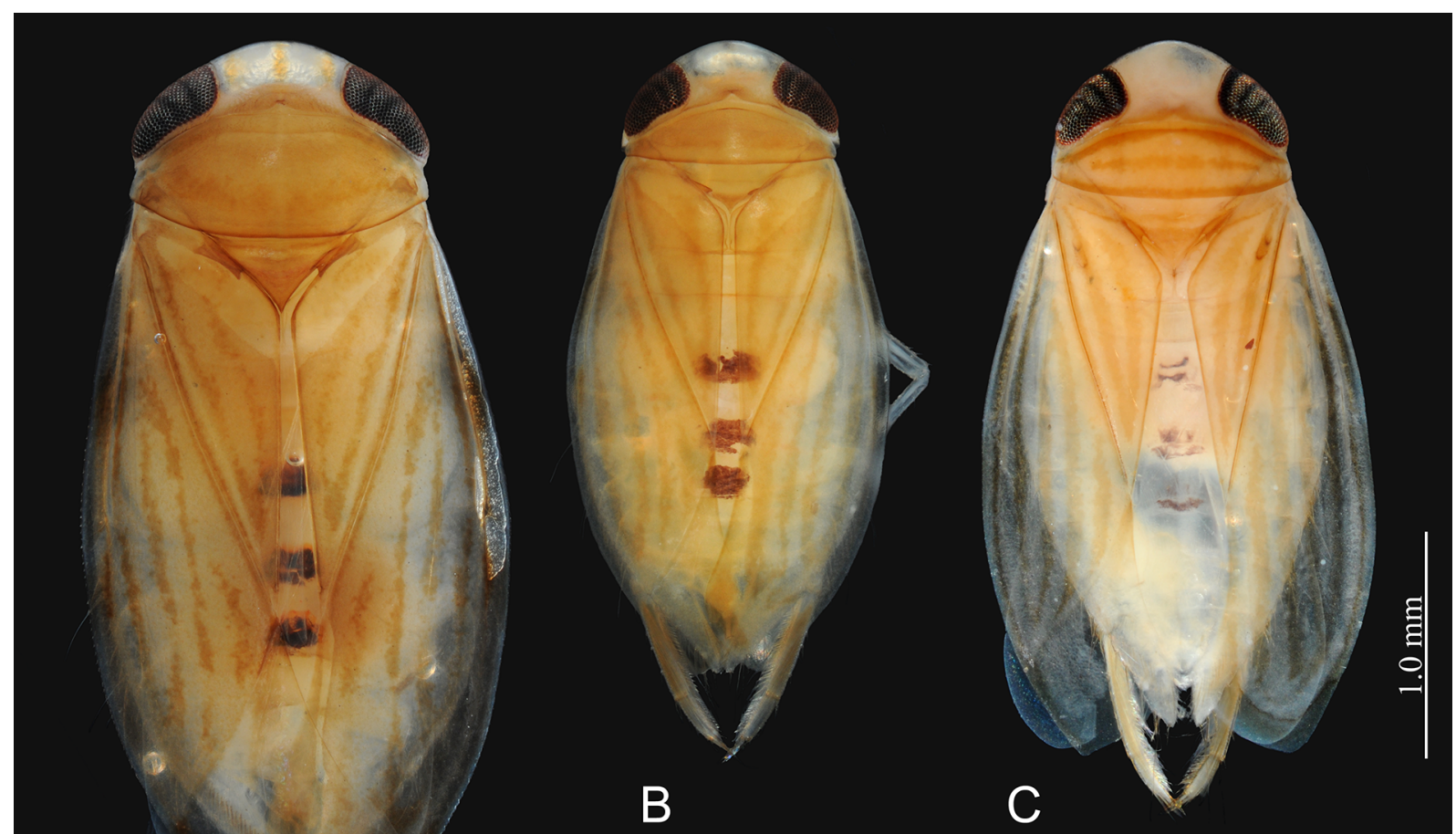

A

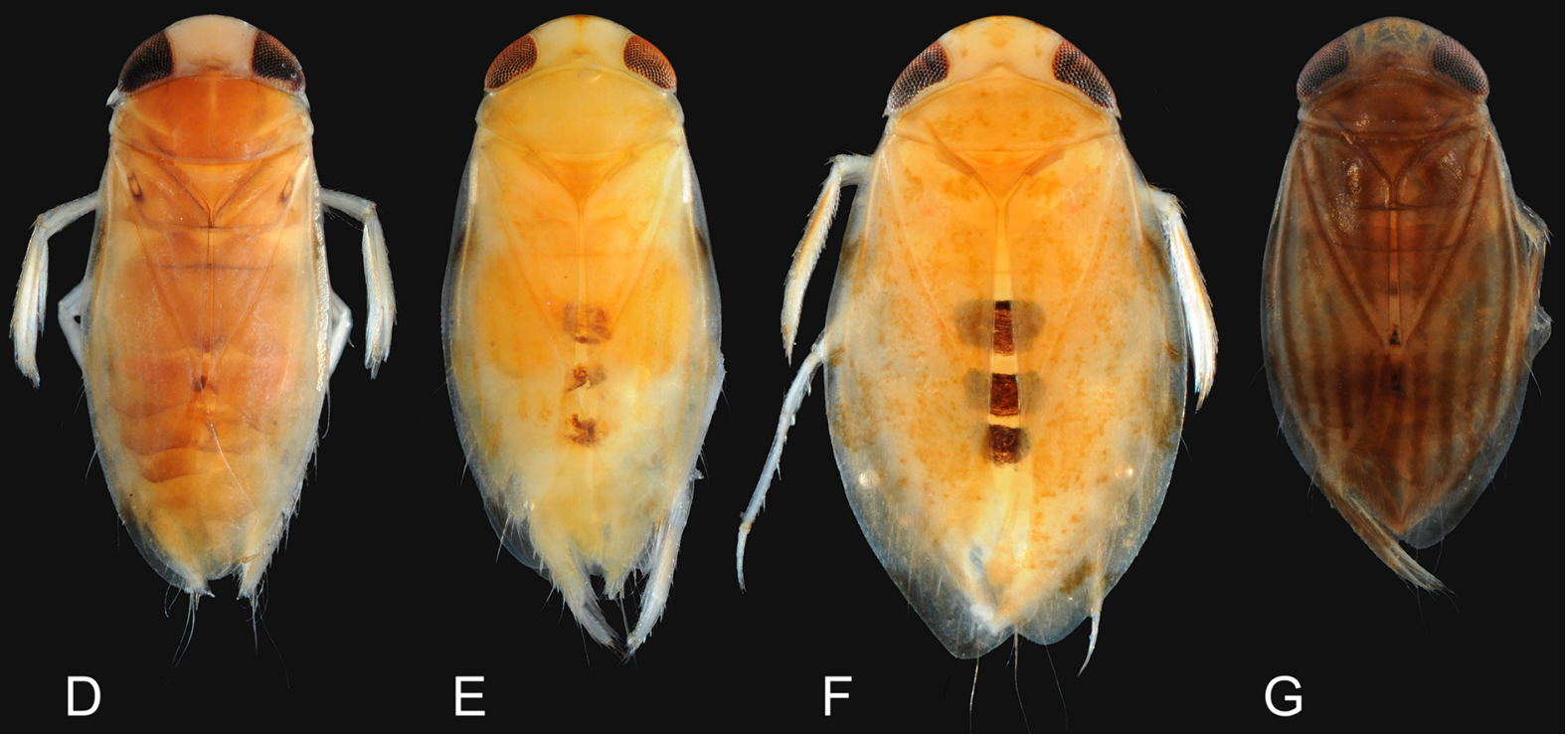

Fig. 1. Habitus photos of species of Micronecta Kirkaldy, 1897. A. M. scutellaris (Stål, 1858), ठิ (ZVNU). B. M. sedula Horváth, 1905, ô (ZVNU). C. M. siva (Kirkaldy, 1897), o (ZVNU). D. M. jaczewskii Wróblewski, 1962, đ̂ (ZVNU). E. M. decorata Lundblad, 1933, ô (ZRC). F. M. desertana Distant, 1920, ठ̊ (ZVNU). G. M. ludibunda Breddin, 1905, ठ̊ (ZVNU). All to the same scale. 
Males: fore femur with four spines in proximal third ventrally, four spines on middle third and a pair of spines on distal third dorsally; fore tibia with a pair of spines on distal third; palar claw slender, straight. Median lobe of sternite VII with two long setae. Free lobe sub-rectangular, posterior margin concave, lateral angle produced, with about 10 long setae (Fig. 2E). Left paramere: shaft stout, apical part slightly swollen, apex obtuse, mesial side with minute spine-like scales; basal lobe tongue-shaped (Fig. 2G). Right paramere: shaft slender slightly curved pre-apically, apex narrowly rounded (Fig. 2F).

\section{Material examined}

VIETNAM - Quang Ninh Prov.• 1 Ô, 1 q; Dong Rui; 12 Sep. 2019; T.A.N. Nguyen leg.; \#1902; ZVNU. - Ninh Binh Prov. 1 o, 1 ; Gia Vien, Van Long Wetland Nature Reserve; 25 Aug. 2002; Q.K. Hoang and V.K. Dinh leg.; VNNB0201; ZRC. - Thua Thien Hue Prov. 5 ô $\hat{\jmath}, 6$ q $q$; Quang Dien District, Quang Loi Commune, Con Toc; 7 May 2012; A.D. Tran leg.; TAD1212; ZVNU.

\section{Distribution}

Vietnam: Hoa Binh (Chine), Ninh Binh (Cuc Phuong), and Quang Tri (Wróblewski 1962, 1967); first records from Quang Ninh, Ninh Binh (Van Long), Thua Thien Hue. Specimens from Thua Thien Hue were collected in the brackish water of a coastal lagoon. Other countries: Russia (Khanka Lake), Korea, Japan, eastern China (Wróblewski 1960, 1968; Nieser et al. 2005).

\section{Remarks}

See Remarks under $M$. siva.

Micronecta (Basileonecta) siva (Kirkaldy, 1897)

Fig. 1C

Sigara striata Fieber, 1844: 14, pl. 1 fig. 22-24 (type locality uncertain) (junior secondary homonym of Notonecta striata Linnaeus, 1758) (nec Fabricius).

Sigara siva Kirkaldy, 1897a: 240 (new name for Sigara striata).

Micronecta striata - Kirkaldy 1898: 3. — Distant 1906: 50, fig. 30 (descriptive notes). — Lundblad 1933b: 101, table IV (additional notes).

Micronecta siva - Kirkaldy 1905: 261 (list); 1908: 209 (synonyms). — Hutchinson 1940: 371-376, figs 94-100 (redescription, synonym list). - Fernando 1964: 607-608, figs 6, 13, 24, 36 (habitat, distribution). - Wróblewski 1968: 771, 776 (nomenclature, checklist); 1972a: 26, 29, figs 38, 42, tables 1-2 (key). - Jansson 1995: 29 (catalogue). — Nieser \& Chen 1999: 79, 80-81, fig. 54, table 2 (key, distribution catalogue). - Nieser 2002b: 270, figs 3, 8, table 2 (diagnosis, distribution).

\section{Diagnosis}

Body length 2.7-3.4. Pronotum distinctly longer than median head length, with three distinct transverse dark stripes across pronotum width (Fig. 1C). Hemelytron: corium with four distinct longitudinal dark stripes; embolium with a long, continuous dark stripe (Fig. 1C).

Males: fore femur with two longitudinal rows which both have four spines; fore tibia with one subapical spine; palar claw slender, straight. Free lobe sub-rectangular, posterior margin nearly straight, lateral angle produced. Left paramere: shaft stout, mesial side of apical part serrated, apex blunt. Right paramere: shaft slender, slightly curved at distal third, apex narrowly rounded (see Wróblewski 1972a: figs 38, 42).

\section{Material examined}

VIETNAM - Dong Nai Prov. • 1 q; Vinh Cuu, Ma Da, Bo Hao lotus pond; 15 Apr. 2010; T.D. Pham leg.; PTD1010; ZVNU. 


\section{Distribution}

Vietnam: Nghe An and Ha Tinh (Wróblewski 1967); Dong Nai (first record). Other countries: widespread from India and Sri Lanka to China and Southeast Asia (Myanmar, Thailand, Indonesia) (Lunblad 1933b; Nieser \& Chen 1999; Nieser 2002b).

\section{Remarks}

Among species of the subgenus Basileonecta, M. siva is unique in having distinct transverse stripes on the pronotum and dark longitudinal stripes on the hemelytra. The left and right parameres of $M$. siva look like those of $M$. sedula, but their detailed structures are clearly different. In M. sedula, the apex of the left paramere is swollen, and the shaft of the right paramere is curved at around on the distal fourth. In $M$. siva, the apex of the left paramere is not swollen, and the shaft of the right paramere is curved at the distal third.

Among the three Asian species of the subgenus Basileonecta, M. sedula has similar marking patterns on the hemelytra to those of M. scutellaris, but it is a distinctly smaller species (body length not more than $3.4 \mathrm{~mm}$ ), its left paramere is not twisted pre-apically, and its right paramere is not expanded pre-apically.

Micronecta (Ctenonecta) jaczewskii Wróblewski, 1962

Figs $1 \mathrm{D}, 2 \mathrm{H}-\mathrm{K}$

Micronecta jaczewskii Wróblewski, 1962: 178-180, figs 1-8 (type locality: Hanoi, Vietnam).

Micronecta jaczewskii - Wróblewski 1967: 239, figs 9-10 (descriptive notes); 1968: 775 (checklist). Nieser 2000: 285, figs 29-30 (record Thailand, key). — Nieser et al. 2005: 190-191 (record China).

\section{Diagnosis}

Body length 2.1-2.5. Pronotum distinctly longer than median head length. Hemelytron (Fig. 1D) with indistinct longitudinal markings.

Males: fore femur with row of seven spines on proximal third ventrally; fore tibia without spine (Fig. 2H); palar claw, median lobe of sternite VII and free lobe (Fig. 2I) as in diagnosis of Ctenonecta. Left paramere: shaft stout, apex blunt (Fig. 2K). Right paramere: shaft broad at base, constricted at distal half, then expanded and constricted again before narrowly rounded apex; basal lobe with a distinct hump on mesial side, near base of shaft (Fig. 2J).

\section{Material examined}

VIETNAM - Cao Bang Prov. 3 đ̊̊, 3 우; Trung Khanh, Duc Hong Commune, stream; 19 Dec. 2013; A.D. Tran et al. leg.; TAD1376; ZVNU. - Phu Tho Prov. • 1 đ̊; Xuan Son N.P., Xoan stream, near its confluence with Ha Bang stream; 21 ${ }^{\circ} 5.303^{\prime}$ N, 104 57.559' E; 27 Aug. 2014; T.S. Nguyen leg.; TS1407; ZVNU. - Hanoi • $2 \hat{\jmath} \hat{\jmath}, 1$ क; Nhue River, in Lien Mac area; 25 Mar. 2010; T.M. Pham

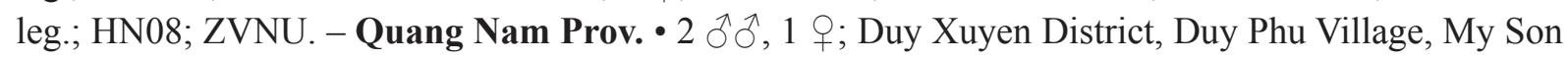
hamlet, My Son Sanctuary; $15^{\circ} 46.228^{\prime}$ N, 10807.155' E; Apr. 2017; T.D. Chu leg.; MS1723; ZVNU.

\section{Distribution}

Vietnam: Lao Cai, Hanoi, Ha Tinh (Wróblewski 1962, 1967); first records for Cao Bang, Phu Tho, Quang Nam. Other countries: Thailand, China (Nieser 2000; Nieser et al. 2005). 

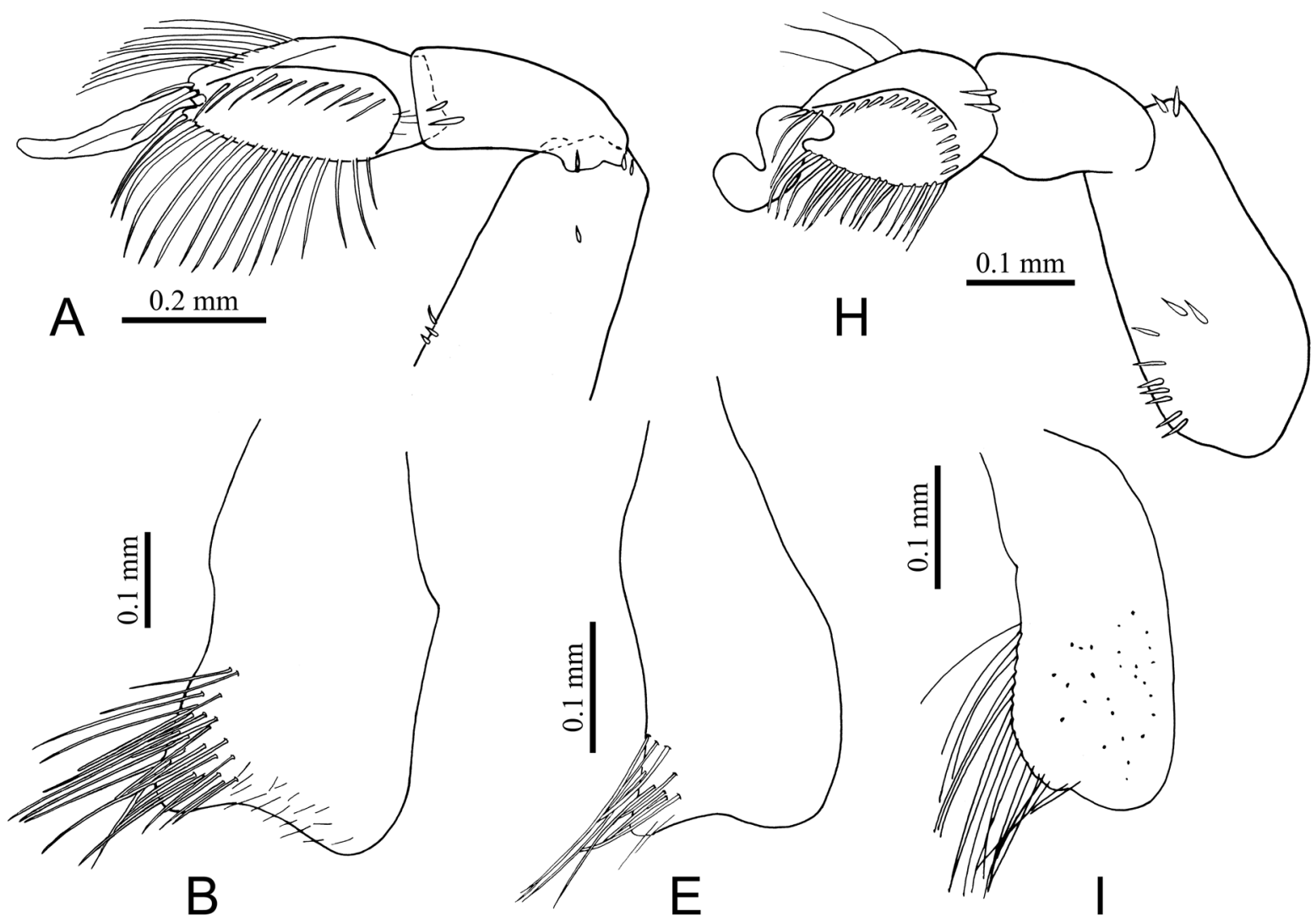

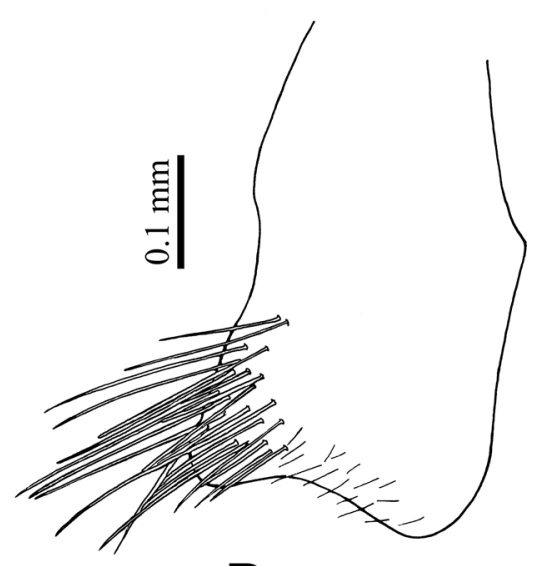

B

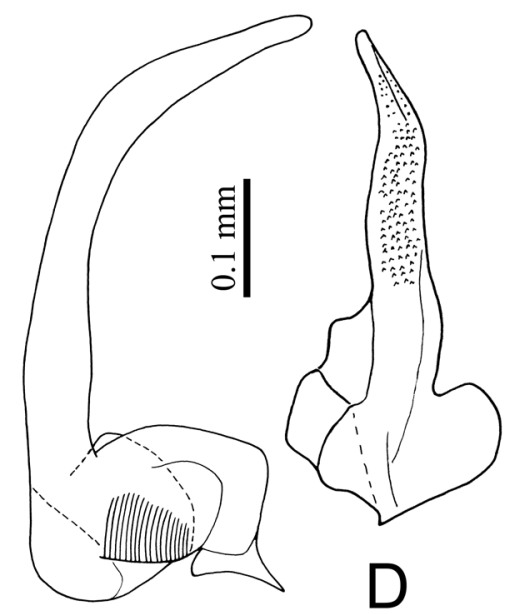

C
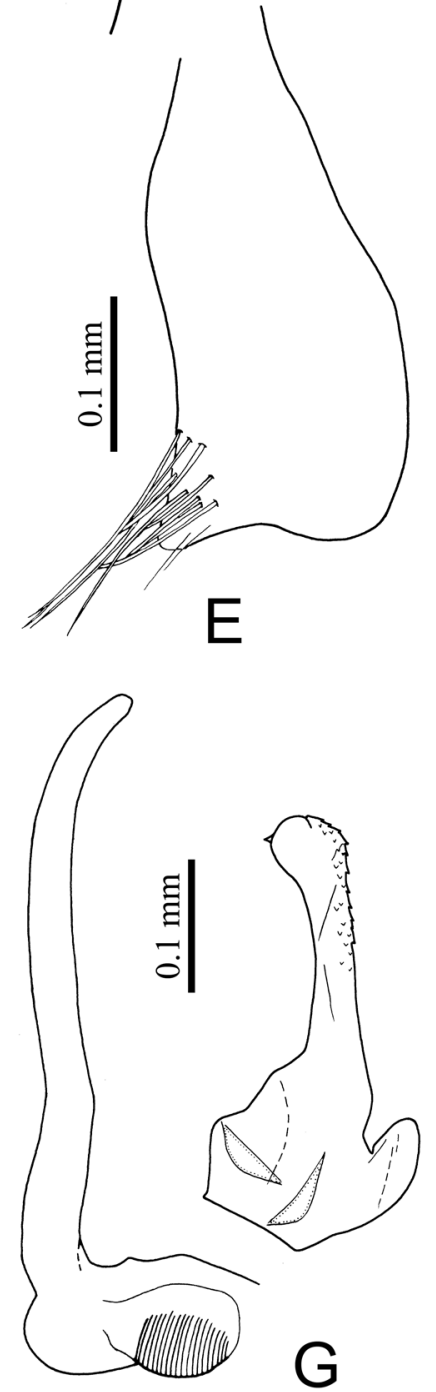

$\mathrm{F}$

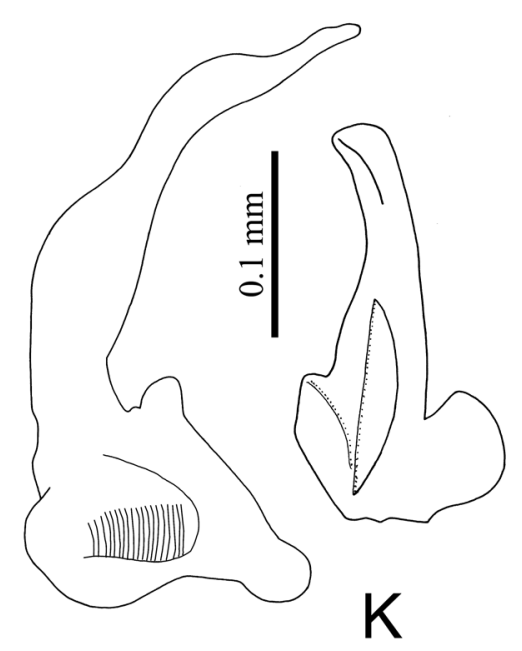

$J$

Fig. 2. Morphological features of species of Micronecta Kirkaldy, 1897, $\widehat{\jmath}$. A-D. M. scutellaris (Stål, 1858) (ZVNU). E-G. M. sedula Horváth, 1905 (ZVNU). H-K. M. jaczewskii Wróblewski, 1962 $(\mathrm{ZVNU}) . \mathrm{A}, \mathrm{H}=$ fore leg; $\mathrm{B}, \mathrm{E}, \mathrm{I}=$ free lobe; $\mathrm{C}, \mathrm{F}, \mathrm{J}$ = right paramere; $\mathrm{D}, \mathrm{G}, \mathrm{K}=$ left paramere. 


\title{
Remarks
}

The male of this species can easily be separated from other species of Micronecta by its distinct shape of the right paramere (Fig. 2J), together with its unique palar claw (Fig. $2 \mathrm{H}$ ) and the presence of combs of setae on the middle tibia.

\section{Micronecta (Dichaetonecta) decorata Lundblad, 1933}

\author{
Figs $1 \mathrm{E}, 3 \mathrm{~A}-\mathrm{C}$
}

Micronecta decorata Lundblad, 1933b: 93-94, fig. 29, pl. XIX fig. 3 (type locality: Sumatra, Indonesia).

Micronecta decorata - Wróblewski 1968: 775 (checklist). — Fernando \& Cheng 1974: 39. — Nieser 2000: 287 (key); 2002b: 266, fig. 13 (diagnosis, distribution). — Chen et al. 2015: 35-37, figs 14, $24,30-31,43,51,58,66,74-75,90$ (redescription).

\section{Diagnosis}

Body length 1.2-2.4. Pronotum distinctly longer than median head length. Hemelytron(Fig. 1E) generally yellowish brown, with four indistinct, broken longitudinal brownish stripes; embolium yellowish with three brown spots.

Males: fore femur with a pair of spines in proximal third, one spine on distal third dorsally; fore tibia with a pair of spines on distal margin; palar claw knife-shaped. Median lobe of sternite VII with a pointed apex and one long seta (see Chen et al. 2015: fig. 58). Free lobe large, apically broadened, posterior margin produced into an obtuse angle, lateral angle with 10-15 long setae (Fig. 3A). Left paramere: shaft slender, constricted pre-apically, apex slightly twisted (Fig. 3C). Right paramere: shaft evenly curved, from distal fourth tapering towards narrowly rounded apex (Fig. 3B).

\section{Material examined}

VIETNAM - Lao Cai Prov. • 1 ふ̋; Sa Pa, Sin Chai, Muong Hoa stream (Cat stream); 27 Oct. 2013; A.D. Tran. et al. leg.; TAD1365; ZVNU • 1 ô, 1 क; Sa Pa, Cat Cat, Muong Hoa stream (Cat stream); 27 Oct. 2013; Q.H. Ngo et al. leg.; TAD1367; ZVNU. - Hanoi • 1 ô, 1 q; Ba Vi N.P., Ba Trai, Ri stream; 67 m a.s.1.; 27 Apr. 2012; Q.H. Ngo leg.; TAD1209; ZVNU. - Lam Dong Prov. • 2 ภิ ô, 2 q \%; Da Lat, Datanla waterfall; 22 May 2003; A.D. Tran leg.; TAD0333a; ZRC. - Kien Giang Prov. • 2 $\lesssim$ Phu Quoc Island, downstream of Da Ban stream; 1 Dec. 2010; A.D. Tran leg.; TAD1026; ZVNU.

\section{Distribution}

First records for Vietnam. Other countries: mainly in Southeast Asia, from Thailand and Peninsular Malaysia to Indonesia (Sumatra, Java) and Borneo (Sabah) (Lundblad 1933b; Chen et al. 2015).

\section{Remarks}

See Remarks under M. sahlbergi.

\section{Micronecta (Dichaetonecta) desertana Distant, 1920} Figs 1F, 3D-F

Micronecta desertana Distant, 1920: 206 (type locality: Hurmuk, Persian side of Perso-Afghan-Baluch boundary, Iran).

Micronecta desertana concanensis Hutchinson, 1940: 390-392, figs 160-163.

Micronecta desertana dravida Hutchinson, 1940: 392-394, figs 164-167. 
Micronecta desertana - Hutchinson 1933: 398. - Chen 1960: 104 (key). - Wróblewski 1968: 775 (subspecies list); 1972a: 42, 50, figs 57, 63 (additional notes, key). — Nieser 2000: 286 (key).

Micronecta desertana desertana - Hutchinson 1940: figs 152-159 (additional description). — Jansson 1995: 29 (catalogue).

Micronecta desertana concanensis - Wróblewski 1972a: 42 (downgraded to "form").

Micronecta desertana dravida - Wróblewski 1967: 236, figs 6-8 (first record for Vietnam).

\section{Diagnosis}

Body length 1.2-2.4. Pronotum about as long as median head length, slightly narrower than head width. Hemelytron (Fig. 1F) generally pale, with four indistinct, broken longitudinal brownish stripes.

Males: fore femur with a row of seven spines in proximal and middle third; fore tibia with three spines distally; palar claw narrow, apical part slightly recurved. Median lobe of sternite VII with two long setae and a pointed apex. Free lobe sub-rectangular, posterior margin nearly straight, angles rounded, lateral angle with ca eight long setae (Fig. 3D). Left paramere: shaft styliform, apical part slightly constricted
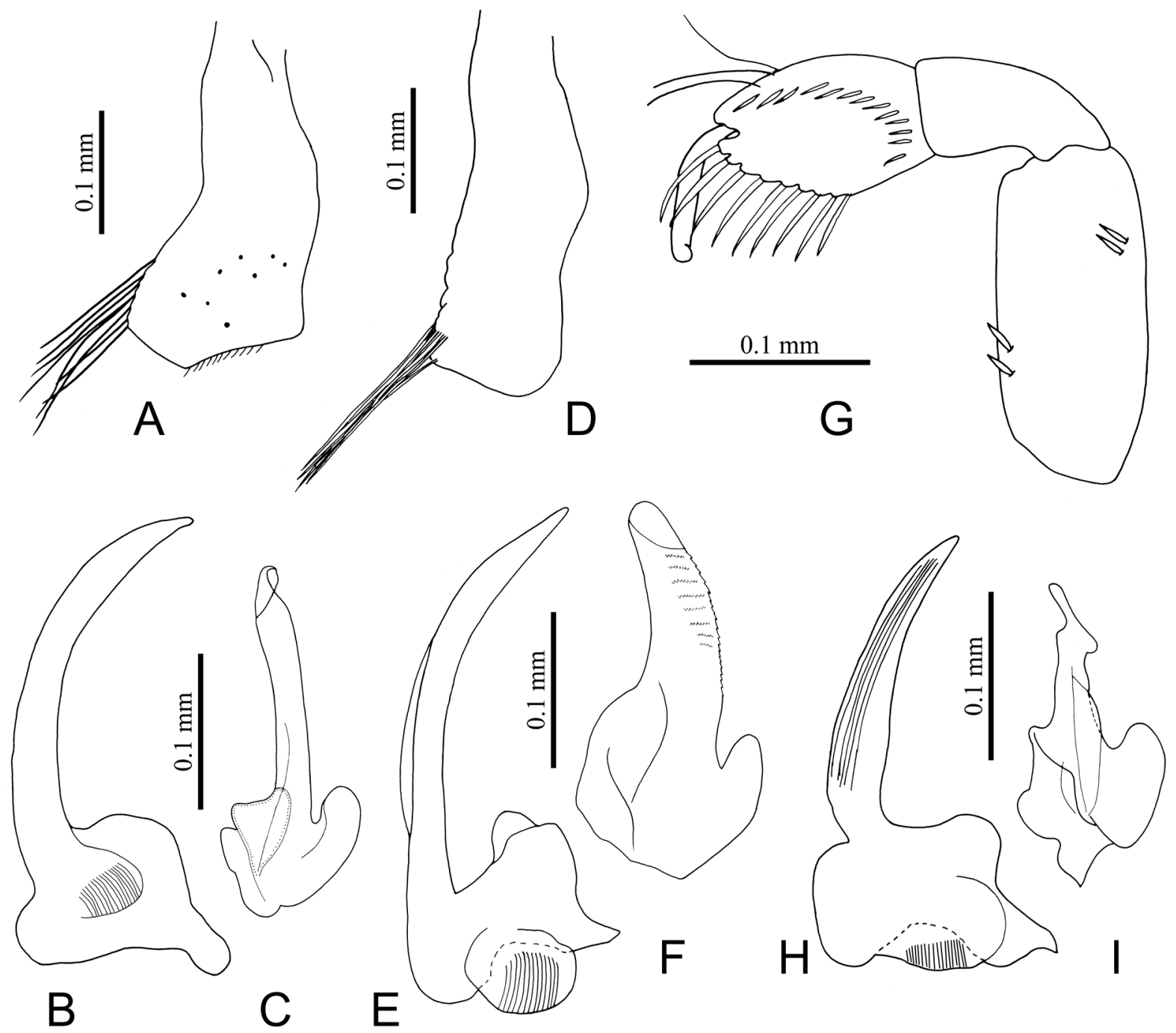

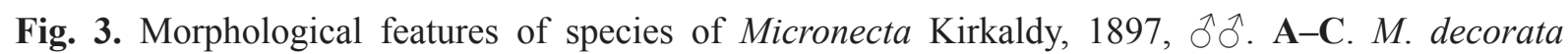
Lundblad, 1933 (ZVNU). D-F. M. desertana Distant, 1920 (ZVNU). G-I. M. johorensis Fernando, 1964 (ZVNU). A, D = free lobe; B, E, H = right paramere; C, F, I = left paramere; $G=$ fore leg. 
but not twisted (Fig. 3F). Right paramere: shaft evenly curved, from distal fourth tapering towards narrowly rounded apex (Fig. 3E).

\section{Material examined}

VIETNAM - Hanoi • 4 ふึત, 3 우; Ba Vi N.P., Khoang Xanh, Tien stream; 95 m a.s.l.; 27 Apr. 2012;

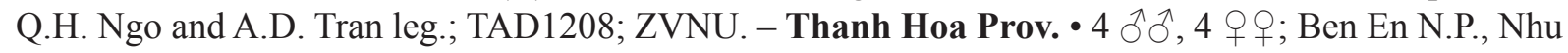
Xuan, Xuan Quy, Song Chang ranger station, Khe Xa Manh stream, under Xa Manh bridge; 12 Mar. 2013; T.D. Pham leg.; BE1311; ZVNU. - Quang Binh Prov. • 2 ô, 4 우; Phong Nha, a stream W of Forest ranger station No.4; 15 Aug. 2001; A.D. Tran leg.; VNQB0103; ZRC.

\section{Distribution}

Vietnam: Ninh Binh (Cuc Phuong) (Wróblewski 1967); first records from Hanoi, Thanh Hoa, Quang Binh. Other countries: India, Iran (Wróblewski 1968).

\section{Remarks}

See Remarks under M. sahlbergi.

\section{Micronecta (Dichaetonecta) johorensis Fernando, 1964} Fig. 3G-I

Micronecta johorensis Fernando, 1964: 17-18, figs 1-9 (type locality: Johor, Peninsular Malaysia).

Micronecta johorensis - Nieser 2000: 287 (key); 2002b: 265, 267-268 (diagnosis, key).

\section{Diagnosis}

Body small, ovate, length 1.5-1.8 (brachypterous). Pronotum shorter than median head length. Dorsum colour pale yellowish. Pronotum with a pair of transverse brown marks. Dark patterns on hemelytra reticulate; embolium with five dark patches; membrane reduced.

Males: fore femur with a pair of spines in proximal third ventrally, a large and two small spines in distal third, and a pair of spines distally; fore tibia with one spine on middle third, and a pair of spines on distal margin; palar claw narrow, parallel sided, apically bent (Fig. 3G). Median lobe of sternite VII with two long setae and a serrated triangular apex. Free lobe: mesial angle broadly rounded, lateral angle produced, posterior margin straight, two long setae restricted to lateral angle. Left paramere: shaft relatively short and flattened, on mesial side near the middle with a large triangular tooth, apex of shaft narrowly rounded; basal part with a prominent projection on opposite side of large subovate basal lobe (Fig. 3I). Right paramere: shaft stout, longitudinally striated, apex rounded (Fig. 3H).

\section{Material examined}

VIETNAM - Phu Tho Prov. • 1 ð (brachypterous); Xuan Son N.P., Coi stream, site 1, by the road to Tan Son; $21^{\circ} 09.204^{\prime}$ N, $104^{\circ} 56.927^{\prime}$ E; 8 May 2016; T.S. Nguyen leg.; TS1617; ZVNU.

\section{Distribution}

First record for Vietnam. Other countries: Malaysia, Singapore (Nieser 2002a).

\section{Remarks}

Nieser (2002a) already noted the similarities and differences between three closely related species M. johorensis, M. dentifera Nieser, 2002, and M. eucosmeta Hutchinson, 1940. These three species can 
be placed in the subgenus Dichaetonecta as they possess a rather narrow palar claw, and the median lobe of sternite VII bears two long setae. The longitudinally striated shaft of the right paramere is a unique diagnostic characteristic for M. johorensis. Also see Remarks under M. sahlbergi.

Micronecta (Dichaetonecta) ludibunda Breddin, 1905

Figs $1 \mathrm{G}, 4 \mathrm{~A}-\mathrm{C}$

Micronecta ludibunda Breddin, 1905a: 57 (type locality: Bogor, Indonesia).

(For an extensive synonymy list, see Tinerella 2008.)

\section{Diagnosis}

Body length 1.9-2.4. Pronotum slightly longer than median head length. Pronotum: with a pair of dark oval rings, somtimes fragmented, reduced to streaks and spots, or absent. Hemelytron (Fig. 1G): corium with four longitudinal brown stripes; embolium with three brown marks.

Males: fore femur with two spines on proximal third and a pair of spines on distal third; fore tibia without spine; palar claw moderately widened, apex truncate. Median lobe of sternite VII with one or two long setae (sometimes absent) and a pointed apex (see Tinerella 2013: fig. 21f). Free lobe large, distally slightly broadened, posterior margin slightly concave, lateral angle with ca 10-15 long setae (Fig. 4A). Left paramere: shaft slender, constricted pre-apically; apex flattened, broadened and subovate; basal lobe large, tongue-shaped (Fig. 4C). Right paramere: shaft evenly curved, from distal fourth tapering towards narrowly rounded apex (Fig. 4B).

\section{Material examined}

VIETNAM - Lao Cai Prov. 1 đ̧; Sa Pa, Cat Cat, Muong Hoa stream; 22 Apr. 2011; N.H. Dinh et al. leg.; DNH11.01; ZVNU. - Vinh Phuc Prov. • 1 +; Tam Dao N.P., Ho Xanh (Green Lake); 17 Jun. 2003; A.D. Tran leg.; TAD0353; ZRC. - Hanoi • 1 ô, 1 क; Lotus pond 1 near West Lake Water Park (left); 17

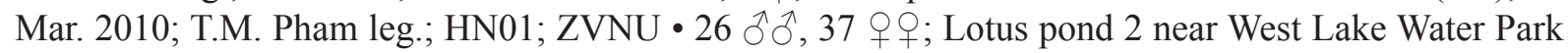
(right); 17 Mar. 2010; A.D. Tran leg.; ZVNU • $3 \widehat{\partial} \widehat{\partial}, 9$ 우우; Lotus pond 2 near West Lake Water Park (right); 20 Mar. 2010; A.D. Tran leg.; ZVNU $\bullet 8$ $\hat{\partial}, 1$ q; Lotus pond 2 near West Lake Water Park (right); 30 Mar. 2010; A.D. Tran leg.; ZVNU • 1 §, 1 o+; West Lake; 17 Mar. 2010; T.M. Pham leg.; HN03; ZVNU • 21 ふึ, 25 우; Thanh Xuan District, Thanh Huong Lake (used for recreational fishing),

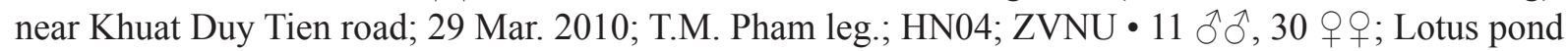
1 near West Lake Water Park (left); 18 Aug. 2010; A.D. Tran leg.; ZVNU • 1 đ̊; Nhue River; 18 Aug.

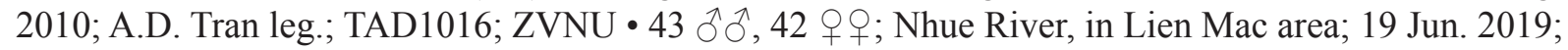
T.N. Ha leg.; NHHN19.01; ZVNU • 1 क ; Ba Vi N.P., Minh Quang, Cai stream; 65 m a.s.1.; 26 Apr. 2012; Q.H. Ngo et al. leg.; TAD1207; ZVNU. - Dong Nai Prov. 1 q; Cat Tien N.P.; 13 May 2003; A.D. Tran leg.; night collecting; TAD0302; ZRC 1 §̊;; Vinh Cuu, Ma Da, Bo Hao Lake, east side, near forest ranger station; 10 Apr. 2009; A.D. Tran leg.; TAD0906; ZVNU • 1 \%; Cat Tien N.P., Bau Sau (Crocodile Lake); 6 Nov. 2009; A.D. Tran leg.; TAD0929; ZVNU • 3 ồ, 1 우 Vinh Cuu, Ma Da stream, near Rang Rang Forest ranger station (near bridge); 13 Apr. 2010; T.D. Pham leg.; PTD1006; ZVNU • $4 \hat{\delta} \widehat{\delta}$, 6 o. ; Vinh Cuu, Ma Da stream, near Rang Rang Forest ranger station, ca $400 \mathrm{~m}$ downstream from

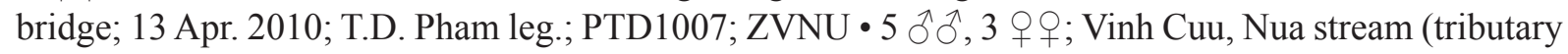

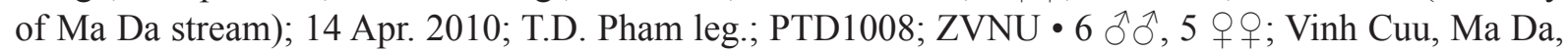
Bo Hao Lake, east side, near forest ranger station; 15 Apr. 2009; T.D. Pham leg.; PTD1009; ZVNU • 3 ડ̄o 11 o $q$; Tri An Lake (Chien Khu D bridge); 15 Apr. 2010; T.D. Pham leg.; PTD1011; ZVNU • 3 우 ; Vinh Cuu, Ma Da, Bo Hao Lake, east side, near forest ranger station; 16 Apr. 2010; A.D. Tran

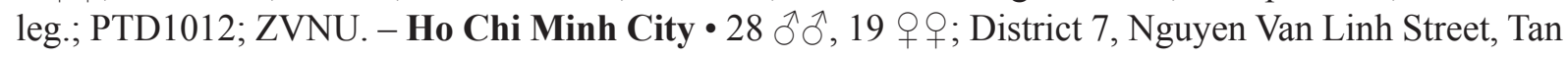


My Lake; 27 Apr. 2019; T.N. Ha leg.; NHSG19.01; ZVNU • 1 \%; District 2, Cao Duc Lan Street, Hai Ho Park, small lake; 1 May 2019; T.N. Ha leg.; NHSG19.03; ZVNU • 19 $\widehat{\jmath}, 11$ o of; District 2, Cao Duc Lan Street, Hai Ho Park, large lake; 1 May 2019; T.N. Ha leg.; NHSG19.04; ZVNU. - Ba RiaVung Tau Prov. • 1 क; Con Dao, Dam Trau area, Ong Ta stream; 13 Apr. 2010; A.D. Tran et al. leg.; TAD1009; ZVNU. - Ca Mau Prov. • 3 ổ ${ }^{2}, 1$ क; Tran Hoi commune, Vo Doi hamlet, Doi 1; 16 Apr. 2018; T.A.N. Nguyen leg.; CM1814; ZVNU • 1 o ; Tran Hoi commune, Vo Doi hamlet, Doi 1; 16 Apr. 2018; T.A.N. Nguyen leg.; CM1817; ZVNU • 1 Ô, 5 q $\odot$; U Minh District, Khanh An commune, hamlet \#14; 17 Apr. 2018; T.A.N. Nguyen leg.; CM1821; ZVNU. - Kien Giang Prov. • 1 q; Phu Quoc Island, Tranh stream (at lower section); 30 Nov. 2010; A.D. Tran et al. leg.; TAD1021; ZVNU.

\section{Distribution}

Vietnam: Hanoi (Wróblewski 1967); first records for Lao Cai, Vinh Phuc, Dong Nai, Ho Chi Minh City, Ba Ria-Vung Tau, Ca Mau, and Kien Giang (Phu Quoc Island).. Other countries: widespread from India, Sri Lanka (Hutchinson 1940; Wróblewski 1972a), Thailand (Wróblewski 1968), Cambodia (Zettel et al. 2017), Indonesia (Nieser \& Chen 1999), Peninsular Malaysia, Singapore (Nieser 2002b) to Solomon Islands (Tinerella 2013).
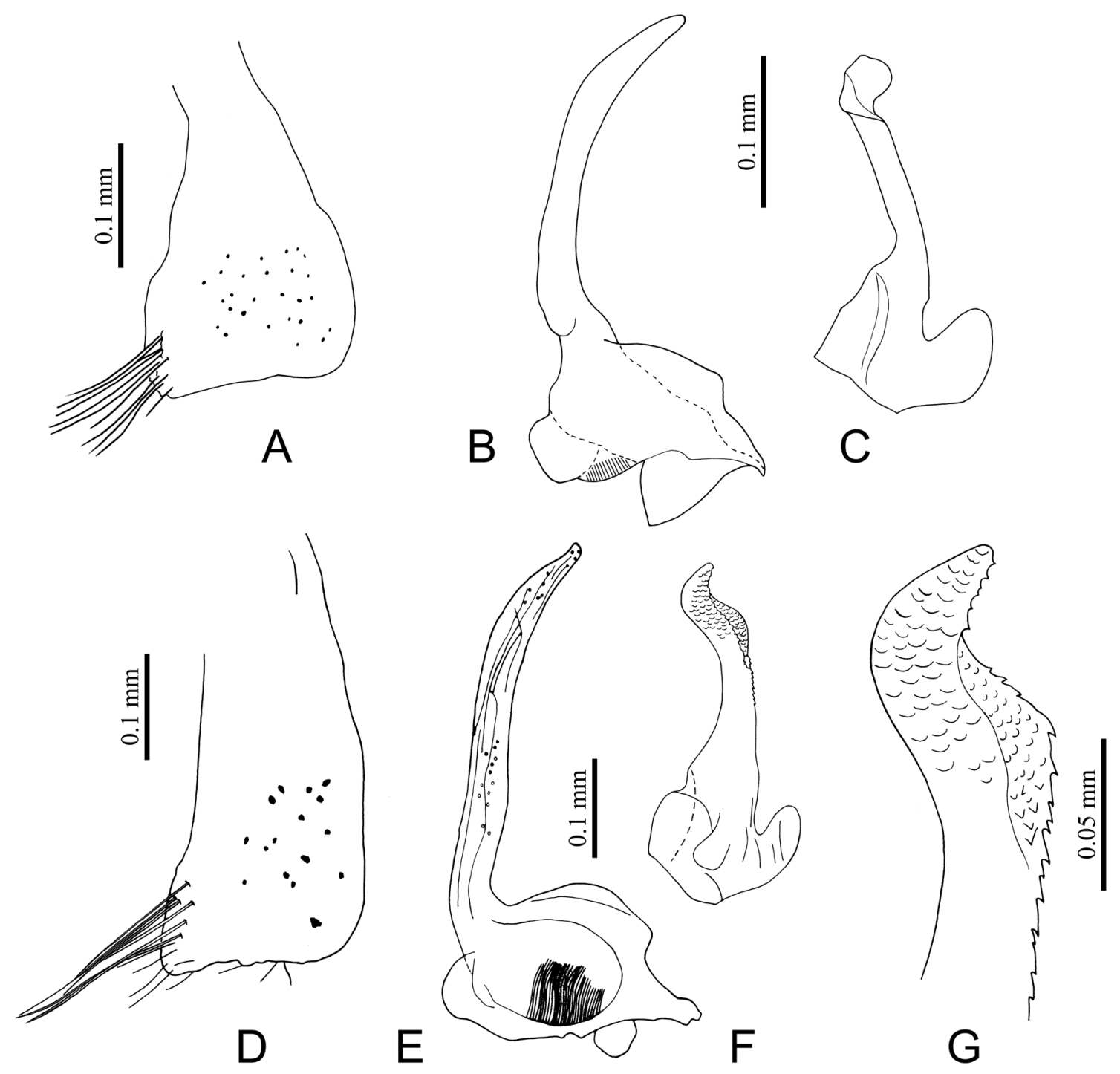

Fig. 4. Morphological features of species of Micronecta Kirkaldy, 1897, §ðð. A-C. M. ludibunda Breddin, 1905 (ZVNU). D-G. M. sahlbergi (Jakovlev, 1881) (ZVNU). A, D = free lobe; B, E = right paramere; $\mathrm{C}, \mathrm{F}=$ left paramere; $\mathrm{G}=$ apical part of left paramere. 


\section{Remarks}

Besides structural characteristics, $M$. ludibunda can usually be recognised by a pair of dark oval marks on the pronotum. This characteristic, however, is variable. In some specimens of M. ludibunda, the dark oval marks on the pronotum are fragmented, less distinct, or even absent. Micronecta ludibunda is also considered related to M. malayana Leong, 1966, from Peninsular Malaysia, in both the colour pattern of the pronotum and the general form of the left paramere (Nieser 2002b). The characteristics for separating these two species are the apical part of the left paramere, which is broader in M. malayana, and the pattern of hemelytra, which is more reticulate, without distinct stripes in M. malayana. Also see Remarks under M. sahlbergi.

Micronecta (Dichaetonecta) sahlbergi (Jakovlev, 1881)

Fig. 4D-G

Sigara sahlbergi Jakovlev, 1881: 213-214 (type locality: Amur, Russia).

Micronecta formosana Matsumura, 1915: 114-115, 119, pl. III, fig. 8 (type locality: Taiwan).

Micronecta sahlbergi - Horváth 1899: 101 (key). - Hutchinson 1940: 373-374 (listed as possibly identical to M. siva). - Wróblewski 1960: 306-309, pl. XV (redescription, synonymised M. formosana with M. sahlbergi); 1963: 476-478 (distribution); 1968: 776 (checklist). — Yang 1967: 46 (key). — Jansson 1995: 27 (catalogue).

Micronecta formosana - Chen 1960: 104, 106, pl. I (key, redescription).

\section{Diagnosis}

Body length 2.2-3.1. Pronotum slightly longer than median head length. Hemelytron punctate, generally pale.

Males: fore femur with a set of four spines on proximal third ventrally; fore tibia without spine; palar claw narrow. Median lobe of sternite VII with one long seta and a long and narrowly rounded apex. Free lobe posteriorly strongly broadened, posterior margin nearly straight, lateral angle produced (Fig. 4D). Left paramere: shaft slender, mesial side with barbs, apical part sinuate, covered with small scales, apex narrowly rounded; basal lobe tongue-shaped (Fig. 4F-G). Right paramere: shaft evenly curved, from distal fourth tapering towards narrowly rounded apex (Fig. 4E).

\section{Material examined}

VIETNAM - Hanoi • 1 ठ̊; Nhue River, in Lien Mac area; 25 Mar. 2010; T.M. Pham leg.; HN08; ZVNU.

\section{Distribution}

First record for Vietnam. Other countries: Russia (Amur-Ussuri), Korea, China (Beijing, Hong Kong, and southern China), Taiwan (Wrósblewski 1960, 1963, 1968; Chen 1960).

\section{Remarks}

Wróblewski (1963) and Jansson (1995) placed M. sahlbergi in the subgenus Basileonecta. Subsequently, Nieser et al. (2005) placed it in the subgenus Dichaetonecta without explanation. We find that this species matches the definition of Dichaetonecta rather than Basileonecta, by having a moderately widened palar claw, a well-developed median lobe of sternite VII with one long seta, and a distally-widened free lobe.

The five species of Dichaetonecta occurring in Vietnam can easily be separated from each other by the structures of the left paramere. The left paramere of $M$. decorata is apically constricted and twisted. That of M. ludibunda is constricted before widening to a broad, flat, and suboval apex. The left paramere of 
M. sahlbergi is uniquely sinuate at the apical part, which is covered with small scales. In M. desertana, the apical part of left paramere is rather simple, only slightly constricted, but neither twisted nor sinuate. The left paramere of $M$. johorensis has a large triangular tooth near the middle section of the shaft. The right paramere of $M$. johorensis is unique in having longitudinal striations on the stout shaft. In addition, the shape of the free lobe of $M$. decorata is clearly distinct from that of the other three species besides $M$. johorensis, with the posterior margin produced into an obtuse angle, while in the other three species the posterior margin of the free lobe is straight or slightly concave. The free lobe of M. ludibunda is more like that of $M$. sahlbergi, with both having a more strongly widened distal part. The free lobe of M. desertana is only slightly widened at the distal part.

Micronecta (Indonectella) grisea (Fieber, 1844)

Figs 5A, 6A-D

Sigara grisea Fieber, 1844: 14, table 1, fig. 21 (type locality not specified).

Micronecta thyesta Distant, 1910: 349-350 (type locality: Madhupur, India).

Micronecta pilosella Matsumura, 1915: 115, 119 (type locality: Taiwan).

Micronecta grisea - Kirkaldy 1908: 209 (list). - Wróblewski 1968: 772-773, 775 (synonymy, checklist); 1972a: 23-25, 50, tables 1-2, figs 36, 40 (additional notes, key). — Fernando \& Cheng 1974: 37. - Jansson 1995: 30-31 (catalogue). - Nieser \& Chen 1999: 79-80, table 2, fig. 44 (key, notes, distribution). - Nieser 2000: 286, fig. 31 (key); 2002b: 265, 267, fig. 10 (key, notes). Nieser et al. 2005: 190 (checklist).

Micronecta pilosella - Chen 1960: 117 (synonymised with M. thyesta).

Micronecta thyesta - Hutchinson 1940: 363-365, figs 64-75 (redescription, assigned to subgenus Indonectella). - Wróblewski 1962: 177 (notes); 1967: 240 (notes); 1968: 772 (synonymised with M. grisea). — Fernando 1964: 606, fig. 11, 22, 33 (diagnosis). — Leong 1966: 84, 88 (notes, key).

\section{Diagnosis}

Body length 3.0-3.1. Pronotum slightly longer than median head length; clearly narrower than head width. Hemelytron (Fig. 5A) translucent or greyish brown, usually with two broken longitudinal dark stripes; embolium with a large spot in the middle and two smaller spots on two sides.

Males: fore femur with a pair of spines on proximal third; fore tibia with a spine on middle third (Fig. 6A); palar claw, median lobe of sternite VII and free lobe (Fig. 6B) as in diagnosis for subgenus. Left paramere: shaft slender, evenly arched; distal part with small barbs; apex recurved, flattened, thus appearing flag-like; basal lobe short and broad (Fig. 6D). Right paramere: shaft distally curved, tapering from distal half towards narrowly rounded apex (Fig. 6C).

\section{Material examined}

VIETNAM - Ninh Thuan Prov. 3 ổ đ̧; Nui Chua N.P., Da Vach Lake; 27 Jun. 2004; N.V. Quang leg.; NC-01; ZRC.

\section{Distribution}

Vienam: Hanoi, Lao Cai, Ninh Binh (Cuc Phuong), Nghe An, Ha Tinh (Wróblewski 1962, 1967); first record for Ninh Thuan. Other countries: widespread from India, Sri Lanka to southern China, Taiwan, Peninsular Malaysia, and Indonesia (Sumatra, Java) (Leong 1966; Fernando \& Cheng 1974; Nieser \& Chen 1999; Nieser et al. 2005). 


\section{Remarks}

This species can easily be recognised by the relatively large body (length ca $3.0 \mathrm{~mm}$ ), the absence of a strigil, the shape of the the free lobe, and the shape of the apical part of the left paramere (Fig. 6B, D).

Micronecta (Lundbladella) guttatostriata Lundblad, 1933

Figs 5B, 6E-H

Micronecta guttatostriata Lundblad, 1933b: 101-102, pl. I (type locality: Java, Indonesia).

Micronecta guttatostriata - Wróblewski 1967: 240, 242-243, figs 11-16 (redescription, assigned to subgenus Lundbladella); 1968: 775 (checklist). — Nieser 2000: 287, fig. 39 (key); 2002b: 266, fig. 7 (notes, key). — Polhemus 2017: 127 (record Cambodia).

\section{Diagnosis}

Body length 2.0-2.4. Dorsum generally dark brown. Pronotum slightly longer than median head length, with two transverse yellow stripes on anterior part. Hemelytron (Fig. 5B) with yellowish brown background and longitudinal yellowish stripes usually fragmented into small dots; embolium with three translucent patches.

Males: fore femur with a pair of spines on proximal third ventrally; fore tibia without spine (Fig. 6E); palar claw, median lobe of sternite VII and free lobe (Fig. 6F) as in diagnosis for subgenus. Left paramere: shaft slender, basally straight and curved at distal fourth; basal lobe broad, trapezoid (Fig. 6H). Right paramere: shaft broadly curved, distal half strongly broadened (Fig. 6G).

\section{Material examined}

VIETNAM - Cao Bang Prov. 1 ô; Bao Lam, near Bao Lam district town, Ban Chim stream, tributary of Gam River; 20 Dec. 2013; A.D. Tran et al. leg.; TAD1382; ZVNU. - Phu Tho Prov. • 1 ô; Xuan Son N.P., Ha Bang stream, near its confluence with Xoan stream; $21^{\circ} 5.318^{\prime}$ N, $104^{\circ} 58.87^{\prime}$ E; 26 Aug. 2014; T.S Nguyen. leg.; TS1406; ZVNU • 1 q; Xuan Son N.P., Coi stream, site 1, by the road to Tan Son; $21^{\circ} 09.204^{\prime}$ N, $104^{\circ} 56.927^{\prime}$ E; 27 Aug. 2015; T.S. Nguyen leg.; TS8517; ZVNU • 2 우; Xuan Son N.P., Ha Bang stream, Ha Bang village area; $21^{\circ} 04.343^{\prime}$ N, $104^{\circ} 59.182^{\prime}$ E; 7 May 2016; T.S. Nguyen leg.; TS1610; ZVNU. - Hanoi • 1 ô; Ba Vi N.P., Minh Quang, Cai stream; 65 m a.s.l.; 26 Apr. 2012; Q.H. Ngo et al. leg.; TAD1207; ZVNU • 1 \&; Ba Vi N.P., Khoang Xanh, Tien stream; 95 m a.s.l.; 27 Apr. 2012; Q.H. Ngo and A.D. Tran leg.; TAD1208; ZVNU. - Thanh Hoa Prov. • 1 ơ; Ben En N.P., Nhu Xuan, Khe May stream; Dec. 2012; T.D. Pham leg.; BE1206; ZVNU • 1 q; Pu Luong Nature Reserve, Quan Hoa, Phu Nghiem, Dong Tam, Luong stream; 15 Mar. 2013; T.D. Pham leg.; PL 1301; ZVNU. Nghe An Prov. • 1 ภ, 1 क; Con Cuong, near Tung Huong, Khe Num stream; 21 Dec. 2012; Q.H. Ngo leg.; NQH1211; ZVNU • 6 ô, 8 우; Pu Mat N.P., Chat stream, tributary of Choang stream; 1 Sep. 2020; A.D. Tran et al. leg.; TAD20-14; ZVNU. - Dong Nai Prov.・ 1 +; Cat Tien N.P., Ben Cu stream; 5 Nov. 2009; A.D. Tran leg.; TAD0928; ZVNU • 1 \&; Vinh Cuu, Ma Da stream, near Rang Rang Forest ranger station, ca $400 \mathrm{~m}$ downstream from bridge; 13 Apr. 2010; T.D. Pham leg.; PTD1007; ZVNU.

\section{Distribution}

Vietnam: Ninh Binh (Cuc Phuong) (Wróblewski 1967); first records for Cao Bang, Phu Tho, Hanoi, Thanh Hoa, Nghe An, Dong Nai. Other countries: southwestern China, Thailand, Indonesia, Peninsular Malaysia, Cambodia (Lundblad 1933b; Nieser 2000, 2002b; Nieser et al. 2005; Polhemus 2017).

\section{Remarks}

In Vietnam, M. guttatostriata is one of two species without a strigil; the other one is M. grisea. Micronecta guttatostriata can be separated from the latter by its distinctly smaller size, with body length of around 2.0-2.4 mm, and the unique colour pattern of the pronotum. In addition, the shape of the free lobe and the parameres are reliable characteristics for identifying this species. 


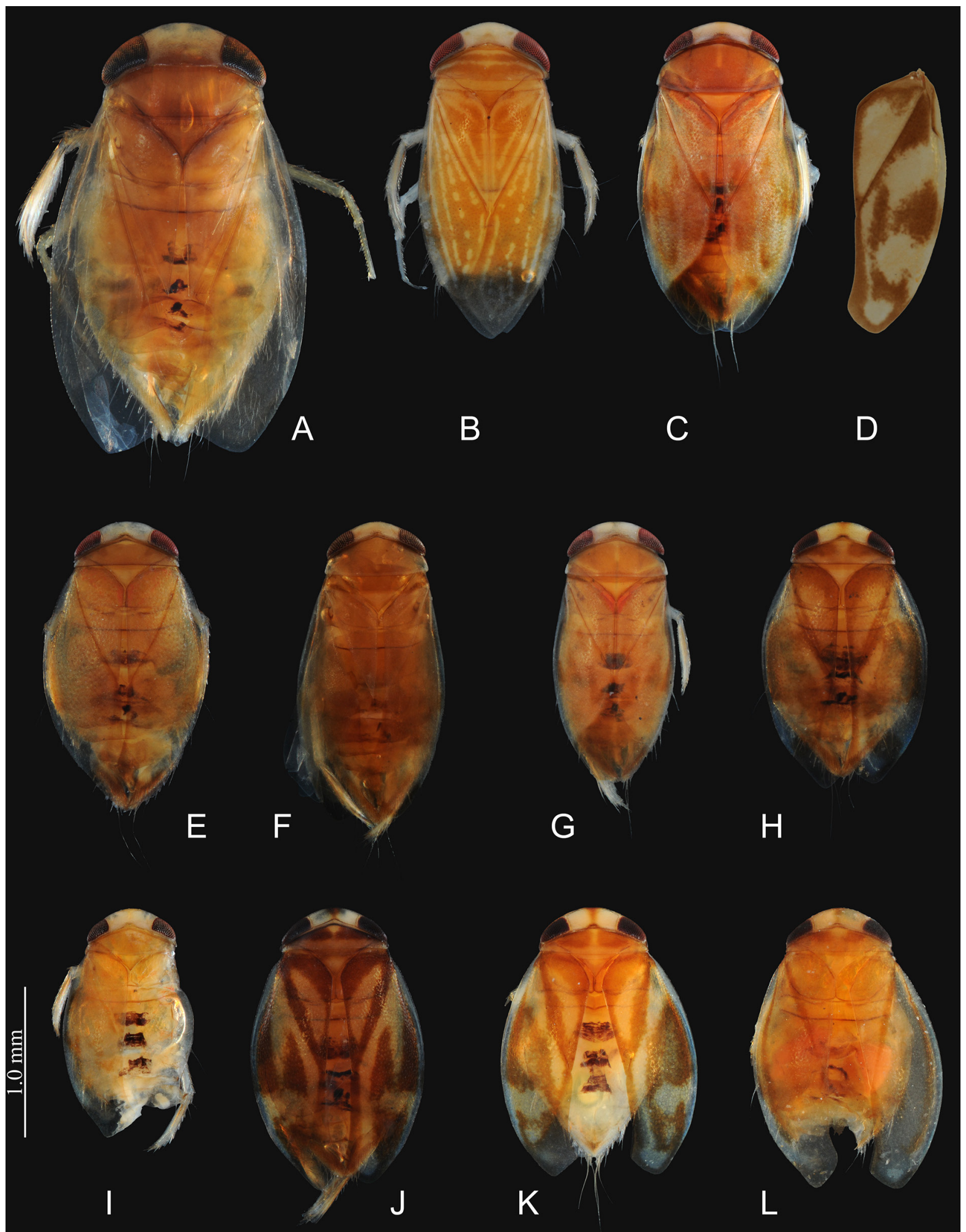

Fig. 5. Habitus photos of species of Micronecta Kirkaldy, 1897, ふૈર. A. M. grisea (Fieber, 1844) (ZRC). B. M. guttatostriata Lundblad, 1933 (ZVNU). C. M. drepani Nieser, 2000 (ZVNU). D. M. erythra Nieser, Chen \& Yang, 2005, right hemelytron (ZVNU). E. M. cultellata sp. nov., holotype (ZVNU). F. M. anatolica Lindberg, 1922 (ZVNU). G. M. arcuata sp. nov., holotype (ZVNU). H. M. fulvopicta sp. nov., holotype (ZVNU). I. M. acuminata sp. nov., holotype (ZVNU), right hemelytron and genitalia dissected. J-L. M. vietnamica sp. nov., J = holotype (ZVNU). All to the same scale. 

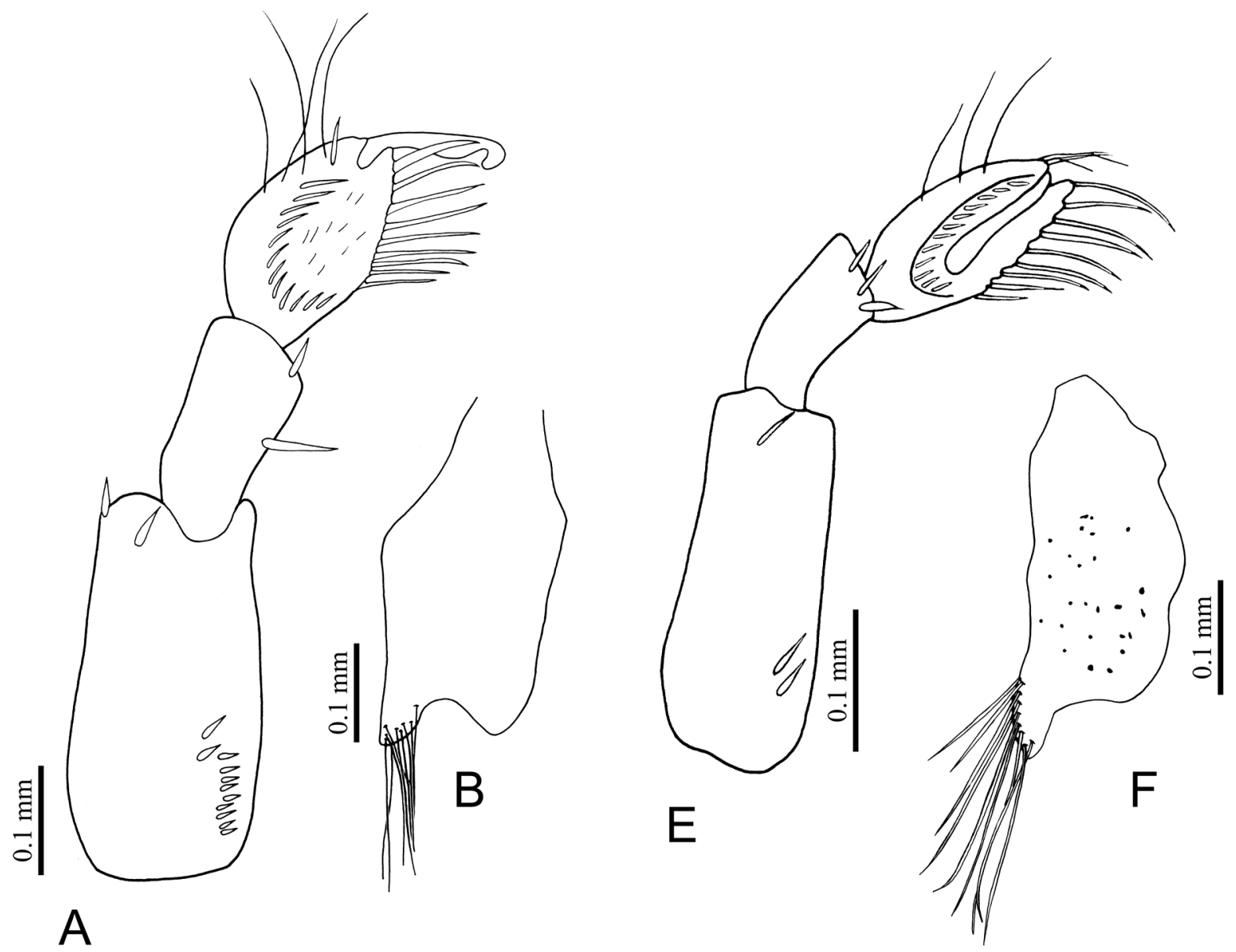

A
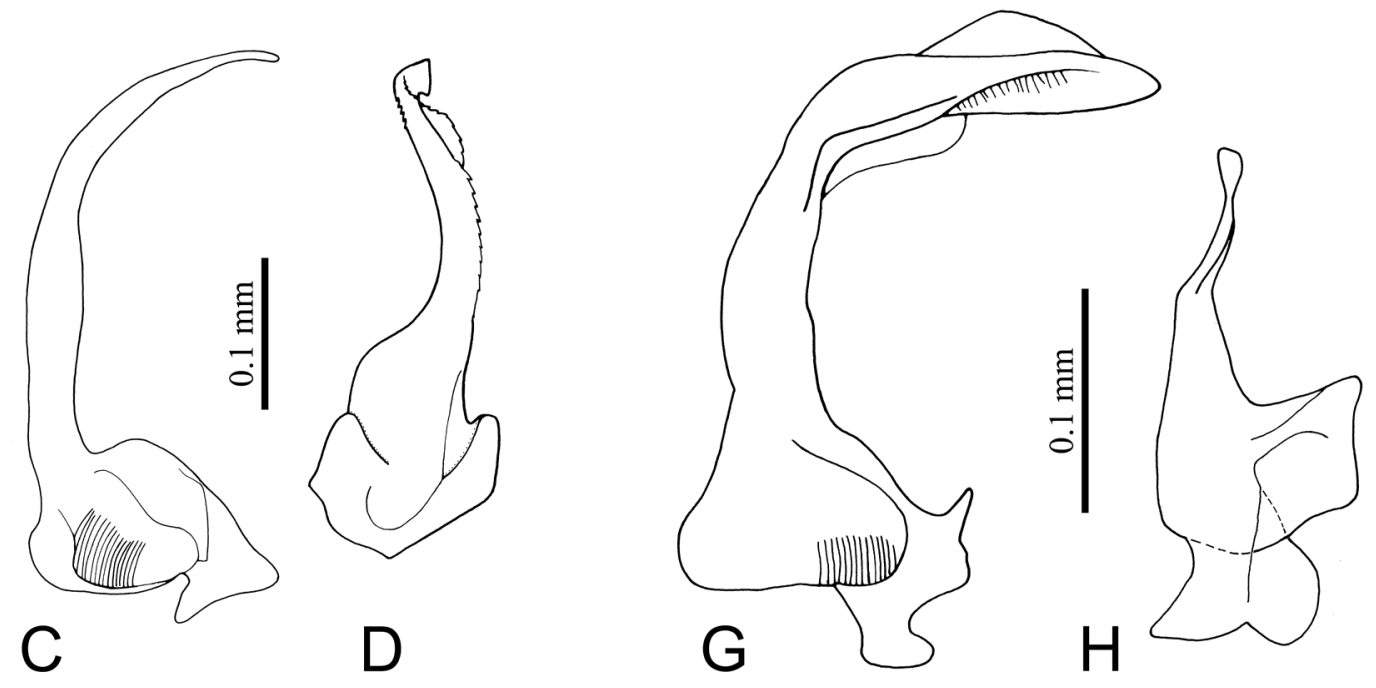

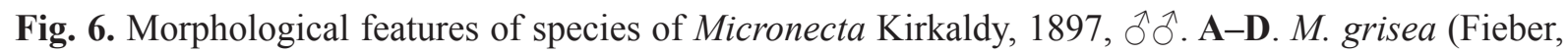
1844) (ZVNU). E-H. M. guttatostriata Lundblad, 1933 (ZVNU). A, E = fore leg; B, F = free lobe; C, $\mathrm{G}=$ right paramere; $\mathrm{D}, \mathrm{H}=$ left paramere. 


\section{Micronecta (Micronecta) drepani Nieser, 2000}

Figs $5 \mathrm{C}, 7 \mathrm{~A}-\mathrm{C}$

Micronecta drepani Nieser, 2000: 278-281, 287, figs 1-10 (type locality: northern Thailand).

Micronecta drepani - Nieser et al. 2005: 190, 191 (notes, checklist). — Zettel et al. 2017: 40 (record Cambodia).

\section{Diagnosis}

Body length 1.9-2.1. Pronotum slightly longer than median head length. Hemelytron punctate, corium with patchy, indistinct brown markings.

Males: fore femur with a pair of spines on proximal third, two spines distally; fore tibia with three spines on distal third ventrally; palar claw large, sub-triangular with straight apical margin. Median lobe of sternite VII short and broad with four long setae and an angular apex. Free lobe slightly expanded posteriorly, mesial angle rounded, lateral angle produced with ca 20 long setae (Fig. 7A). Left paramere: shaft broad, flattened, basal part of shaft with a short ridge running to lateral margin, apex rounded; basal lobe long, tongue-shaped (Fig. 7C). Right paramere: shaft evenly curved, parallel sided, apex rounded (Fig. 7B).

\section{Material examined}

VIETNAM - Ha Giang Prov. 1 ô, 2 우; Vi Xuyen, Xin Chai commune, Da stream by the road from Thanh Thuy to Lao Chai; 9 May 2014; A.D. Tran et al. leg.; TAD1405; ZVNU・1 ठ̂; Xin Man, road 178, tributary of Nam Yen River, near bridge ca 2 km from Coc Pai town; 11 May 2014; A.D. Tran et al. leg.; TAD1412; ZVNU • 1 ภ, 1 क; Xin Man, Nam Dan commune, Thac Tien-Deo Gio, waterfall and stream;

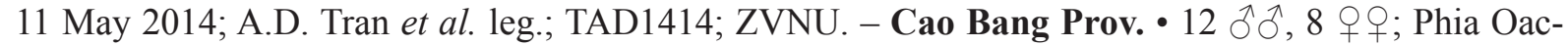
Phia Den N.P., road to Quang Thanh commune, Khue Lan stream; 29 Oct. 2020; V.V. Nguyen et al. leg.; PO20-07; ZVNU. - Bac Kan Prov. 8 ô ${ }^{\lambda}, 9$ 우; Ba Be, Hoang Tri commune, Hoang Tri waterfall; 22 Aug. 2012; A.D. Tran et al. leg.; TAD1218; ZVNU. - Lang Son Prov. 3 ô $\hat{\text {, }, ~} 9$ q $o+$; Loc Binh, Mau Son, Khuoi Tang stream; 590 m a.s.l.; 6 Nov. 2020; A.D. Tran et al. leg.; TAD20-34; ZVNU. - Phu Tho Prov. 2 9 ; Xuan Son N.P., Ban Coi, Coi stream, site 3, by the road to Tan Son; 7 Jun. 2013; A.D. Tran

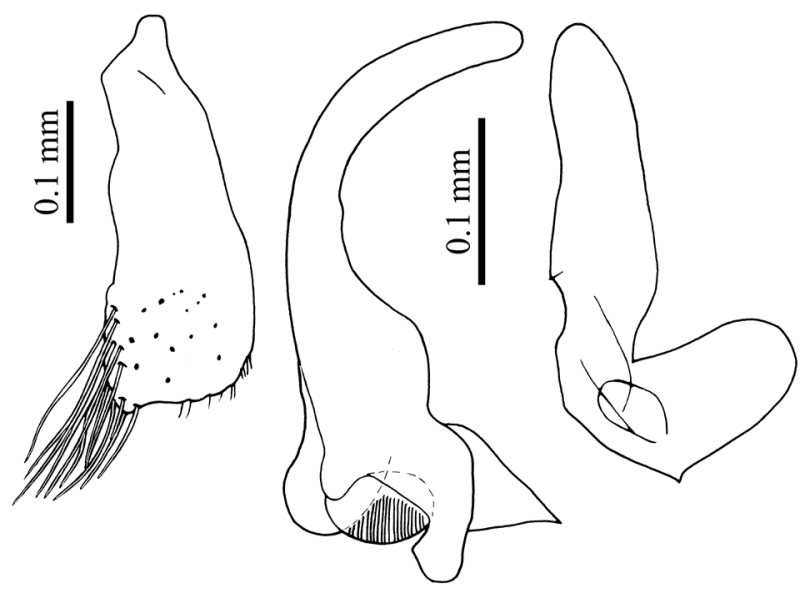

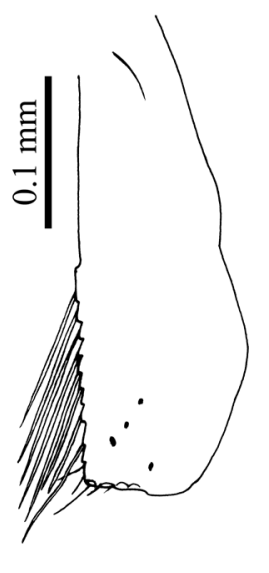

D

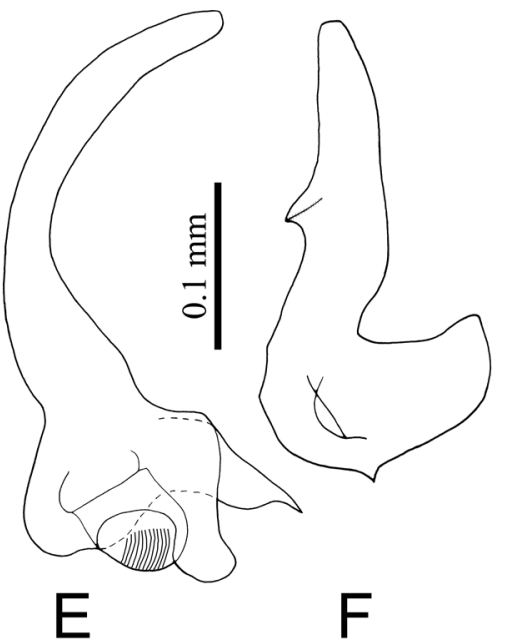

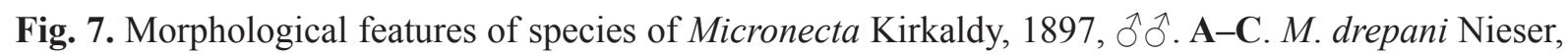
2000 (ZVNU). D-F. M. erythra Nieser, Chen \& Yang, 2005 (ZVNU). A, D = free lobe; B, E = right paramere; $\mathrm{C}, \mathrm{F}=$ left paramere. 
et al. leg.; TAD1339; ZVNU • 3 ふैगे, 2 우; Xuan Son N.P., Dong Son, Than stream, site 2; 29 Aug. 2013; A.D. Tran et al. leg.; TAD1347; ZVNU • $3 \hat{\partial} \hat{\partial}, 10$ 우; Xuan Son N.P., Xoan stream, near its confluence with Ha Bang stream; 21 ${ }^{\circ} 5.303^{\prime}$ N, 10457.559' E; 27 Aug. 2014; T.S. Nguyen leg.; TS1407; ZVNU • 4 ô, 4 우; Xuan Son N.P., Lap stream, the second concrete bridge from Ngoc waterfall;

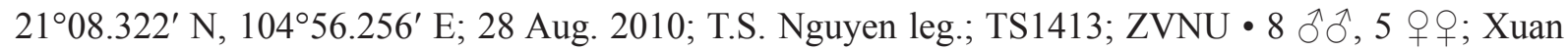
Son N.P., Than stream, site 2; $21^{\circ} 11.257^{\prime}$ N, $104^{\circ} 52.382^{\prime}$ E; 28 Aug. 2014; T.S. Nguyen leg.; TS1415;

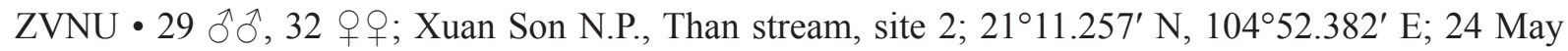

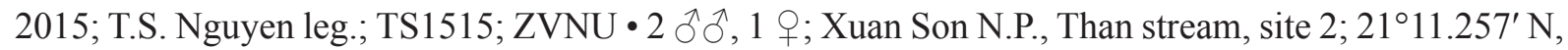
10452.382' E; 8 May 2016; T.S. Nguyen leg.; TS1615; ZVNU • 3 ふぇ, 7 우; Xuan Son N.P., Coi stream, site 2, near concrete bridge; $21^{\circ} 09.130^{\prime} \mathrm{N}, 104^{\circ} 56.761^{\prime}$ E; 29 Apr. 2014; T.S. Nguyen leg.;

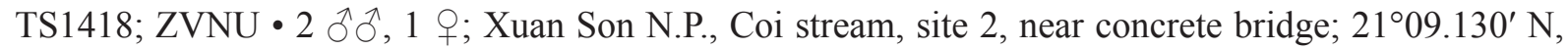

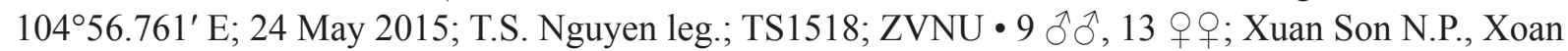
stream, Xoan village area; $21^{\circ} 05.270^{\prime} \mathrm{N}, 1^{\circ} 4^{\circ} 57.591^{\prime} \mathrm{E}$; 23 May 2015; T.S. Nguyen leg.; TS1509; ZVNU • 1 ○’, 8 우우 Xuan Son N.P., Xoan stream, Xoan village area; $21^{\circ} 05.270^{\prime}$ N, $104^{\circ} 57.591^{\prime}$ E; 26 Aug. 2015; T.S. Nguyen leg.; TS8509; ZVNU • $4 \hat{\jmath} \widehat{\partial}, 4$ $q$ q ; Xuan Son N.P., Xoan stream, Xoan

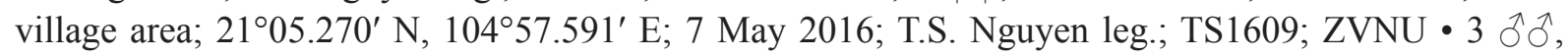
7 우; Xuan Son N.P., Than stream, site 3; $21^{\circ} 11.393^{\prime}$ N, 104 52.625’ E; 27 Aug. 2015; T.S. Nguyen leg.; TS8516; ZVNU • 5 $\widehat{\partial}, 1$ \% ; Xuan Son N.P., Lap stream, the first concrete bridge from Ngoc waterfall;

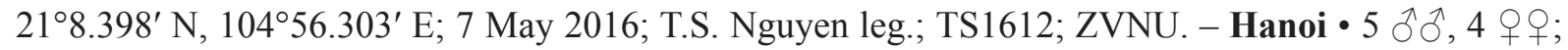
Ba Vi N.P., Minh Quang, Cai stream; 65 m a.s.1; 17 Dec. 2011; Q.H. Ngo et al. leg.; TAD1126; ZVNU •

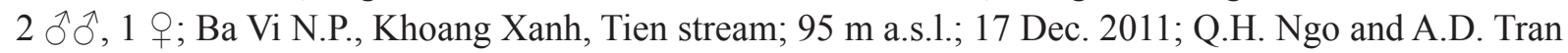
leg.; TAD1127; ZVNU・ 4 ठ̊̄, 4 우; Ba Vi N.P., Minh Quang, Cai stream; 65 m a.s.1.; 26 Apr. 2012; Q.H. Ngo et al. leg.; TAD1207; ZVNU • 1 §ै; Ba Vi N.P., Khoang Xanh, Tien stream; 95 m a.s.1.; 27 Apr. 2012; Q.H. Ngo and A.D. Tran leg.; TAD1208; ZVNU. - Vinh Phuc Prov. 2 ồ 1 , 1 ; Tam Dao N.P., Suoi Mo (upstream of Thac Bac waterfall); 16 Jun. 2003; A.D. Tran leg.; TAD0350; ZRC 5 ठð 5 q o⿱; Tam Dao N.P., Suoi Mo; 9 and 15 Jul. 2019; A.D. Tran leg.; ZVNU. - Quang Binh Prov. • 2 + O ; Phong Nha, Chay stream; 17 Jul. 2004; A.D. Tran leg.; DY0410; ZRC. - Quang Nam Prov. •

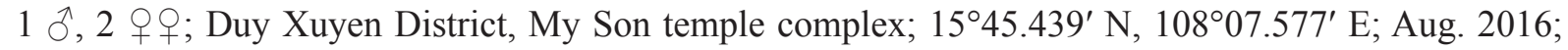
T.D. Chu leg.; MS1614; ZVNU • 1 q; Duy Xuyen District, My Son temple complex; $15^{\circ} 45.482^{\prime}$ N,

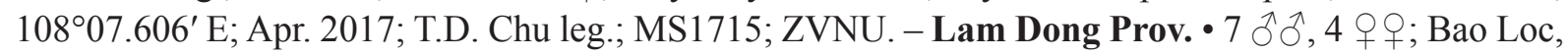
Damb'ri waterfall; 19 May 2003; A.D. Tran leg.; TAD0326; ZRC.

\section{Distribution}

China (Yunnan), Thailand (Nieser et al. 2005), Cambodia (Zettel et al. 2017). First records for Vietnam.

\section{Remarks}

See Remarks under M. cultellata sp. nov.

\section{Micronecta (Micronecta) erythra Nieser, Chen \& Yang, 2005}

Figs 5D, 7D-F

Micronecta erythra Nieser, Chen \& Yang, 2005: 191-192, 194, figs 1-11 (type locality: Yunnan, China).

\section{Diagnosis}

Body length 1.5-1.6 (brachypterous). Pronotum slightly shorter than median head length, lateral margins of pronotum short. Hemelytron light brown with scattered small red dots and distally with a transverse irregularly-shaped dark mark (Fig. 5D). 
Males: fore femur with a pair of spines on distal third, one spine on dorsal margin of distal third and two spines dorsodistally; fore tibia with one spine on distal third; palar claw broadened distally, apex rounded. Median lobe of sternite VII short and broad, with four long setae and an angular apex. Free lobe slightly expanded at middle part, then tapering posteriorly, mesial angle rounded, lateral angle square, with ca 17 long setae (Fig. 7D). Left paramere: shaft broad, flattened, lateral side with a distinct triangular projection, apex rounded; basal lobe length greater than its width, sub-trapezoid (Fig. 7F). Right paramere: shaft evenly curved, distal half parallel sided, apex rounded (Fig. 7E).

\section{Material examined}

VIETNAM - Phu Tho Prov. $・ 2$ $\widehat{\jmath}$ (brachypterous); Xuan Son N.P., Coi stream, site 1, by the road to Tan Son; $21^{\circ} 09.204^{\prime}$ N, $104^{\circ} 56.927^{\prime}$ E; 8 May 2016; T.S. Nguyen leg.; TS1617; ZVNU.

\section{Distribution}

Previously only known from China (Yunnan). First records for Vietnam (Phu Tho).

\section{Remarks}

According to the description by Nieser et al. (2005), the hemelytron of this species is marked with small red dots, but our specimens do not exhibit this characteristic. However, our sample is too small to determine whether intra-populational variations in colouration may be present. Other morphological characteristics of our specimens totally match the original description. Also see Remarks under M. cultellata sp. nov.

\section{Micronecta (Micronecta) cultellata sp. nov. urn:lsid:zoobank.org:act:A59D915E-EEA7-4278-B2B0-4C0707189B6F}

Figs 5E, 8

\section{Diagnosis}

Body length 1.6-2.2. Pronotum slightly shorter than median head length, lateral margin of pronotum short. Hemelytron punctate, orangish (Fig. 5E).

Males: fore femur with a pair of spines on proximal third ventrally, one spine in distal third, three spines distally, and one long seta dorsodistally; fore tibia without spine; palar claw broad, apex rounded (Fig. 8A). Median lobe of sternite VII short and broad, with an angular apex and four long setae (Fig. 8C). Free lobe long, mesial angle obtuse, lateral angle square, with ca 20 long setae (Fig. 8D). Left paramere: shaft broad, flattened, apex narrowly rounded; basal lobe sub-rectangular (Fig. 8F). Right paramere: shaft evenly curved, distal half parallel sided, apex rounded; pars stridens processus with ca 30 ridges (Fig. 8E).

\section{Etymology}

The species epithet refers to the shape of the left paramere's shaft, which resembles the blade of a knife.

\section{Material examined}

\section{Holotype}

VIETNAM • \’; Lao Cai Prov., Sa Pa, Trung Chai, km 119 Nat. Road \#4D; 28 Oct. 2013; Q.H. Ngo et al. leg.; TAD1370; ZVNU.

\section{Paratypes}

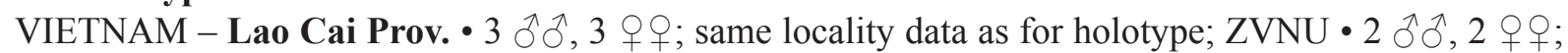
same locality data as for holotype; NHMW • 4 ठðં; Sa Pa, Nam Cang, Nam Cang stream; 23 Oct. 2012; 


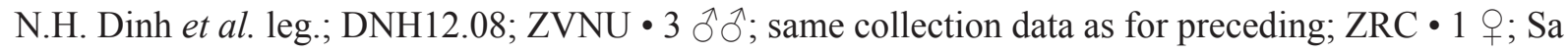
$\mathrm{Pa}$, waterfall by roadside from Nui Xe to $\mathrm{Sa} \mathrm{Pa}$ town, ca $13 \mathrm{~km}$ from Sa Pa; 25 Oct. 2013; A.D. Tran et al. leg.; TAD1358b; ZVNU • 1 क ; Sa Pa, Thanh Phú, Nậm Cang stream; 26 Oct. 2013; A.D. Tran et al. leg.; TAD1359; ZVNU • 1 \%; Sa Pa, Cat Cat, Ho stream (tributary of Muong Hoa stream); 27 Oct. 2013; A.D. Tran et al. leg.; TAD1366; ZVNU. - Ha Giang Prov. • 1 ऊ ${ }^{\top}$; Vi Xuyen, Xin Chai commune, Da stream by the road from Thanh Thuy to Lao Chai; 9 May 2014; A.D. Tran et al. leg.; TAD1405; ZVNU • 1 ऽ, 1 + ; Xin Man, Nam Dan commune, Thac Tien-Deo Gio, stream $100 \mathrm{~m}$ below waterfall; 11 May 2014; A.D. Tran et al. leg.; TAD1413; ZVNU. - Cao Bang Prov. • 2 q $o$; Quang Uyen, road 207, Doc Lap commune, stream \#2; 18 Dec. 2013; A.D. Tran et al. leg.; TAD1374; ZVNU.

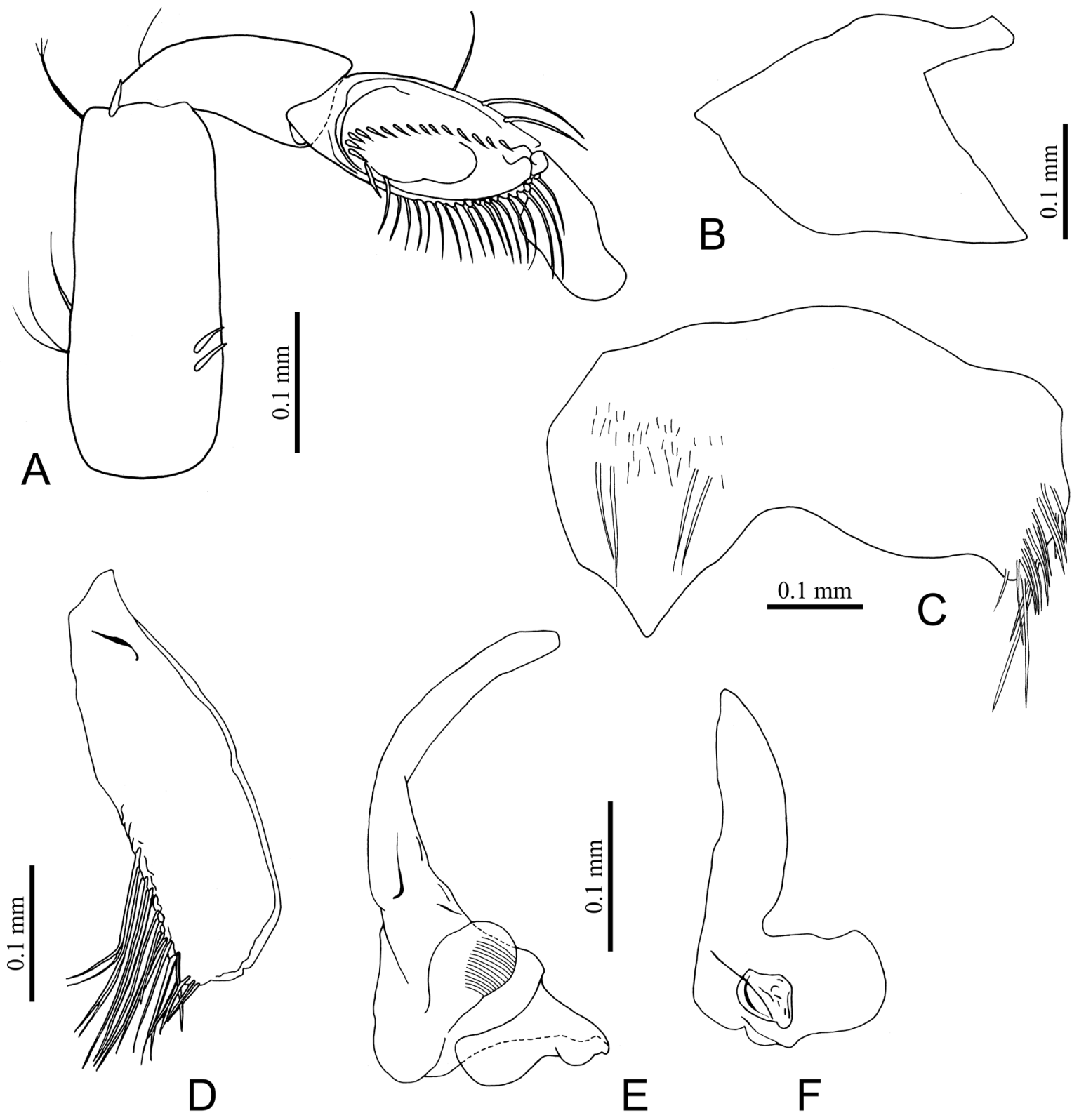

Fig. 8. Morphological features of Micronecta cultellata sp. nov., đ̂, paratype (ZVNU). A. Fore leg. B. Prestrigilar flap. C. Sternite VII and median lobe. D. Free lobe. E. Right paramere. F. Left paramere. 


\section{Description}

Colour (Fig. 5E). Dorsum generally light orangish. Frons and vertex pale yellowish, eyes reddish brown. Pronotum light greyish brown. Hemelytron light orangish, without distinct mark. Suture between clavus and corium brownish, a band with minute red dots along anterior margin of clavus. Membrane translucent apically. Venter of thorax and abdomen, and legs brownish yellow.

\section{Structural characteristics}

Macropterous Males. Body length 1.78-2.16 (holotype: 1.93), width 1.0-1.16 (holotype: 1.13). Head width $0.75-0.78$ (holotype: 0.70 ), slightly wider than pronotum. Pronotum about four times as wide as long, width 0.71 , length 0.18 . Synthlipsis about twice the posterior width of an eye $(0.35: 0.18)$. Lengths of leg segments: fore leg: femur 0.30 , tibia 0.17 , pala 0.14 ; middle leg: femur 0.65 , tibia 0.20 , tarsus 0.34 , claw 0.16; hind leg: femur 0.45 , tibia 0.36 , tarsus I 0.36 , tarsus II 0.18 , claw 0.05 . Prestrigilar flap on segment V elongated, with weakly acute apex (Fig. 8B). Strigil present. Median lobe of sternite VII, free lobe, and parameres as in diagnosis.

Macropterous females. Body length 1.63-2.09, width 0.9-1.19. Head width 0.74-0.80, slightly wider than pronotum. Pronotum about four times as wide as long, width 0.75 , length 0.19 . Synthlipsis about twice the posterior width of an eye $(0.36: 0.19)$. Lengths of leg segments: fore leg: femur 0.27 , tibiotarsus 0.21 ; middle leg: femur 0.76 , tibia 0.27 , tarsus 0.32 , claw 0.20 ; hind leg: femur 0.41 , tibia 0.32 , tarsus I 0.36, tarsus II 0.16, claw 0.09 .

\section{Distribution}

Vietnam: northern area (Cao Bang, Ha Giang, Lao Cai).

\section{Remarks}

Micronecta cultellata sp. nov. is similar to M. drepani and M. erythra in the general form of the right paramere, with the evenly curved shaft, and in the shape of the free lobe. These three species can be separated from each other by the characteristics as follows. Micronecta erythra has a distinct colour pattern on the hemelytra and a distinct triangular projection on the lateral side of the left paramere. Micronecta drepani has dark marks on the hemelytra, but they do not form a distinct pattern. The left paramere of $M$. drepani has a short ridge running onto the lateral margin of the shaft, and the apex of the shaft is broad. Micronecta cultellata sp. nov. has a light orangish dorsum, without dark markings, and its left paramere lacks modifications on the lateral margin, with the apex narrow. The right paramere of $M$. drepani differs from that of $M$. erythra and $M$. cultellata sp. nov. by having a thicker, swollen basal part of the shaft (on the mesial side). This structure is not swollen in M. erythra and M. cultellata sp. nov., but gradually tapering to the distal part instead.

\section{Micronecta (Micronecta) anatolica Lindberg, 1922}

Figs 5F, 9A-E

Micronecta anatolica Lindberg, 1922: 116 (type locality: Anatolia, Turkey). Micronecta parvula Lindberg, 1922: 116 (type locality: Jericho, Israel). Micronecta wui kashmirica Hutchinson, 1940: 356-358, figs 32-37, 41, 45-47 (type locality: Kashmir). Micronecta yemenensis Brown, 1951: 255 (type locality: Migyal-el-Alaf, Yemen).

Micronecta parvula - Wróblewski 1968: 774 (synonymised with M. anatolica). Micronecta wui kashmirica - Wróblewski 1968: 754, 775 (synonymised with M. anatolica). Micronecta yemenensis - Wróblewski 1968: 774-775 (synonymised with M. anatolica). 


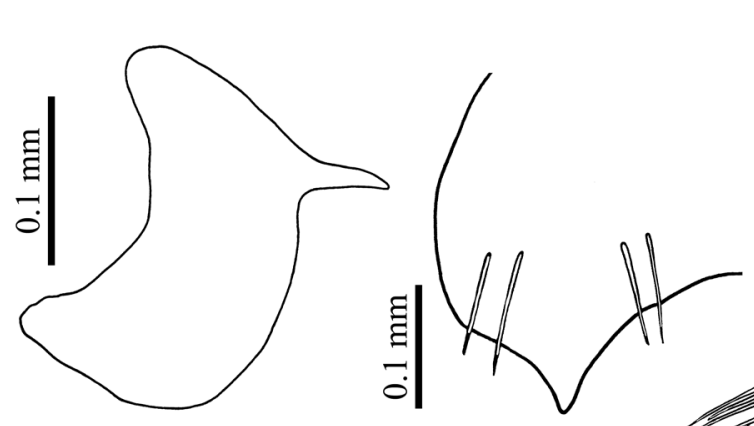

A

B
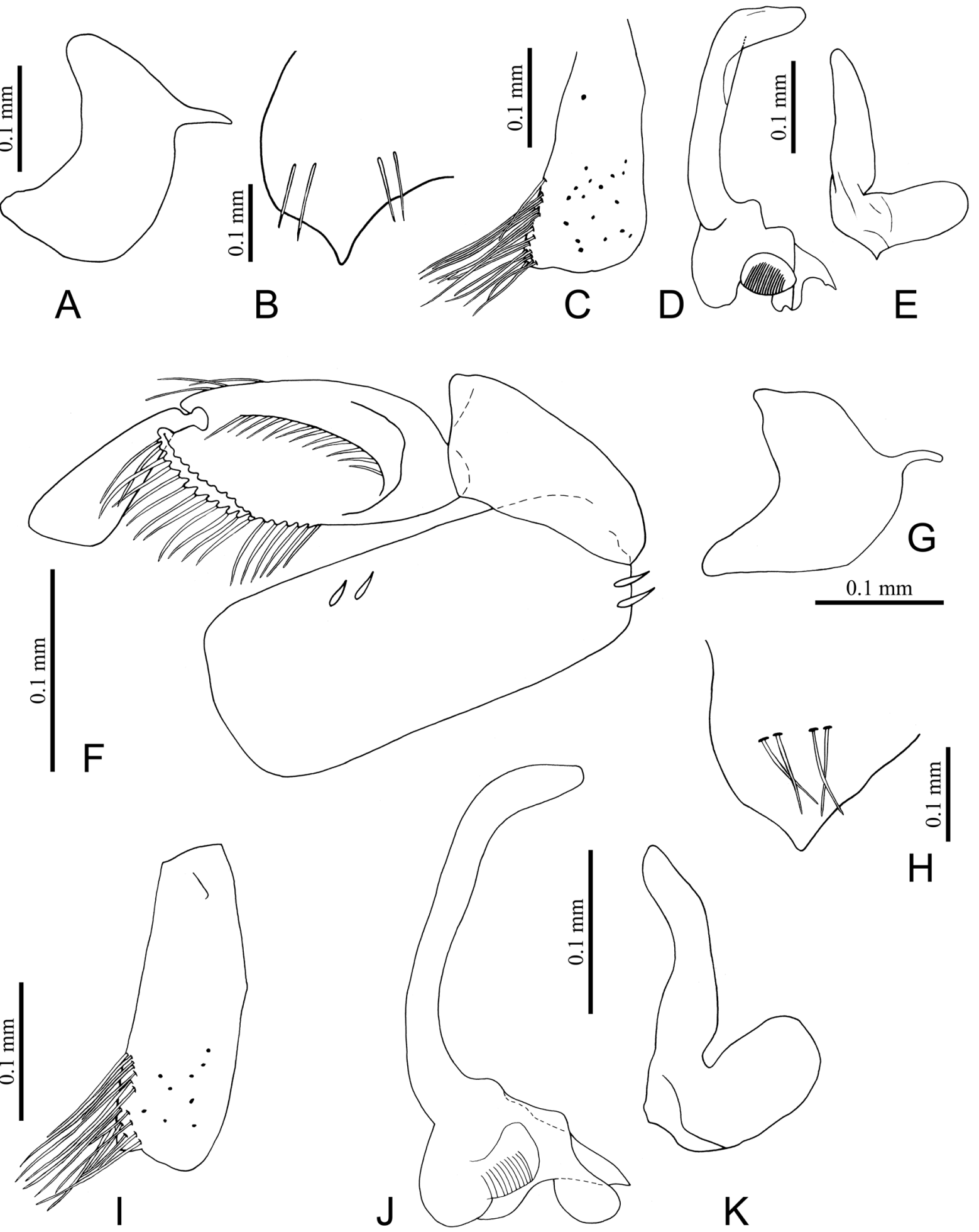

Fig. 9. Morphological features of species of Micronecta Kirkaldy, 1897, §ð. A-E. M. anatolica Lindberg, 1922 (ZVNU). F-K. M. arcuata sp. nov., paratype (ZVNU). A, G = prestrigilar flap; B, H = median lobe of sternite VII; C, I = free lobe; D, J = right paramere; $\mathrm{E}, \mathrm{K}=$ left paramere; $\mathrm{F}=$ fore leg. 
Micronecta anatolica - Wróblewski 1968: 754, 774-775 (synonymical notes, additional morphological notes, checklist); 1972a: 45, 49, figs 62, 68 (additional morphological notes, key). — Nieser 2000: 287, figs 40-41 (key).

Micronecta anatolica anatolica - Jansson 1995: 31 (catalogue).

\section{Diagnosis}

Body length 2.0-2.5. Protonum distinctly longer than median head length. Hemelytron generally brown.

Males: fore femur with two spines on distal third ventrally and a pair of spines distally; fore tibia without spines; palar claw broadened distally, apex rounded. Median lobe of sternite VII short, with four long setae and an angular apex (Fig. 9B). Free lobe slightly expanded posteriorly, mesial angle rounded, lateral angle square with ca 15 long setae (Fig. 9C). Left paramere: shaft broad, flat, tapering towards rounded apex; basal lobe long, tongue-shaped (Fig. 9E). Right paramere: shaft parallel sided, strongly bent (at angle of nearly $90^{\circ}$ ) at distal fourth, then tapering towards narrowly rounded apex; base with a distinct hump on mesial side, near base of shaft (Fig. 9D).

\section{Material examined}

VIETNAM - Lao Cai Prov. • 11 ふ̋ $\widehat{\partial}, 4$ 우; Sa Pa, Ban Ho, Nam Pu stream (tributary of Muong Hoa

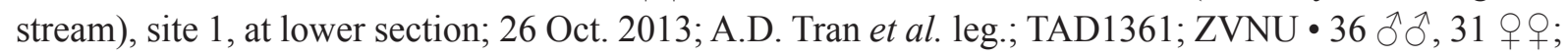
$\mathrm{Sa}$ Pa, Thanh Phu, near junction of Nam Cang and Muong Hoa streams; 26 Oct. 2013; Q.H. Ngo leg.; TAD1360; ZVNU.

\section{Distribution}

Vietnam: Lao Cai (Wróblewski 1962). Other countries: widespread from the Middle East (Saudi Arabia, Iran, Turkey), through South Asia (Afghanistan, Sri Lanka, India, Himalayan region) to Southeast Asia (Wróblewski 1968).

\section{Remarks}

See Remarks under M. acuminata sp. nov.

Micronecta (Micronecta) arcuata sp. nov. urn:lsid:zoobank.org:act:388F73BC-CA08-4397-8570-B2B163B622AC

Figs $5 \mathrm{G}, 9 \mathrm{~F}-\mathrm{K}$

\section{Diagnosis}

Body length 1.6-2.2. Pronotum longer than median head length. Hemelytron punctate, with brown markings at middle part.

Males: fore femur with a pair of spines on middle third ventrally, two spines on distal third dorsally; fore tibia without spine; pala: lower row with ca 18 bristles, upper row with ca 12 bristles; palar claw sub-triangular, apical margin nearly straight (Fig. 9F). Median lobe of sternite VII short, with four long setae and an angular apex (Fig. 9H). Free lobe sub-rectangular, mesial angle rounded, lateral angle square with ca 17 long setae, posterior margin slightly sinuate (Fig. 9I). Left paramere: shaft broad, flat, and evenly curved outwards; apex narrowly rounded; basal lobe large, sub-rectangular (Fig. 9K). Right paramere: shaft parallel sided, strongly bent at distal fourth (by ca $45^{\circ}$ ), slightly thickened before rounded apex; pars stridens processus with ca 15 ridges (Fig. 9J). 
HA T.N. \& TRAN A.D., Micronectidae from Vietnam

\section{Etymology}

The species epithet 'arcuata' refers to the shape of the right paramere, which is slender and bent like a bow.

\section{Material examined}

\section{Holotype}

VIETNAM • 3 ; Ha Giang Prov., Vi Xuyen, Nat' road 2, Phuong Do commune, Phuong Do stream, near bridge; 9 May 2014; A.D. Tran et al. leg.; TAD1407; ZVNU.

\section{Paratypes}

VIETNAM - Ha Giang Prov. • $4 \widehat{\partial} \widehat{\jmath}, 1$ क; same locality data as for holotype; ZVNU. - Lang Son Prov. • 1 J ; Loc Binh, Mau Son, Khuoi Tang stream; 590 m a.s.1.; 6 Nov. 2020; A.D. Tran et al. leg.; TAD20-34; ZVNU. - Phu Tho Prov. • 1 ô, 2 o $\circ$; Xuan Son N.P., Ban Cai, Cai stream, site 3, by the road to Tan Son; 7 Jun. 2013; A.D. Tran et al. leg.; TAD1339; ZVNU • 2 ổ, 2 우; Xuan San N.P., Kim Thuong, Ha Bang stream; 28 Aug. 2013; A.D. Tran et al. leg.; TAD1344; ZVNU • 1 o; Xuan Son N.P., Ban Coi, Coi stream, site 1, water from underground; 29 Aug. 2013; A.D. Tran et al. leg.; TAD1349; ZVNU • 1 ô, 2 우; Xuan Son N.P., Tan Ong stream, 4 km from Chin Tang waterfall;

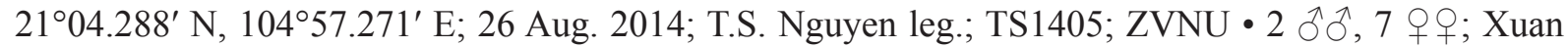
Son N.P., Xoan stream, near its confluence with Ha Bang stream; 21 ${ }^{\circ} 5.303^{\prime}$ N, 104 ${ }^{\circ} 57.559^{\prime}$ E; 27 Aug.

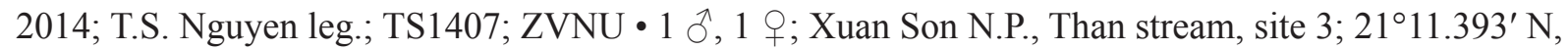

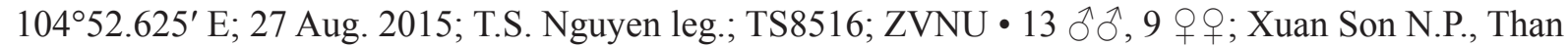

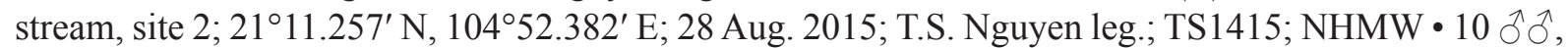
14 우; Xuan Son N.P., Ha Bang stream, Ha Bang village area; $21^{\circ} 04.343^{\prime}$ N, 104 $59.182^{\prime}$ E; 25 May

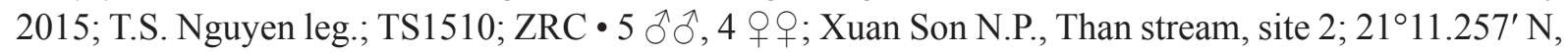
10452.382' E; 24 May 2015; T.S. Nguyen leg.; TS1515; ZVNU • 3 ổ ${ }^{\circ}$; Xuan Son N.P., Xoan stream, near Lang Village; $21^{\circ} 5.453^{\prime}$ N, 104 $56.122^{\prime}$ E; 21 May 2015; T.S. Nguyen leg.; TS1501; ZVNU •

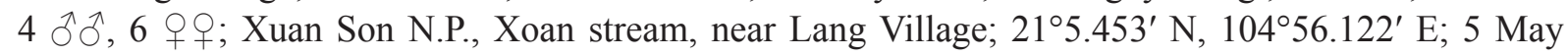

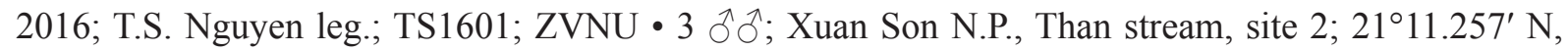

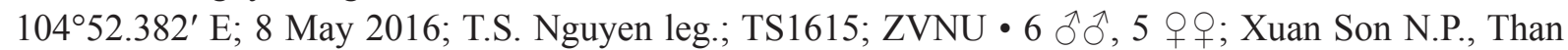
stream, site 3; $21^{\circ} 11.393^{\prime} \mathrm{N}, 1^{\circ} 4^{\circ} 52.625^{\prime}$ E; 7 May 2016; T.S. Nguyen leg.; TS1616; ZVNU • 1 ठ’ $^{\prime}$ Xuan Son N.P., Xoan stream, near its confluence with Ha Bang stream; 21 ${ }^{\circ} 5.303^{\prime}$ N, 104 $57.559^{\prime}$ E; 22 May 2015; T.S. Nguyen leg.; TS1507; ZVNU・3 $\partial^{\lambda}, 4$ + $\odot$; Xuan Son N.P., Xoan stream, near its confluence with Ha Bang stream; 21 ${ }^{\circ} 5.303^{\prime}$ N, $1^{\circ} 4^{\circ} 57.559^{\prime}$ E; 5 May 2015; T.S. Nguyen leg.; TS1607; ZVNU • $6 \partial^{\lambda}, 3$ 우; Xuan Son N.P., Xoan stream, Xoan village area; $2^{\circ} 05.270^{\prime}$ N, 104 ${ }^{\circ} 57.591^{\prime}$ E; 23 May

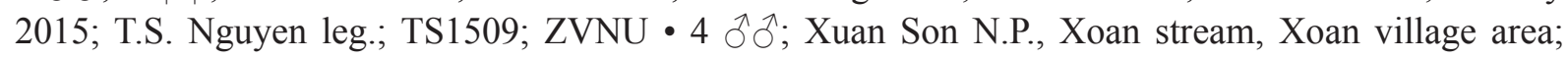
$21^{\circ} 05.270^{\prime}$ N, $104^{\circ} 57.591^{\prime}$ E; 7 May 2016; T.S. Nguyen leg.; TS1609; ZVNU • 1 ơ $^{\top}$; Xuan Son N.P., Tan Ong stream, $4 \mathrm{~km}$ from Chin Tang waterfall; $21^{\circ} 04.288^{\prime} \mathrm{N}, 1^{\circ} 4^{\circ} 57.271^{\prime} \mathrm{E}$; 22 May 2015; T.S. Nguyen leg.; TS1505; ZVNU • 1 ô, 1 \&; Xuan Son N.P., Ha Bang stream, near its confluence with Xoan stream;

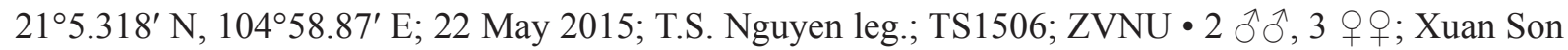
N.P., Ha Bang stream, near its confluence with Xoan stream; 21 ${ }^{\circ} 5.318^{\prime}$ N, $104^{\circ} 58.87^{\prime}$ E; 6 May 2016; T.S. Nguyen leg.; TS1606ĐT; ZVNU • 1 §,, 2 우; Xuan Son N.P., Ha Bang stream, Ha Bang village

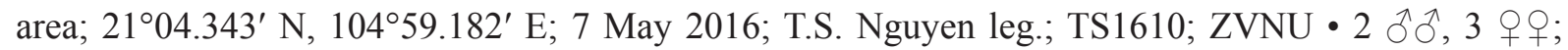
Xuan Son N.P., Coi stream, site 1, by the road to Tan Son; $21^{\circ} 09.204^{\prime}$ N, $104^{\circ} 56.927^{\prime}$ E; 8 May 2016; T.S. Nguyen leg.; TS1617; ZVNU • 1 Ô, 5 우; Xuan Son N.P., Coi stream, site 2, near concrete bridge; $21^{\circ} 09.130^{\prime} \mathrm{N}, 1^{\circ} 4^{\circ} 56.761^{\prime} \mathrm{E}$; 24 May 2015; T.S. Nguyen leg.; TS1518; ZVNU • 1 đ̊, 2 q ; Xuan Son N.P., Lap stream, the second concrete bridge from Ngoc waterfall; $21^{\circ} 08.322^{\prime} \mathrm{N}, 104^{\circ} 56.256^{\prime} \mathrm{E}$;

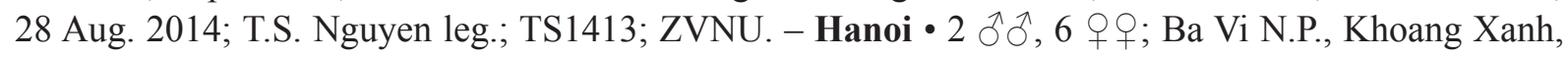
Tien stream; 95 m a.s.1.; 27 Apr. 2012; Q.H. Ngo and A.D. Tran leg.; TAD1208; ZVNU. - Hoa Binh 


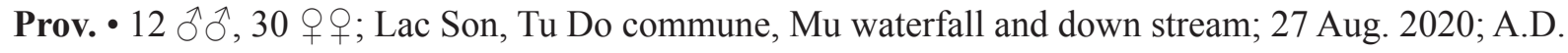
Tran, P.L. Le and T.C. Nguyen leg.; TAD20-02; ZVNU.

\section{Description}

Colour (Fig. 5G). Dorsum generally orangish-brownish yellow. Frons and vertex pale yellowish, eyes reddish brown. Pronotum yellowish brown, with one longitudinal yellow stripe on anterior part and two transverse yellow stripes on posterior part. Hemelytron with minute red dots scattered especially on hyaline anterior band of clavus, on boundary between corium and embolium. Corium with three obscure light brown markings at middle part. Membrane translucent and brownish. Venter of thorax and abdomen, and legs pale or light yellow.

\section{Structural characteristics}

Macropterous males. Body length 1.63-2.16 (holotype: 1.73), width 1.0-1.13 (holotype: 0.81). Head width $0.62-0.66$ (holotype: 0.63$)$. Pronotum about 2.5 times as wide as long $(0.70: 0.29)$. Pronotum slightly wider than head. Synthlipsis about 1.5 times as wide as posterior width of an eye $(0.30: 0.23)$. Lengths of leg segments: fore leg: femur 0.28 , tibia 0.13 , pala 0.12 ; middle leg: femur 0.58 , tibia 0.20 , tarsus 0.25 , claw 0.18 ; hind leg: femur 0.45 , tibia 0.28 , tarsus I 0.29 , tarsus II 0.12 , claw 0.03 . Prestrigilar flap on segment V with short apex (Fig. 9G). Strigil present. Median lobe of sternite VII, free lobe, and parameres as in diagnosis.

Macropterous females. Body length 1.63-2.09, width 0.94-1.19. Head width 0.64-0.67. Pronotum about 2.5 times as wide as long $(0.67: 0.22)$. Pronotum slightly wider than head. Synthlipsis about 1.5 times as wide as posterior width of an eye $(0.32: 0.20)$. Lengths of leg segments: fore leg: femur 0.23 , tibiotarsus 0.2 ; middle leg: femur 0.55 , tibia 0.2 , tarsus 0.3 , claw 0.18 ; hind leg: femur 0.41 , tibia 0.29 , tarsus I 0.28 , tarsus II 0.12 , claw 0.03 .

\section{Distribution}

Northern Vietnam: Ha Giang, Phu Tho, Hanoi.

\section{Remarks}

See Remarks under M. acuminata sp. nov.

Micronecta (Micronecta) fulvopicta sp. nov. urn:1sid:zoobank.org:act:B05FC9D1-ACE2-48C9-AFC0-A2C14AA8C34B

Figs $5 \mathrm{H}, 10$

\section{Diagnosis}

Body length 1.6-2.0. Pronotum: longer than median head length; with two transverse dark marks anteriorly. Hemelytron punctate, with distinct large dark marks.

Males: fore femur with two spines on proximal third ventrally, one spine on distal third dorsally, one pair of spines distally, one long seta dorsodistally; fore tibia without spine; palar claw distally widened, apical margin rounded (Fig. 10A). Median lobe of sternite VII short, with acute apex and four long setae (Fig. 10C). Free lobe sub-rectangular, mesial angle rounded, lateral angle square, with ca 10 long setae, posterior margin slightly concave (Fig. 10D). Left paramere: shaft broad, flat, distal part straight; apex narrowly rounded; basal lobe large, sub-rectangular (Fig. 10F). Right paramere: shaft parallel sided, strongly bent (at angle of nearly $90^{\circ}$ ) at distal fourth, apex rounded; pars stridens processus with ca 20 ridges (Fig. 10E). 


\section{Etymology}

The species epithet refers to the yellowish brown, tawny markings on the dorsum.

\section{Material examined}

\section{Holotype}

VIETNAM • đ’; Thanh Hoa Prov., Pu Hu Nature Reserve, Quan Hoa, Hien Chung, Ban Pheo, Ham stream; 9 Apr. 2013; T.D. Pham leg.; PH1303; ZVNU.

\section{Paratypes}

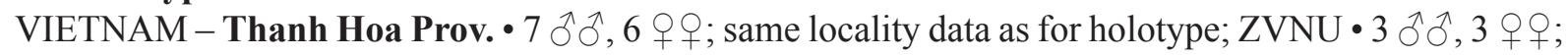

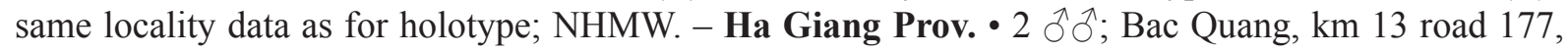
Tan Lap commune, waterfall and stream, ca $86 \mathrm{~km}$ to Coc Pai town; 10 May 2014; A.D. Tran et al. leg.; TAD1410; ZRC. - Cao Bang Prov. 2 q $o$; Bao Lac, Hung Dao commune, Nhi Ao River, near Nam Xui bridge; 20 Dec. 2013; A.D. Tran et al. leg.; TAD1380; ZVNU. - Nghe An Prov. • 1 ô, 3 q $q$; Pu Mat N.P., Khe Kem waterfall and stream, site \#1; 18 Apr. 2013; A.D. Tran et al. leg.; TAD1310; ZVNU.

\section{Description}

Colour (Fig. 5H). Dorsum generally brownish yellow. Frons and vertex light yellow, eyes dark reddish brown. Pronotum yellowish with a pair of transverse brownish marks anteriorly. Clavus bordered by dark brown mark, becoming thicker at anterior margin. Corium with a large irregular-shaped brown
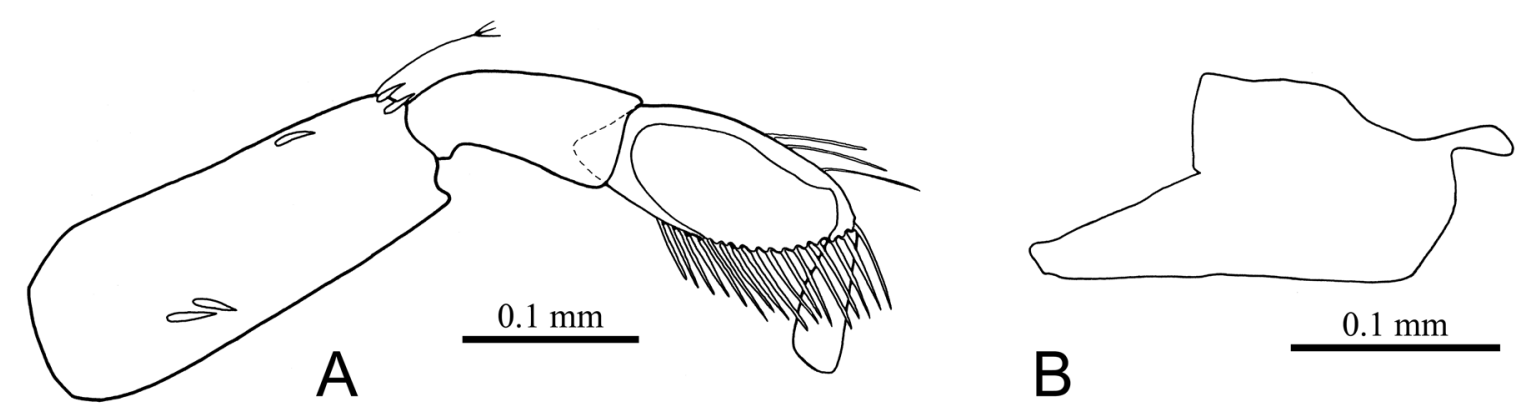

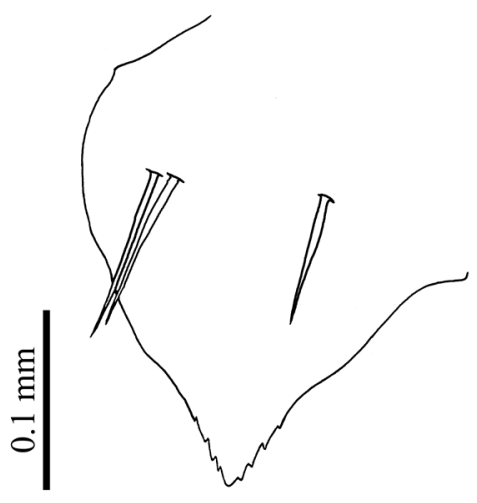

C

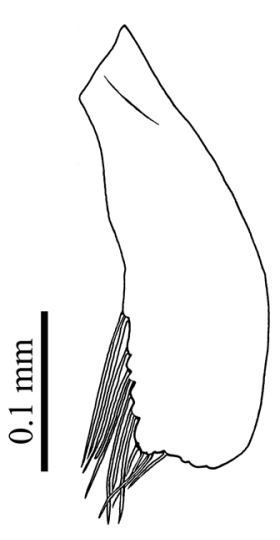

$\mathrm{D}$

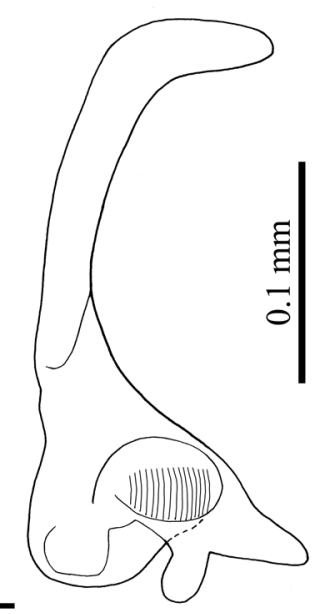

$\mathrm{E}$

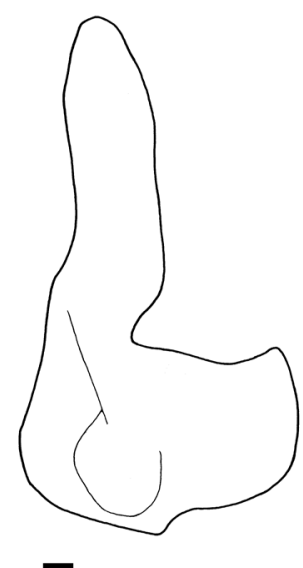

$\mathrm{F}$

Fig. 10. Morphological features of Micronecta fulvopicta sp. nov., ô, paratype (ZVNU). A. Fore leg. B. Prestrigilar flap. C. Median lobe of sternite VII. D. Free lobe. E. Right paramere. F. Left paramere. 
mark on middle part. Embolium and membrane transculent. Venter of thorax and abdomen, and legs pale brownish yellow.

\section{Structural characteristics}

Macropterous males. Body length 1.63-1.75 (holotype: 1.75), width 1.0-1.13 (holotype: 1.05). Head width $0.64-0.70$ (holotype: 0.68 ). Pronotum slightly wider than head. Pronotum short, about four times as wide as long $(0.71: 0.18)$. Synthlipsis 1.5 times as wide as posterior width of an eye $(0.32: 0.21)$. Lengths of segments: fore leg: femur 0.23 , tibia 0.14 , pala 0.14 ; middle leg: femur 0.65 , tibia 0.20 , tarsus 0.32 , claw 0.16 ; hind leg: femur 0.43 , tibia 0.32 , tarsus I 0.34 , tarsus II 0.16 , claw 0.03 . Prestrigilar flap on segment V with prolonged apex (Fig. 10B). Strigil present. Median lobe of sternite VII, free lobe, and parameres as in diagnosis.

Macropterous Females. Body length 1.63-2.0, width 0.94-1.19. Head width 0.67-0.72. Pronotum short, about four times as wide as long $(0.66: 0.16)$. Head slightly wider than pronotum. Synthlipsis 1.5 times as wide as posterior width of an eye $(0.31: 0.20)$. Lengths of segments. fore leg: femur 0.23 , tibiotarsus 0.23 ; middle leg: femur 0.59 , tibia 0.22 , tarsus 0.30 , claw 0.16 ; hind leg: femur 0.40 , tibia 0.32 , tarsus I 0.32 , tarsus II 0.15 , claw 0.03 .

\section{Distribution}

Northern Vietnam: Ha Giang, Cao Bang, Thanh Hoa, Nghe An.

\section{Remarks}

See Remarks under M. acuminata sp. nov.

Micronecta (Micronecta) acuminata sp. nov. urn:1sid:zoobank.org:act:525BBA05-C47E-447A-A643-64535995CF4F Figs 5I, 11

\section{Diagnosis}

Body length 1.3-1.5. Pronotum: longer than median head length. Hemelytron punctate, yellowish with indistinct yellowish brown markings.

Males: fore femur with two spines on middle third, one pair of spines in distal third dorsally; fore tibia without spine; palar claw distally widened, apical margin rounded (Fig. 11A). Median lobe of sternite VII short, with angular apex and one or two long setae (Fig. 11C). Free lobe sub-rectangular, mesial angle rounded, lateral angle square, with ca 12 long setae, posterior margin slightly sinuate (Fig. 11D). Left paramere: shaft broad, flat, strongly constricted before an acute apex; basal lobe longer than wide, sub-rectangular, distal margin curved (Fig. 11F). Right paramere: shaft parallel sided, distal fourth strongly curved (by nearly $45^{\circ}$ ) and slightly thickened before rounded apex; pars stridens processus with ca 20 ridges (Fig. 11E).

\section{Etymology}

The word 'acuminata' refers to the acuminate apex of the left paramere.

\section{Material examined}

Holotype

VIETNAM • $\widehat{\jmath}$, Dong Nai Prov., Vinh Cuu, Ma Da stream, near Rang Rang Forest ranger station (near bridge); 13 Apr. 2010; T.D. Pham leg.; PTD1006; ZVNU. 


\section{Paratypes}

VIETNAM - Dong Nai Prov. $・ 2 \hat{\jmath} \hat{\jmath}, 2$ 우; same locality data as holotype; ZVNU ・ $1 \hat{\jmath}, 3$ q $\propto$; Vinh Cuu, Ma Da stream, near Rang Rang Forest station (near bridge); 9 Apr. 2009; A.D. Tran leg.; TAD0902; ZVNU • 3 ડ̄ô, 3 + + ; Vinh Cuu, Ma Da, Suoi Sai (Sai stream), near bridge; 11 Apr. 2009; A.D. Tran leg.; TAD0907; ZVNU • 1 ô; Vinh Cuu, Vinh An, Rang stream; 20 Apr. 2009; A.D. Tran leg.; TAD0913; ZVNU • 2 우; Cat Tien N.P., Sa Mach stream, near Sa Mach Forest ranger station; 20 Apr. 2009; A.D. Tran leg.; TAD0914; ZVNU.

\section{Description}

Colour (Fig. 5I). Dorsum brownish yellow to brown. Frons and vertex pale yellowish, eyes dark brown. Pronotum light yellowish brown, disk unmarked. Clavus with a hyaline band covered by microscopic red dots along anterior margin. Corium with scattered small brownish marks. Membrane generally transculent. Venter of thorax and abdomen, and legs light yellow.

\section{Structural characteristics}

Macropterous males. Body length 1.3-1.47 (holotype: 1.44), width 0.72-0.82 (holotype: 0.81). Head width $0.59-0.63$ (holotype: 0.61 ). Head slightly wider than pronotum. Pronotum short, about four times as wide as long $(0.59: 0.15)$. Synthlipsis ca 1.5 times as wide as posterior width of an eye $(0.28: 0.18)$. Lengths of leg segments: fore leg: femur 0.2 , tibia 0.14 , pala 0.16 ; middle leg: femur 0.47 , tibia 0.19 , tarsus 0.24 , claw 0.12 ; hind leg: femur 0.4 , tibia 0.29 , tarsus I 0.27 , tarsus II 0.14 , claw 0.03 .
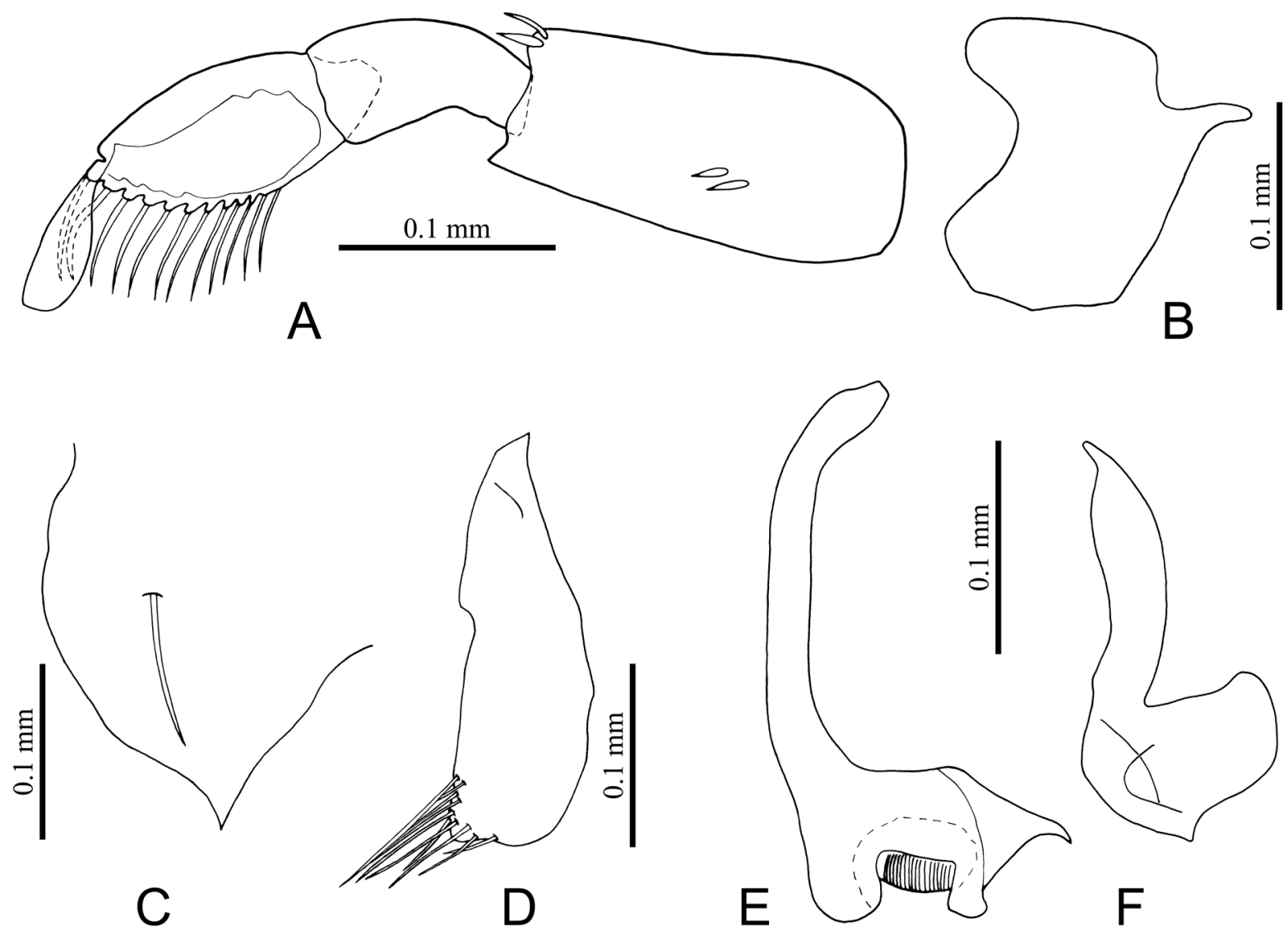

Fig. 11. Morphological features of Micronecta acuminata sp. nov., §, paratype (ZVNU). A. Fore leg. B. Prestrigilar flap. C. Median lobe of sternite VII. D. Free lobe. E. Right paramere. F. Left paramere. 
Prestrigilar flap on segment V with prolonged apex (Fig. 11B). Strigil present. Median lobe of sternite VII, free lobe, and parameres as in diagnosis.

Macropterous Females. Body length 1.37-1.53, width 0.76-0.81. Head width 0.59-0.63. Head slightly wider than pronotum. Pronotum short, nearly four times as wide as long $(0.58: 0.16)$. Synthlipsis 1.5 times as wide as posterior width of an eye $(0.30: 0.18)$. Lengths of leg segments: fore leg: femur 0.21 , tibiotarsus 0.2 ; middle leg: femur 0.5 , tibia 0.2 , tarsus 0.27 , claw 0.14 ; hind leg: femur 0.41 , tibia 0.27 , tarsus I 0.27 , tarsus II 0.14 , claw 0.03 .

\section{Distribution}

Vietnam: Dong Nai.

\section{Remarks}

Among species of Micronecta occurring in Vietnam, four species, M. anatolica, M. arcuata sp. nov., M. fulvopicta sp. nov., and M. acuminata sp. nov., may be more closely related to each other, based on the general shapes of the prestrigilar flap (see Figs 9A, G, 10B, 11B), the median lobe of sternite VII (see Figs 9B, H, 10C, 11C), the free lobe (which is sub-rectangular, see Figs 9C, I, 10D, 11D), and the general form of the left and right parameres. In particular, the shaft of their right paramere is mostly parallel sided and straight at the proximal part, strongly bent at the distal fourth, and the apical part is simple, not distinctly broadened. The shaft of their right parameres is broad and flat, with the lateral margin sinuate and without any projection; and the basal lobe of the right paramere is very large and broad.

All four species mentioned above, however, can be reliably separated from each other by the following characteristics.

In M. anatolica, the basal lobe of the left paramere is elongate and subovate, while that of other three species is broader and sub-rectangular. The base of the right paramere of M. anatolica has a distinct hump on the mesial margin near the beginning of the shaft, whereas this hump is less distinct in M. arcuata sp. nov., and absent in both $M$. fulvopicta sp. nov. and $M$. acuminata sp. nov. The apical part of the right paramere of $M$. anatolica is similar to that of M. fulvopicta sp. nov., which narrows towards the apex, while that of $M$. arcuata sp. nov. is more similar to that of M. acuminata sp. nov., which is slightly thickened before the apex.

Micronecta arcuata sp. nov. is distinct from the other three species in the form of the shaft of the left paramere, which is distinctly curved laterad. That of M. acuminata sp. nov. is also different, with an acuminate apical part. The form of the left paramere of $M$. acuminata sp. nov. is similar to that of M. acuta (Lundblad, 1933); however, the latter species lacks a strigil and its right paramere is clearly different (see Lundblad 1933b: fig. 37e).

Besides structural charateristics, Micronecta fulvopicta sp. nov. has a distinct colour pattern on the dorsum, with strongly defined dark marks on the head, pronotum, and hemelytra (Fig. 5H). Its colour pattern is somewhat similar to that of M. vietnamica sp. nov., but the dark marks on the hemelytra of M. fulvopicta sp. nov. are broader than in the latter species. The structure of the parameres will also separate the two species (see also Remarks under M. vietnamica sp. nov.).

Micronecta (Micronecta) vietnamica sp. nov.

urn:1sid:zoobank.org:act:FFBEFA51-B20A-43BC-A91E-7EFA22350817

Figs 5J-L, 12

\section{Diagnosis}

Body length 1.5-1.8. Pronotum longer than median head length. Dorsum colour pale yellowish. Hemelytron punctate, with large dark markings, sometimes indistinct (Fig. 5J-L). 
Males: fore femur with two spines on proximal third ventrally, one spine in distal third dorsally, two spines distally, one pair of long setae dorsodistally; fore tibia without spine; palar claw petaloid, apex truncate (Fig. 12A). Median lobe of sternite VII with angular apex and four long setae (Fig. 12C). Free lobe long, parallel sided, mesial angle broadly rounded, lateral angle nearly square with ten long setae (Fig. 12D). Left paramere: shaft broad, flat, proximal part curved, distal part nearly straight, apex rounded; basal lobe tongue-shaped (Fig. 12F). Right paramere: shaft slender and parallel sided proximally, distal third curved, apex narrowly rounded; pars stridens processus with ca 25 ridges (Fig. 12E).

\section{Etymology}

This new species is named after the country of the type locality.

\section{Material examined}

\section{Holotype}

VIETNAM • đ̇; Hanoi, Ba Vi N.P., Khoang Xanh, Tien stream; 95 m a.s.l.; 17 Dec. 2011; Q.H. Ngo and A.D. Tran leg.; TAD1127; ZVNU.

\section{Paratypes}

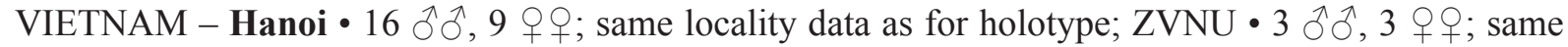
locality data as for holotype; NHMW -1 \%; Ba Vi N.P., Khanh Thuong, Mit stream, forest area;
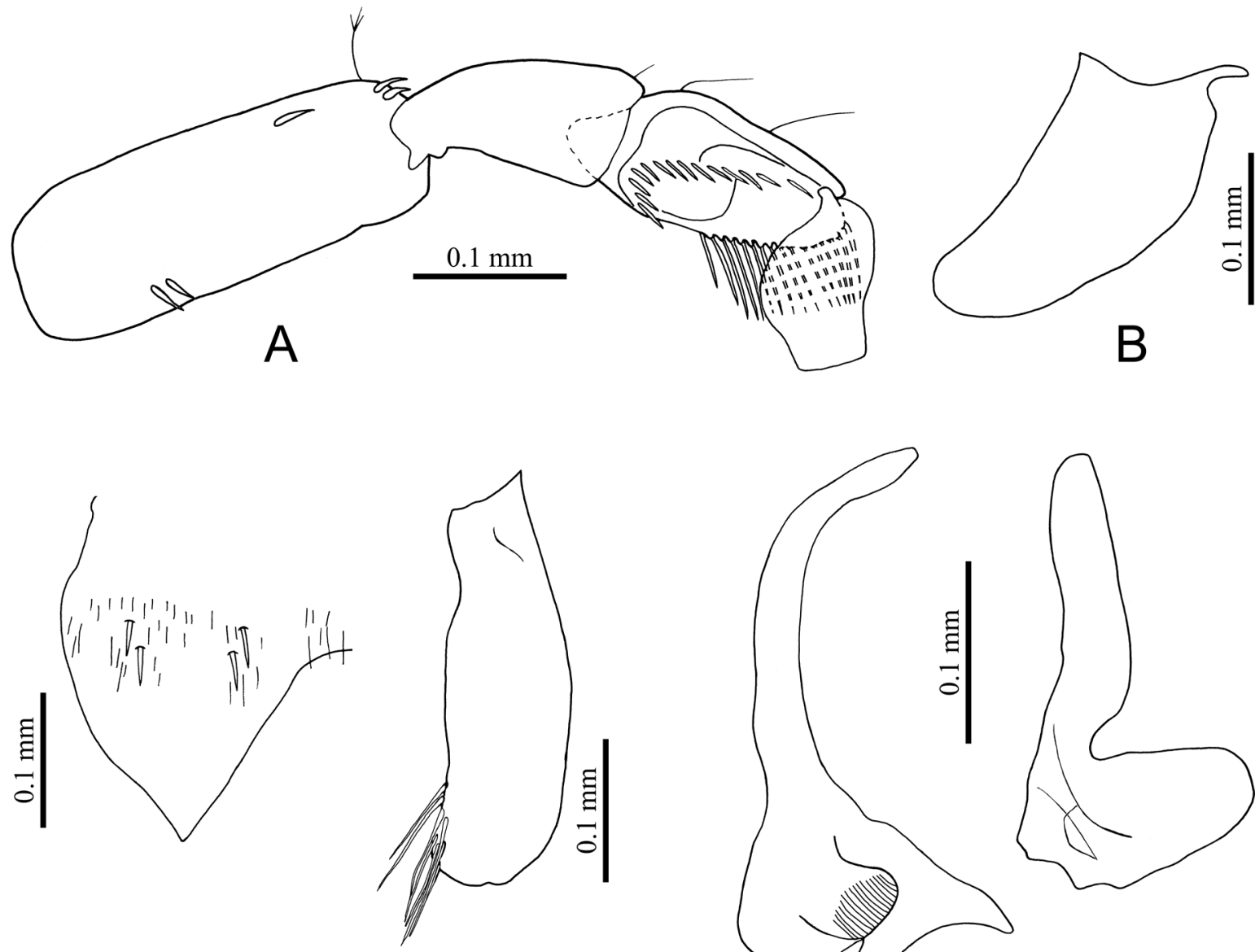

C
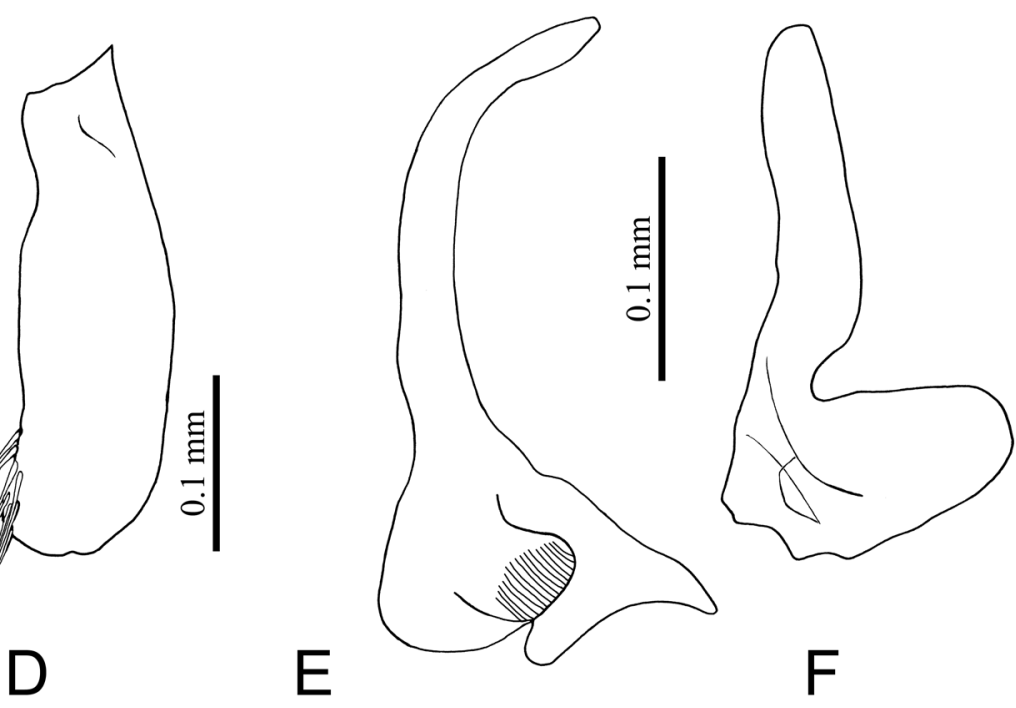

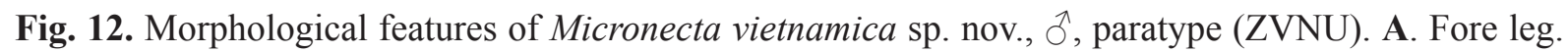
B. Prestrigilar flap. C. Median lobe of sternite VII. D. Free lobe. E. Right paramere. F. Left paramere. 
80 m a.s.1.; 17 Dec. 2011; Q.H. Ngo et al. leg.; TAD1124; ZVNU • 1 ô, 1 o ; Ba Vi N.P., Minh Quang,

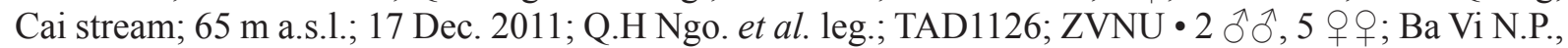
Minh Quang, stream nearby Tan Vien Pagoda; 340 m a.s.l.; 26 Apr. 2012; Q.H. Ngo et al. leg.; TAD1206; ZVNU • 1 O ; Ba Vi N.P., Minh Quang, Cai stream; 65 m a.s.l.; 26 Apr. 2012; Q.H. Ngo et al. leg.;

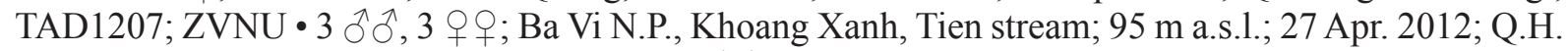
Ngo and A.D. Tran leg.; TAD1208; ZRC • 5 ô ; Ba Vi N.P., Yen Bai, Mo stream; ca $114 \mathrm{~m}$ a.s.1.; 28

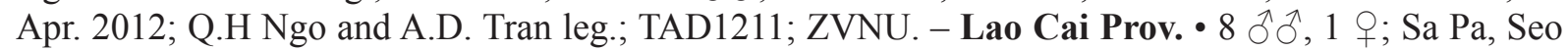
Trung Ho stream; 22 Oct. 2012; N.H. Dinh et al. leg.; DNH12.05; ZVNU • 1 क ; Sa Pa, Nam Sai, Seo Nam Sai stream 1; 24 Oct. 2012; N.H. Dinh et al. leg.; DNH12.09; ZVNU • 1 ô; Sa Pa, Nam Sai, Seo Nam Sai stream 2; 24 Oct. 2012; N.H. Dinh et al. leg.; DNH12.10; ZVNU • 1 ð̊; Sa Pa, Thanh Phu, Nam Cang stream; 26 Oct. 2013; A.D. Tran et al. leg.; TAD1359; ZVNU. - Cao Bang Prov.・ 1 đ; Ha Quang, road 203, Truong Ha commune, stream near Kim Dong tomb; 17 Dec. 2013; A.D. Tran et al. leg.; TAD1371; ZVNU • 6 o 9 ; Phia Oac-Phia Den N.P., road to Quang Thanh commune, Na Leng stream; 29 Oct. 2020; V.V. Nguyen et al. leg.; PO20-06; ZVNU・ 1 Oे, 4 o 9 ; Phia Oac-Phia Den N.P., road to Quang Thanh commune, Khue Lan stream; 29 Oct. 2020; V.V. Nguyen et al. leg.; PO20-07; ZVNU. Lang Son Prov. • 1 ô, 3 우; Loc Binh, Mau Son, Khuoi Tang stream, 590 m a.s.1.; 6 Nov. 2020; A.D.

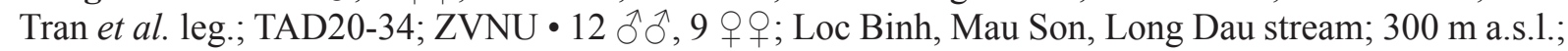
7 Nov. 2020; A.D. Tran et al. leg.; TAD20-36; ZVNU. - Phu Tho Prov.・ 2 đิ ${ }^{\lambda}, 2$ q $q$; Xuan Son N.P., Ban Coi, Coi stream, site 2, near bridge; 7 Jun. 2013; A.D. Tran et al. leg.; TAD1338; ZVNU 1 ठ 2 qक; Xuan Son N.P., Kim Thuong, Xoan stream; 28 Aug. 2013; A.D. Tran et al. leg.; TAD1343; ZVNU • 2 우; Xuan Son N.P., Ban Coi, Coi stream, site 1, water from underground; 29 Aug. 2013; A.D. Tran et al. leg.; TAD1349; ZVNU • 1 क; Xuan Son N.P., Ban Coi, Coi stream, site 3, by the road to Tan Son; 29 Aug. 2013; A.D. Tran et al. leg.; TAD1351; ZVNU • 1 O, 2 우; Xuan Son N.P., stream flows through the road, near Lang Village; $21^{\circ} 5.662^{\prime}$ N, 104 56.236' E; 26 Aug. 2014; T.S. Nguyen leg.; TS1402;ZVNU・ $1 \partial^{\lambda}, 1$; ; Xuan Son N.P., stream flows through the road, near Lang Village; $21^{\circ} 5.662^{\prime} \mathrm{N}$, 10456.236' E; 21 May 2015; T.S. Nguyen leg.; TS1502; ZVNU・ $2 \overbrace{}^{\Uparrow}, 2$ q $O$; Xuan Son N.P., stream flows through the road, near Lang Village; $21^{\circ} 5.662^{\prime}$ N, $104^{\circ} 56.236^{\prime}$ E; 24 Aug. 2015; T.S. Nguyen leg.;

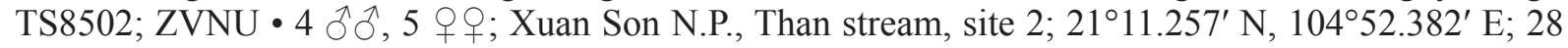

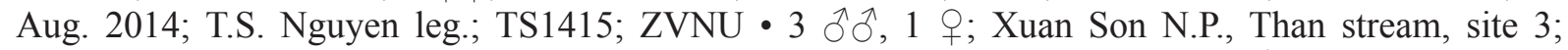
$21^{\circ} 11.393^{\prime} \mathrm{N}, 104^{\circ} 52.625^{\prime}$ E; 28 Aug. 2014; T.S. Nguyen leg.; TS1416; ZVNU・ 1 ð’; Xoan stream, near

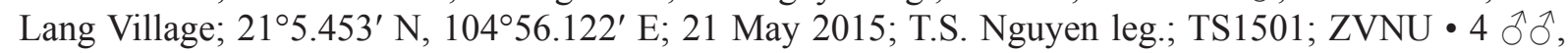
1 웅 Xuan Son N.P., Xoan stream, near its confluence with Ha Bang stream; $21^{\circ} 5.303^{\prime}$ N, $104^{\circ} 57.559^{\prime}$ E; 22 May 2015; T.S. Nguyen leg.; TS1507; ZVNU • 3 우; Xuan Son N.P., Xoan stream, near its confluence with Ha Bang stream; $2^{\circ} 5.303^{\prime} \mathrm{N}, 1^{\circ} 4^{\circ} 57.559^{\prime}$ E; T.S. Nguyen leg.; 6 May 2016, TS1607; ZVNU • 1 ऽ, 8 우; Xuan Son N.P., Ha Bang stream, Ha Bang village area; $21^{\circ} 04.343^{\prime}$ N, $104^{\circ} 59.182^{\prime}$ E; 25

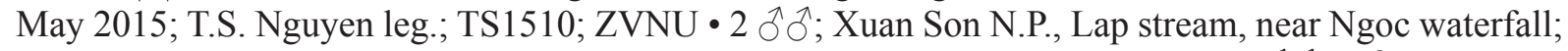

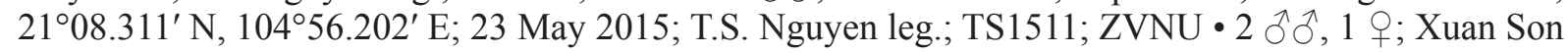
N.P., Than stream, site 1, water flowing from the cave; $21^{\circ} 11.096^{\prime} \mathrm{N}, 104^{\circ} 52.587^{\prime} \mathrm{E}$; 24 May 2015; T.S.

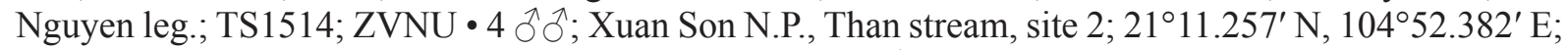
24 Aug. 2015; T.S. Nguyen leg.; TS1515; ZVNU • 1 ภ, 3 우; Xoan stream, near Lang Village; $21^{\circ} 5.453^{\prime}$ N, $104^{\circ} 56.122^{\prime}$ E; 24 Aug. 2015; T.S. Nguyen leg.; TS8501; ZVNU • 3 ổ, 1 q, Xuan Son N.P., Than stream, site 3; $21^{\circ} 11.393^{\prime}$ N, $104^{\circ} 52.625^{\prime}$ E; 27 Aug. 2015; T.S. Nguyen leg.; TS8516; ZVNU • 2 우; Xuan Son N.P., Xoan stream, Xoan village area; $21^{\circ} 05.270^{\prime}$ N, $104^{\circ} 57.591^{\prime}$ E; 23 May 2015; T.S. Nguyen leg.; TS1509; ZVNU • 2 ㅇ; Xuan Son N.P., Xoan stream, Xoan village area;

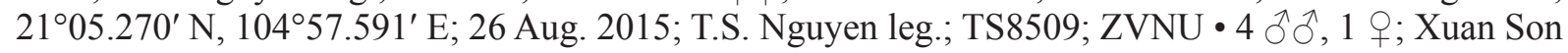
N.P., Xoan stream, Xoan village area; $2^{\circ} 05.270^{\prime}$ N, 10457.591' E; 7 May 2016; T.S. Nguyen leg.;

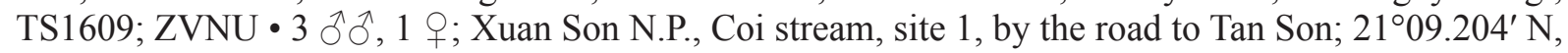

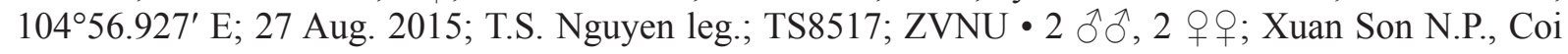
stream, site 1, by the road to Tan Son; $21^{\circ} 09.204^{\prime} \mathrm{N}, 104^{\circ} 56.927^{\prime} \mathrm{E}$; 8 May 2016; T.S. Nguyen leg.; TS1617; ZVNU - 1 क; Xuan Son N.P., Coi stream, site 2, near concrete bridge; $21^{\circ} 09.130^{\prime} \mathrm{N}$,

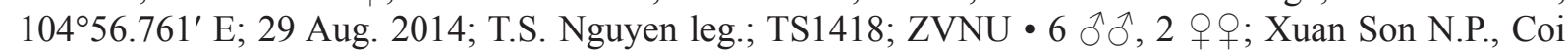
stream, site 2, near concrete bridge; $21^{\circ} 09.130^{\prime} \mathrm{N}, 1^{\circ} 4^{\circ} 56.761^{\prime}$ E; 24 May 2015; T.S. Nguyen leg.; TS1518; ZVNU • $3 \overbrace{}^{\Uparrow} \delta^{\lambda}, 7$ 우; Xuan Son N.P., Coi stream, site 3, in front of the cave; $21^{\circ} 01.190^{\prime}$ N, 


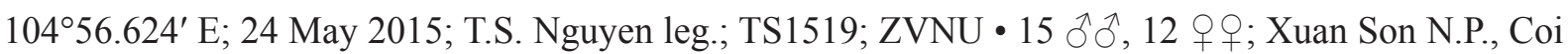
stream, site 3, in front of the cave; $21^{\circ} 01.190^{\prime} \mathrm{N}, 104^{\circ} 56.624^{\prime} \mathrm{E} ; 8$ May 2016; T.S. Nguyen leg.; TS1619; ZVNU • 4 ๙ึ, 3 q $q$; Xuan Son N.P., Tan Ong stream, $2 \mathrm{~km}$ from Chin Tang stream; $21^{\circ} 04.201^{\prime} \mathrm{N}$,

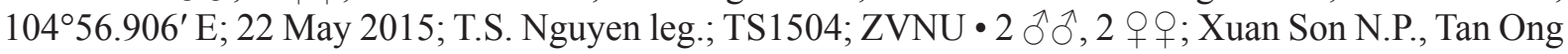

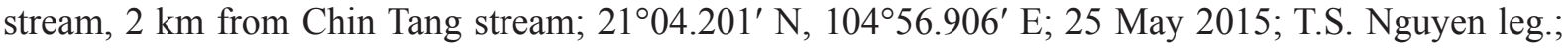
TS8504; ZVNU • 1 क; Xuan Son N.P., Tan Ong stream, 4 km from Chin Tang stream; $21^{\circ} 04.288^{\prime}$ N, 10457.271' E; 26 Aug. 2014; T.S. Nguyen leg.; TS1405; ZVNU • 2 q $q$; Xuan Son N.P., Tan Ong stream, 4 km from Chin Tang stream; $2^{\circ} 04.288^{\prime} \mathrm{N}, 1^{\circ} 4^{\circ} 57.271^{\prime} \mathrm{E} ; 22$ May 2015; T.S. Nguyen leg.; TS1505; ZVNU - 2 qo ; Xuan Son N.P., Ha Bang stream, Ha Bang village area; $21^{\circ} 04.343^{\prime}$ N,

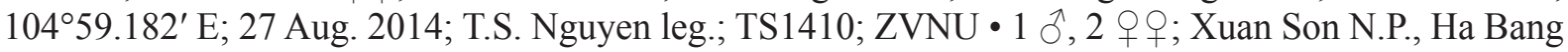

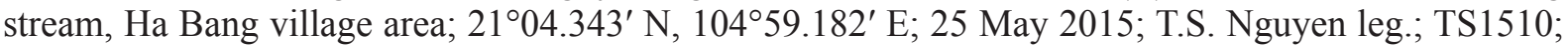

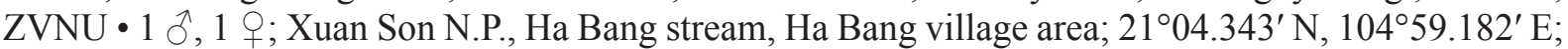
7 May 2016; T.S. Nguyen leg.; TS1610; ZVNU • 1 ठ̊; Xuan Son N.P., Chieng stream, near ranger station; $21^{\circ} 06.072^{\prime} \mathrm{N}, 104^{\circ} 59.433^{\prime}$ E; 27 Aug. 2014; T.S. Nguyen leg.; TS1408; ZVNU・ $1{ }^{\lambda}$; Xuan Son N.P., Lap stream, near the foot of Ngoc waterfall; 21 ${ }^{\circ} 08.311^{\prime}$ N, 104 $56.202^{\prime}$ E; 27 Aug. 2014; T.S. Nguyen leg.; TS1411; ZVNU • 4 우; Xuan Son N.P., Lap stream, near the foot of Ngoc waterfall;

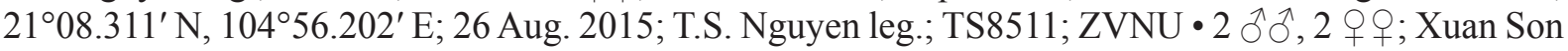
N.P., Lap stream, near the foot of Ngoc waterfall; $21^{\circ} 08.311^{\prime} \mathrm{N}, 104^{\circ} 56.202^{\prime} \mathrm{E} ; 7$ May 2016; T.S. Nguyen leg.; TS1611; ZVNU • 2 $\widehat{\jmath}, 2$ q 9 ; Xuan Son N.P., Lap stream, the first concrete bridge from Ngoc waterfall; 5 Jun. 2013; A.D. Tran et al. leg.; TAD1332; ZVNU • 2 o of; Xuan Son N.P., Lap stream, the first concrete bridge from Ngoc waterfall; $21^{\circ} 8.398^{\prime}$ N, $104^{\circ} 56.303^{\prime}$ E; 26 Aug. 2015; T.S. Nguyen leg.;

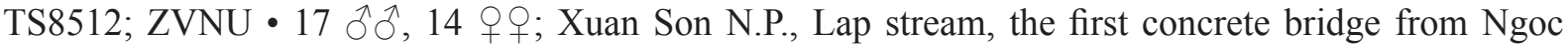

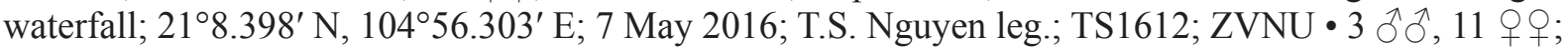
Xuan Son N.P., Lap stream, the second concrete bridge from Ngoc waterfall; 5 Jun. 2013; A.D. Tran et al. leg.; TAD1333; ZVNU • $13 \hat{\partial} \partial^{\lambda}, 18$ q $\circ$; Xuan Son N.P., Lap stream, the second concrete bridge from Ngoc waterfall; $21^{\circ} 08.322^{\prime}$ N, $1^{\circ} 4^{\circ} 56.256^{\prime}$ E; 23 May 2015; T.S. Nguyen leg.; TS1513; ZVNU • $14{ }^{\lambda} \partial^{\lambda}, 22$ 우; Xuan Son N.P., Lap stream, the second concrete bridge from Ngoc waterfall; $21^{\circ} 08.322^{\prime} \mathrm{N}$, 10456.256' E; 7 May 2016; T.S. Nguyen leg.; TS1613; ZVNU. - Hoa Binh Prov. • 4 ô ô, 5 o $q$; Lac Son, Tu Do commune, Mu stream (upstream of Mu waterfall); 27 Aug. 2020; A.D. Tran et al. leg.; TAD20-01; ZVNU. - Thanh Hoa Prov. • 1 \%; Ben En N.P., Nhu Xuan, Tan Binh, stream $300 \mathrm{~m}$ behind Xuan Ly ranger station; 26 Feb. 2013; T.D. Pham leg.; BE1302; ZVNU. - Nghe An Prov. 1 \%; Pu Mat N.P., Khe Kem waterfall and stream, site \#1; 20 Dec. 2012; Q.H. Ngo leg.; NQH1203; ZVNU・11 §ð, 4 우; $\mathrm{Pu}$ Mat N.P., Khe Kem stream, site \#2, ca $300 \mathrm{~m}$ downstream from waterfall; 20 Dec. 2012; Q.H. Ngo leg.; NQH1204; ZVNU • 8 $\widehat{\jmath}, 1$ क ; Pu Mat N.P., Khe Kem stream, site \#3; 20 Dec. 2012;

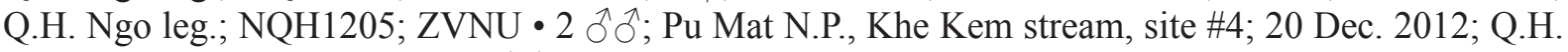
Ngo leg.; NQH1206; ZVNU・ 5 $\widehat{\jmath}, 2$ q 9 ; Con Cuong, Tung Huong Village, Khe Thoi stream; 21 Dec. 2012; Q.H. Ngo leg.; NQH1210; ZVNU • 2 o $ᄋ$; Pu Mat N.P., Khe Kem waterfall and stream, site \#1; 18 Apr. 2013; A.D. Tran et al. leg.; TAD1310; ZVNU • 3 o o ; Pu Mat N.P., Khe Kem waterfall and stream, site \#2, ca $300 \mathrm{~m}$ downstream from waterfall; 18 Apr. 2013; A.D. Tran et al. leg.; TAD1311; ZVNU • 1 ठૈ, 1 क; Pu Mat N.P., Khe Kem stream, site \#3, near visitor's hut; 18 Apr. 2013; A.D. Tran et al. leg.; TAD1312; ZVNU・ 1 o ; Pu Mat N.P., Khe Kem stream, site \#6; 18 Apr. 2013; A.D. Tran et al. leg.; TAD1315; ZVNU • 1 ô, 1 q; Pu Mat N.P., Kem waterfall and stream; 30 Aug. 2020; A.D. Tran, P.L. Le and T.C. Nguyen leg.; TAD20-06; ZVNU • 2 우; Pu Mat N.P., Kem stream, site 3, ca 1.5 km from waterfall; 30 Aug. 2020; A.D. Tran et al. leg.; TAD20-08; ZVNU・ 1 ô; Pu Mat N.P., Chat stream, tributary of Choang stream; 1 Sep. 2020; A.D. Tran et al. leg.; TAD20-14; ZVNU・1 §, 2 q $q$; Pu Mat N.P., Da Mai stream, tributary of Choang stream, near ranger post; 1 Sep. 2020; A.D. Tran and T.C. Nguyen leg.; TAD20-16; ZVNU. - Ha Tinh Prov. 1 q; Vu Quang N.P., a small branch of Song Con River; 23 Apr. 2003; A.D. Tran leg.; TAD0303; ZRC.

\section{Description}

CoLour (Fig. 5J-L). Frons and vertex pale yellowish, vertex with a longitudinal brown mark medially, eyes blackish brown. Pronotum yellowish brown with a pair of dark brown transverse marks. Hemelytron 
hyaline light yellowish. In most of specimens: clavus bordered with dark brown mark, becoming thicker on anterior margin; corium with two dark brown marks on middle part; a dark brown mark extending towards membrane; membrane generally transculent, brownish. Some specimens collected from Cao Bang and Phu Tho with variations in colour pattern of hemelytra. In some specimens from Phu Tho Prov. (Fig. 5K, at localities TS1510, TS1511): markings on hemelytra distinct but brighter overall, marks in middle part more fused into one large mark, and a dark mark (resembling inverted A-shape) just before membrane; membrane light coloured. In specimens from Cao Bang Prov. (Fig. 5L): markings on hemelytra indistinct, less contrasting against background colour of hemelytra; membrane light coloured. Venter of thorax and abdomen brownish yellow and legs pale yellow.

\section{Structural characteristics}

Macropterous males. Body length 1.63-2.16 (holotype: 1.83), width 0.94-1.13 (holotype: 1.08). Head width $0.68-0.77$ (holotype: 0.74$)$. Pronotum short, about five times as wide as long $(0.79: 0.16)$. Pronotum slightly wider than head. Synthlipsis about 1.5 times wider than posterior width of an eye $(0.35: 0.24)$. Lengths of leg segments: fore leg: femur 0.3 , tibia 0.18 , pala 0.14 ; middle leg: femur 0.74 , tibia 0.27, tarsus 0.36 , claw 0.2 ; hind leg: femur 0.58 , tibia 0.4 , tarsus I 0.41 , tarsus II 0.16 , claw 0.04 . Prestrigilar flap on segment V with a short apex (Fig. 12B). Strigil present. Median lobe of sternite VII, free lobe, and parameres as in diagnosis.

Macropterous females. Body length 1.63-2.09, width 0.94-1.19. Head width 0.71-0.77. Pronotum about five times as wide as long $(0.76: 0.16)$. Pronotum slightly wider than head. Synthlipsis about 1.3 times as wide as posterior width of an eye $(0.33: 0.24)$. Lengths of leg segments: fore leg: femur 0.23 , tibiotarsus 0.27 ; middle leg: femur 0.67 , tibia 0.21 , tarsus 0.36 , claw 0.2 ; hind leg: femur 0.6 , tibia 0.36 , tarsus I 0.41 , tarsus II 0.18 , claw 0.09 .

\section{Distribution}

Northern Vietnam: Lao Cai, Cao Bang, Phu Tho, Ha Noi, Thanh Hoa, Nghe An, Ha Tinh.

\section{Remarks}

This new species may be related to the group of M. anatolica, M. arcuata sp. nov., M. acuminata sp. nov., and M. fulvopicta sp. nov., as it also has the elongate sub-rectangular free lobe, the broad and flat shaft of the left paramere, and the slender, distally curved shaft of the right paramere. It has strong dark pattern on the dorsum like M. fulvopicta sp. nov., but its dark marks are usually slenderer, and the patterns on the corium are different, sometimes indistinct (see Fig. 5L). The left paramere of $M$. vietnamica sp. nov. has a rather straight shaft and a trapezoid basal lobe, while in the four species mentioned above, the left paramere has a more sinuate lateral margin of the shaft and the basal lobe is either subovate or subrectangular. The right paramere of $M$. vietnamica sp. nov. is slenderer and strongly curved at the distal third, while that of the four species above is bent or curved at the distal fourth. In addition, the palar claw of $M$. vietnamica sp. nov. is much broader and has a different outline compared to that of $M$. anatolica, M. arcuata sp. nov., M. acuminata sp. nov., and M. fulvopicta sp. nov.

Micronecta (Micronecta) ornitheia Nieser, Chen \& Yang, 2005 Figs 13A, 14A-D

Micronecta ornitheia Nieser, Chen \& Yang, 2005: 190, 197-200, figs 32-41 (type locality: Yunnan, China).

Micronecta ornitheia - Chen, Nieser \& Sangpradub 2006: 779 (record Thailand). 


\section{Diagnosis}

Body length 1.7-1.8. Pronotum longer than median head length. Dorsum generally light brown. Hemelytron with small, irregular-shaped reddish marks, mostly on costal part; embolium with a longitudinal dark grey stripe and two brown patches (Fig. 13A).

Males: fore femur with two spines on middle third, a spine on distal third dorsally, and a pair of spines distally; fore tibia with three large and one small spine on distal third; palar claw distally widened, apical margin rounded. Median lobe of sternite VII narrow, with pointed apex and four long setae (Fig. 14A). Free lobe slightly expanded distally, mesial angle rounded, lateral angle slightly produced with ca 20 long setae, posterior margin nearly straight (Fig. 14B). Left paramere: shaft broad, flat, with a deep notch along lateral margin near base, then followed by a triangular projection, distal part parallel sided, apex of paramere rounded; basal lobe longer than wide, sub-trapezoid (Fig. 14D). Right paramere: shaft slender proximally and club-shaped apically (Fig. 14C).

\section{Material examined}

VIETNAM - Lao Cai Prov. - 36 ふึَ, 31 우; Sa Pa, Thanh Phu, near junction of Nam Cang and

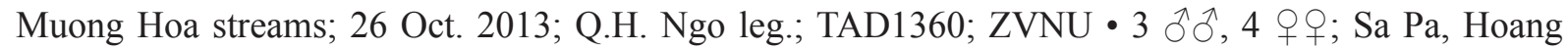

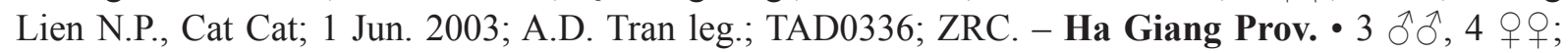
Bac Me, road 176, Minh Son commune, stream at Ban Van bridge; 7 May 2014; A.D. Tran et al. leg.; TAD1403; ZVNU • 1 Ō, 6 q $\circ$; Yen Minh, Na Khe commune, stream near Nat' road 4C; 8 May 2014; A.D. Tran et al. leg.; TAD1404; ZVNU • 2 $\widehat{\jmath}$; Vi Xuyen, Xin Chai commune, Da stream by the road

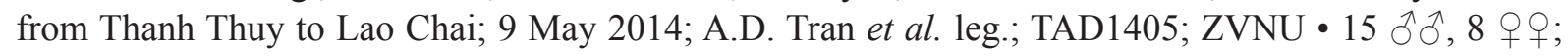
Vi Xuyen, Nat' road 2, Phuong Tien commune, Suu stream, near bridge; 9 May 2014; A.D. Tran et al.

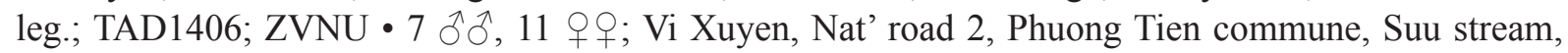
near bridge; 9 May 2014; A.D. Tran et al. leg.; TAD1407; ZVNU • 1 क; Vi Xuyen, National road 4C, Thuan Hoa commune, Nam Dieng stream, ca $12.5 \mathrm{~km}$ to Ha Giang city; 9 May 2014; A.D. Tran et al. leg.; TAD1409; ZVNU 1 त, Xin Man, road 178, tributary of Nam Yen River, near bridge ca $2 \mathrm{~km}$ from Coc Pai town; 11 May 2014; A.D. Tran et al. leg.; TAD1412; ZVNU. - Cao Bang Prov. 5 ô ô, 20 우 ; Trung Khanh, Duc Hong commune, stream; 19 Dec. 2013; A.D. Tran et al. leg.; TAD1376; ZVNU • 1 ô, 4 क 9 ; Bao Lac, Dinh Phung commune, near Tung Suu, stream by the Nat' road 34; 20 Dec. 2013; A.D. Tran et al. leg.; TAD1378; ZVNU • 20 ỗ, 29 क 9 ; Bao Lac, Hung Dao commune, Nhi Ao River, near Nam Xui bridge; 20 Dec. 2013; A.D. Tran et al. leg.; TAD1380; ZVNU • $3 \widehat{\jmath} \widehat{\jmath}, 12$ q 우 Bao Lac, Bao Toan commune, Na Roa Village, Khuoi Rong stream, tributary of Gam River; 20 Dec. 2013; A.D. Tran et al. leg.; TAD1381; ZVNU. - Phu Tho Prov. • 1 ô, 2 q $q$; Xuan Son N.P., Ban Coi, Coi stream, site 3, by the road to Tan Son; 7 Jun. 2013; A.D. Tran et al. leg.; TAD1339; ZVNU • 2 $\sigma^{\lambda}, 1$ \&; Xuan Son N.P., Ha Bang stream, near its confluence with Xoan stream; $21^{\circ} 5.318^{\prime}$ N, $104^{\circ} 58.87^{\prime}$ E; 22 May 2015; T.S. Nguyen leg.; TS1506; ZVNU • 1 §, 2 우우; Xuan Son N.P., Xoan stream, near Lang

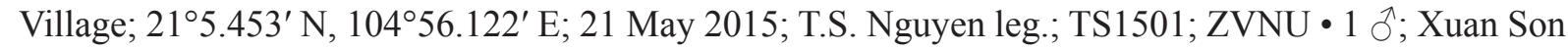
N.P., Xoan stream, Xoan village area; $21^{\circ} 05.270^{\prime}$ N, 104 $57.591^{\prime}$ E; 7 May 2016; T.S. Nguyen leg.; TS1609; ZVNU • 1 J $^{\prime}$; Xuan Son N.P., Chieng stream, near ranger station; $21^{\circ} 06.072^{\prime}$ N, $104^{\circ} 59.433^{\prime}$ E; 27 Aug. 2014; T.S. Nguyen leg.; TS1408; ZVNU • 1 ô, 4 ofo; Xuan Son N.P., Chieng stream, near ranger station; $21^{\circ} 06.072^{\prime} \mathrm{N}, 104^{\circ} 59.433^{\prime} \mathrm{E}$; 22 May 2015; T.S. Nguyen leg.; TS1508; ZVNU • 1 え, 5 우; Xuan Son N.P., Chieng stream, near ranger station; $21^{\circ} 06.072^{\prime}$ N, $104^{\circ} 59.433^{\prime}$ E; 25 Aug. 2015;

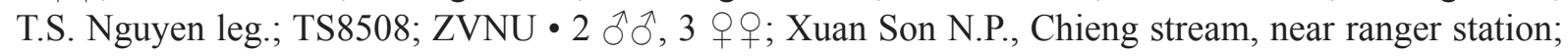

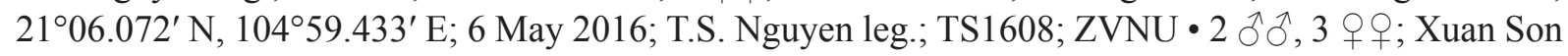
N.P., Coi stream, site 1, by the road to Tan Son; $2^{\circ} 09.204^{\prime}$ N, $104^{\circ} 56.927^{\prime}$ E; 8 May 2016; T.S. Nguyen leg.; TS1617; ZVNU. - Thanh Hoa Prov. • 5 ồ ${ }^{2}, 1$ q; Pu Hu Nature Reserve, Muong Lat, Trung Ly, Co Luong, Cha Lan stream; 4 Apr. 2013; T.D. Pham leg.; PH1301; ZVNU・ 2 ふふ઼; Pu Luong Nature Reserve, Ba Thuoc, Co Lung, Ban Khuyn, Khuyn stream; 18 Mar. 2013; T.D. Pham leg.; PL1303; 

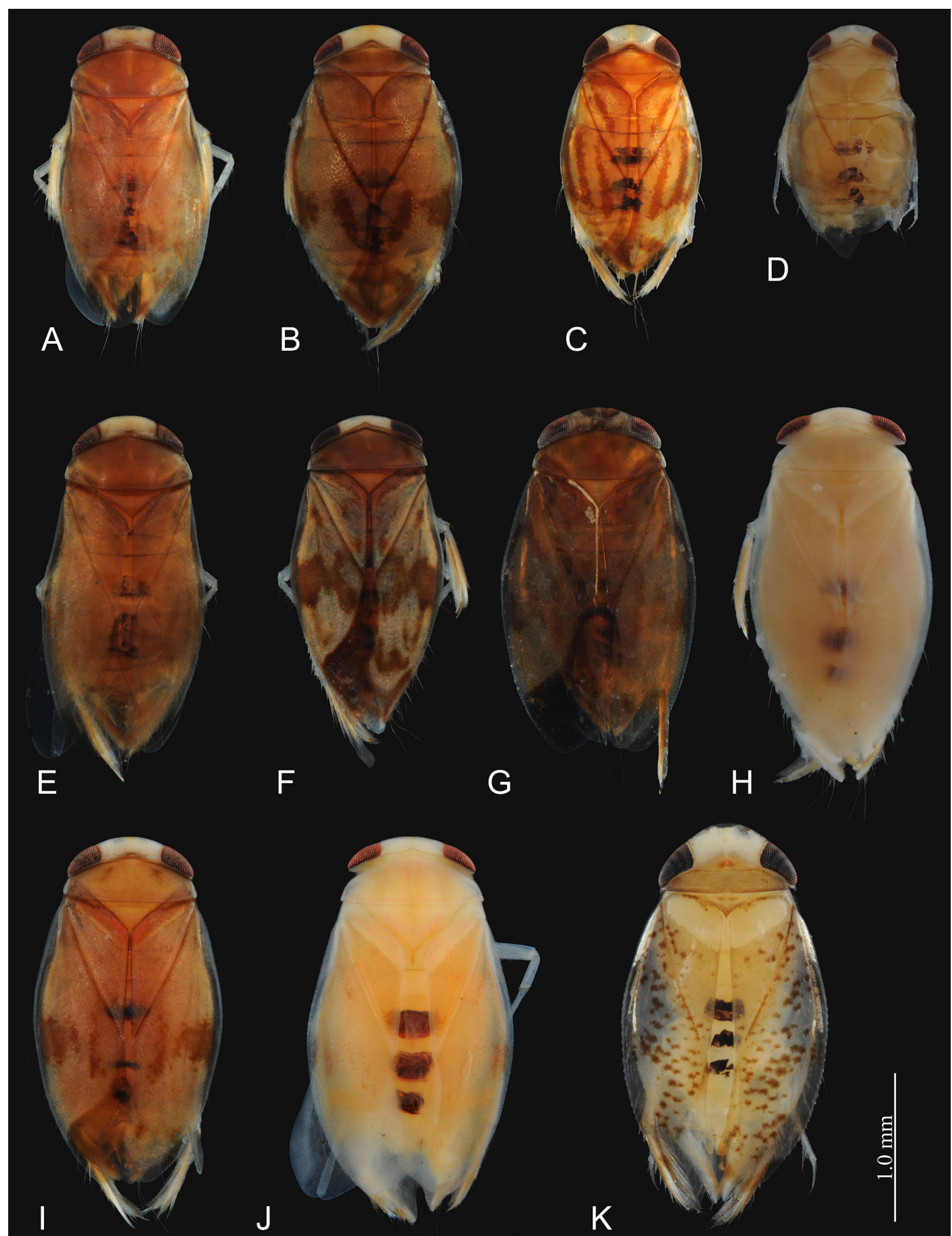

Fig. 13. Habitus photos of species of Micronecta Kirkaldy, 1897, $\widehat{\partial}$. A. M. ornitheia Nieser, Chen \& Yang, 2005 (ZVNU). B. M. tuwanoni Nieser, Chen, Leksawasdi, Thanyakam \& Duangsupa, 2004 (ZVNU). C-D. M. clavata sp. nov., two colour forms (ZVNU), C = holotype. E. M. sinuata sp. nov., holotype (ZVNU). F. M. undulata sp. nov., holotype (ZVNU). G-H. M. nieseri sp. nov., two colour forms (ZVNU), G = holotype. I-J. M. pingae sp. nov., two colour forms (ZVNU), I = holotype. K. M. haliploides Horváth, 1904 (ZVNU). All to the same scale. 


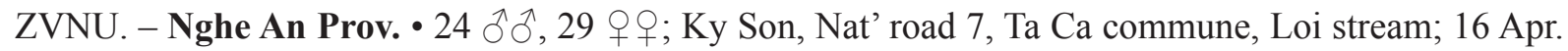
2013; A.D. Tran et al. leg.; TAD1301; ZVNU・ 9 ふ઼

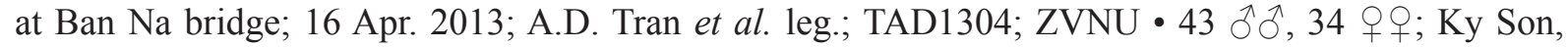
Nat' road 7 at km 182+950, stream at Khe Nan bridge; 16 Apr. 2013; A.D. Tran et al. leg.; TAD1305; ZVNU • 1 ภ, 1 क; Con Cuong, Lien Huong Village, Khe Thoi stream; 21 Dec. 2012; Q.H. Ngo leg.;

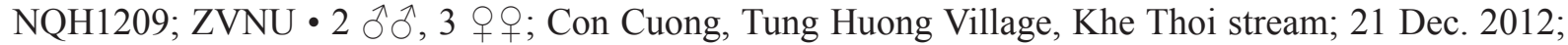

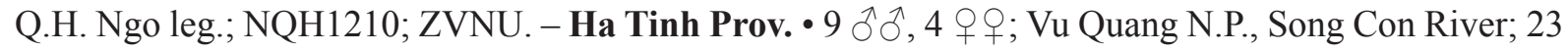
Apr. 2003; A.D. Tran leg.; TAD0302; ZRC.

\section{Distribution}

China, Thailand (Nieser et al. 2005; Chen et al. 2006). First records for Vietnam.

\section{Remarks}

Nieser et al. (2005) already noted the similarity (right paramere) and differences (body length, dorsal colour pattern, and left paramere) between M. ornitheia and M. sanctaecatherinae Hutchinson, 1940,
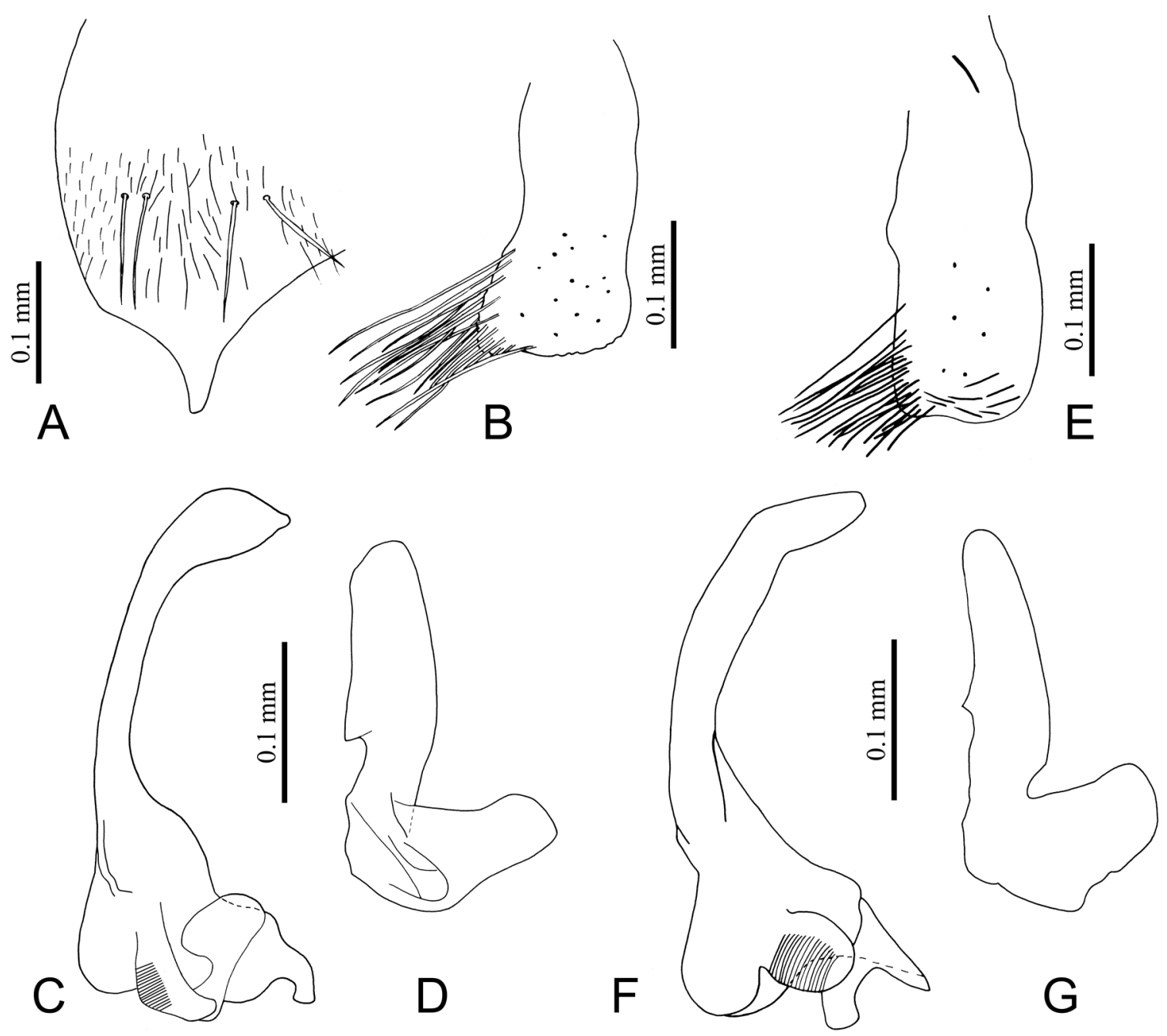

Fig. 14. Morphological features of species of Micronecta Kirkaldy, 1897, §ิð. A-D. M. ornitheia Nieser, Chen \& Yang, 2005 (ZVNU). E-G. M. tuwanoni Nieser, Chen, Leksawasdi, Thanyakam \& Duangsupa, 2004 (ZVNU). A = median lobe of sternite VII; B, E = free lobe; C, F = right paramere; D, $\mathrm{G}=$ left paramere. 
which is only known from India and Sri Lanka. Nieser et al. (2005) also made a comparison between the parameres of M. ornitheia, M. pocsi and related species from China and India. See also Remarks under $M$. clavata sp. nov. for additional differences between $M$. ornitheia and other similar species occurring in Vietnam.

Micronecta pocsi Wróblewski, 1967

Micronecta pocsi Wróblewski, 1967: 232-235, figs 1-5 (type locality: Ha Tinh, Vietnam).

Micronecta pocsi - Wróblewski 1968: 775 (checklist). — Nieser 2000: 287, fig. 37 (key).

\section{Diagnosis}

Body length 1.6-1.8. Pronotum longer than median head length. Dorsum generally brown. Hemelytron with brown markings, weakly contrasting with greyish background.

Males: fore femur with two stout spines on middle part; tibia without spine; palar claw widened distally, apex rounded. Median lobe of sternite VII narrow, with four long setae and a pointed apex. Free lobe expanded distally, mesial angle produced and rounded, posterior margin concave. Left paramere: shaft broad, flat, with a triangular projection nearer to base, distal part parallel sided, apex of paramere rounded; basal lobe large, tongue-shaped. Right paramere: shaft slender proximally and pre-apically with a small notch in upper margin, apical part widened, flap-like (based on description by Wróblewski 1967: figs 1-5).

\section{Material examined}

No material available.

\section{Distribution}

Currently only known from Vietnam, and possibly endemic to the country. Records from Vietnam: Ninh Binh (Cuc Phuong), Nghe An, Ha Tinh (Wróblewski 1967).

\section{Remarks}

This species was reported from various localities in Vietnam, and we conducted samplings in some of those areas. Unfortunately, we have not yet obtained any fresh specimens of $M$. pocsi. This suggests that it is a rare species. If encountered, this species can easily be recognised by the unique structure of the right paramere (see Wróblewski 1967: fig. 1). See also Remarks under M. clavata sp. nov.

Micronecta (Micronecta) tuwanoni Nieser, Chen, Leksawasdi, Thanyakam \& Duangsupa, 2004 Figs 13B, 14E-G

Micronecta tuwanoni Nieser, Chen, Leksawasdi, Thanyakam \& Duangsupa, 2004: 31-34, figs 2, 12-21 (type locality: Chiang Rai, Thailand).

\section{Diagnosis}

Body length 1.8-2.0. Pronotum longer than median head length. Dorsum generally pale brown. Hemelytron punctate, with transverse irregular-shaped dark marks (Fig. 13B).

Males: fore femur with two spines on proximal third, two spines on distal third, and one pair of spines distally; tibia with one spine in proximal third and a pair of spines distally; palar claw moderately widened distally, apex rounded. Median lobe of sternite VII with pointed apex and four long setae. Free lobe sub-rectangular, mesial angle rounded, lateral angle nearly square with ca 35 long setae, posterior 
margin slightly concave (Fig. 14E). Left paramere: shaft broad, flat, with a triangular projection in the middle of lateral margin, distal part parallel sided, apex rounded; basal lobe longer than wide, subtrapezoid (Fig. 14G). Right paramere: shaft slender and parallel sided, curved near base and abruptly bent at distal fourth, apex narrowly rounded (Fig. 14F).

\section{Material examined}

VIETNAM - Phu Tho Prov. 1 đo; Xuan Son N.P., Xoan stream, near Lang Village; $21^{\circ} 5.453^{\prime}$ N,

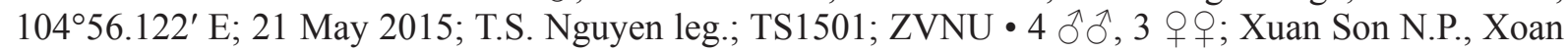
stream, near Lang Village; $1^{\circ} 5.453^{\prime} \mathrm{N}, 104^{\circ} 56.122^{\prime}$ E; 5 May 2016; T.S. Nguyen leg.; TS1601; ZVNU - $5 \overbrace{}^{\lambda}{ }^{\lambda}, 3$ 우; Xuan Son N.P., Coi stream, site 2, near concrete bridge; $21^{\circ} 09.130^{\prime}$ N, $104^{\circ} 56.761^{\prime}$ E; 27 Aug. 2015; T.S. Nguyen leg.; TS8518; ZVNU.

\section{Distribution}

Thailand (Nieser et al. 2004). First record for Vietnam.

\section{Remarks}

Nieser et al. (2004) considered this species related to M. anatolica. The right paramere of M. tuwanoni appears similar to that of $M$. anatolica, both being strongly bent apically. However, the basal part of the right paramere's shaft is curved in M. tuwanoni while it is straight in the latter species. Based on the presence of a triangular projection on the lateral margin of the left paramere and the similar shape of the median lobe of sternite VII, we consider that this species, more closely related to M. ornitheia, M. pocsi, and M. clavata sp. nov. See Remarks under M. clavata sp. nov. for further details.

\section{Micronecta (Micronecta) clavata sp. nov. urn:lsid:zoobank.org:act:B4B1E7DD-177F-498A-9A98-80185920F66D}

Figs $13 \mathrm{C}-\mathrm{D}, 15$

\section{Diagnosis}

Body length 1.4-1.7. Pronotum longer than median head length. Dorsum colour variable. Hemelytron with irregular-shaped light brown marks, sometimes indistinct (Fig. 13C-D).

Males: fore femur with two spines on proximal third ventrally, one spine on distal third dorsally, one pair of spines distally, and one long seta dorsodistally; fore tibia without spine; palar claw moderately widened distally, apex rounded (Fig. 15A). Median lobe of sternite VII with angular apex and three or four long setae (Fig. 15C). Free lobe sub-rectangular, mesial angle rounded, lateral angle nearly square, with ca 10 long setae, posterior margin straight (Fig. 15D). Left paramere: shaft broad, flat, with a triangular projection in the middle of lateral margin, distal part tapering towards rounded apex; basal lobe large, sub-rectangular (Fig. 15F). Right paramere: shaft slender and parallel sided proximally, distal fourth curved, club-shaped with a truncate tip; pars stridens processus with about 20 ridges (Fig. 15E).

\section{Etymology}

The species epithet refers to the club-shaped apex of the right paramere.

\section{Material examined}

Holotype

VIETNAM • ${ }^{7}$; Cao Bang Prov., Ha Quang, road 203, Truong Ha commune, stream near Kim Dong tomb; 17 Dec. 2013; A.D. Tran et al. leg.; TAD1371; ZVNU.

\section{Paratypes}

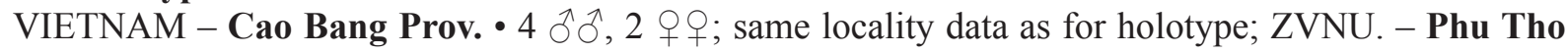
Prov. 2 2 $q$; ; Xuan Son N.P., Chieng stream, near ranger station; $21^{\circ} 06.072^{\prime}$ N, $104^{\circ} 59.433^{\prime}$ E; 27 Aug. 
2014; T.S. Nguyen leg.; TS1408; ZVNU • 1 đ; Xuan Son N.P., Ha Bang stream, near its confluence with

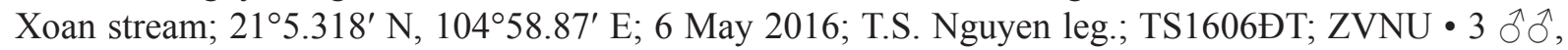

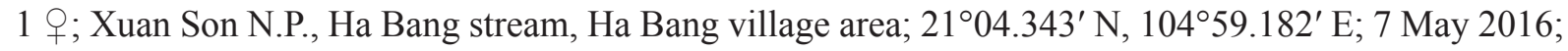
T.S. Nguyen leg.; TS1610; ZRC • 1 o; Xuan Son N.P., Xoan stream, Xoan village area; $21^{\circ} 05.270^{\prime}$ N, 10457.591' E; 7 May 2016; T.S. Nguyen leg.; TS1609; ZVNU • 1 गे; Xuan Son N.P., Kim Thuong, Xoan stream; 28 Aug. 2013; A.D. Tran et al. leg.; TAD1343; ZVNU • 1 ठ̊; Xuan Son N.P., Ban Coi, Coi stream, site 1, water from underground; 29 Aug. 2013; A.D. Tran et al. leg.; TAD1349; ZVNU •

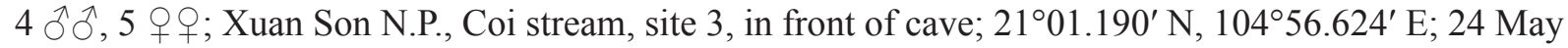
2015; T.S. Nguyen leg.; TS1519; ZVNU • 1 O ; Xuan Son N.P., Coi stream, site 3, in front of cave; $21^{\circ} 01.190^{\prime} \mathrm{N}, 104^{\circ} 56.624^{\prime}$ E; 27 Aug. 2015; T.S. Nguyen leg.; TS8519 ZVNU • 1 đ̊; Xuan Son N.P.,

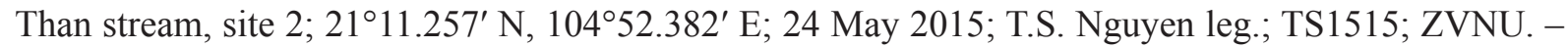
Hanoi -2 ô, 1 q; Ba Vi N.P., Khoang Xanh, Tien stream; 95 m a.s.l.; 17 Dec. 2011; Q.H. Ngo and A.D. Tran leg.; TAD1127; NHMW • 7 $\widehat{\jmath}, 12$ 우; Ba Vi N.P., Khoang Xanh, Tien stream; 95 m a.s.l.; 27 Apr. 2012; Q.H. Ngo and A.D. Tran leg.; TAD1208; ZVNU. - Ha Tinh Prov. 1 \&; Vu Quang N.P., Song Con River; 23 Apr. 2003; A.D. Tran leg.; TAD0302; ZRC.

\section{Description}

Colour (Fig. 13C-D). With two colour forms, especially colour pattern of hemelytra. Darker form, with distinct dark marks on dorsum (specimens from Phu Tho Prov.): frons and vertex pale yellowish,

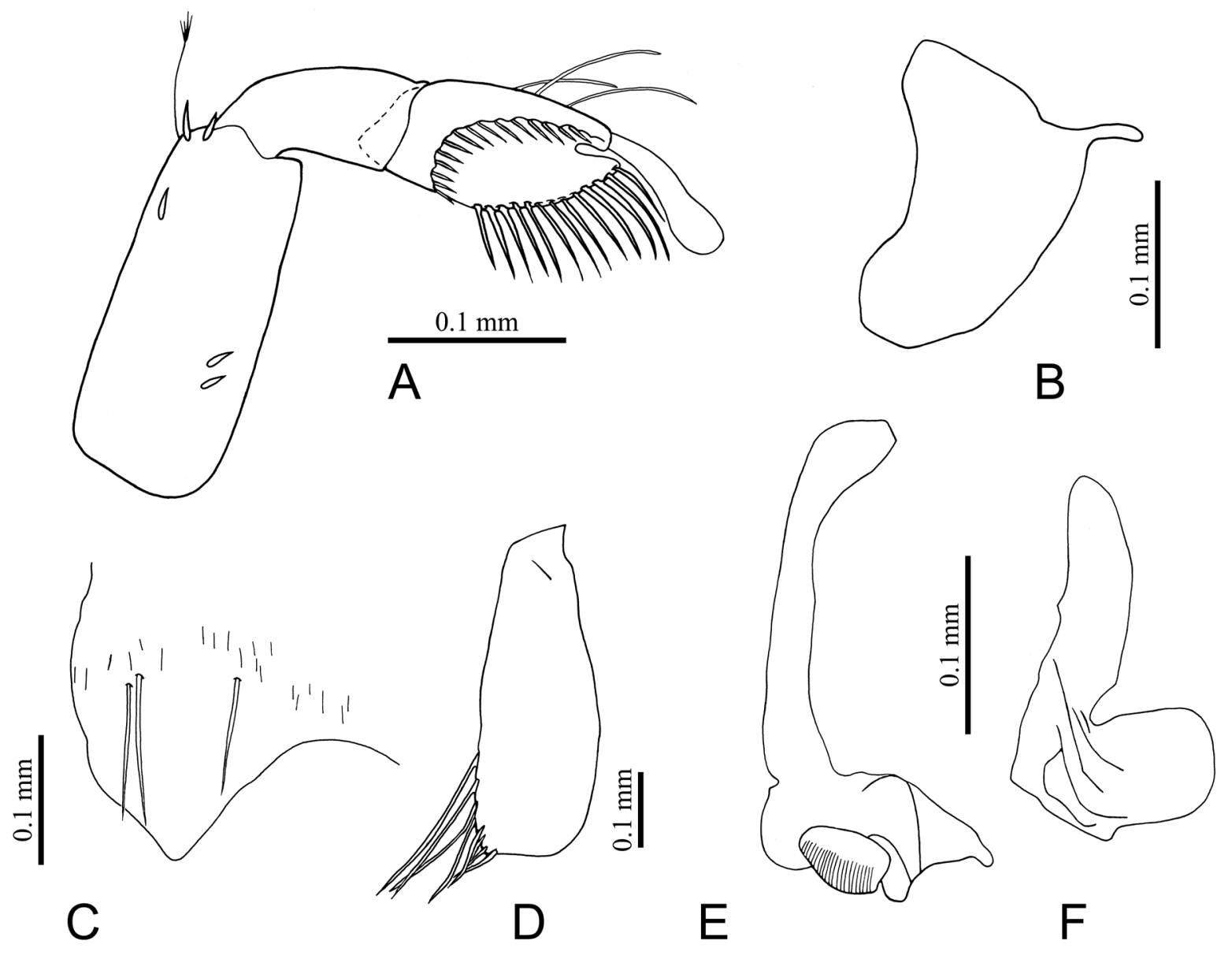

Fig. 15. Morphological features of Micronecta clavata sp. nov., $\widehat{\jmath}$, paratype (ZVNU). A. Fore leg. B. Prestrigilar flap. C. Median lobe of sternite VII. D. Free lobe. E. Right paramere. F. Left paramere. 
eyes dark reddish brown. Pronotum light brown. Clavus with a discrete dark brown stripe parallel to suture margin, and a transverse brown mark at anterior margin. Corium with three distinct longitudinal stripes, confluent posteriorly. Membrane translucent and brown. Venter of thorax and abdomen dark brown and legs brownish yellow. Paler form with dorsum generally light yellowish brown (specimens from Cao Bang Prov.): frons and vertex pale, eyes dark reddish brown. Pronotum pale yellowish brown. Hemelytron hyaline light yellowish. Clavus with brown suture margin. Corium with light brown longitudinal stripes indistinct. Membrane transculent, light yellowish. Venter of thorax and abdomen light yellowish orange, legs pale yellow.

\section{Structural characteristics}

Macropterous males. Body length 1.53-1.75 (holotype: 1.69), width 0.84-1.02 (holotype: 0.95). Head width $0.59-0.72$ (holotype: 0.67). Head slightly wider than pronotum. Pronotum short, about four times as wide as long $(0.61: 0.14)$. Synthlipsis about 1.4 times as wide as posterior width of an eye (0.27:0.19). Lengths of leg segments: fore leg: femur 0.22 , tibia 0.10 , pala 0.13 ; middle leg: femur 0.52 , tibia 0.18 , tarsus 0.25 , claw 0.16 ; hind leg: femur 0.43 , tibia 0.27 , tarsus I 0.30 , tarsus II 0.12 , claw 0.05 . Prestrigilar flap on segment V tongue-shaped (Fig. 15B). Strigil present. Median lobe of sternite VII, free lobe, and parameres as in diagnosis.

Macropterous females. Body length 1.37-1.81, width 0.72-1.02. Head width 0.59-0.68. Head slightly wider than pronotum. Pronotum about four times as wide as long $(0.61: 0.14)$. Synthlipsis 1.6 times as wide as posterior width of an eye $(0.27: 0.17)$. Lengths of leg segments: fore leg: femur 0.18 , tibiotarsus 0.18 ; middle leg: femur 0.5 , tibia 0.18 , tarsus 0.25 , claw 0.14 ; hind leg: femur 0.42 , tibia 0.27 , tarsus I 0.27 , tarsus II 0.12 , claw 0.04 .

\section{Distribution}

Northern Vietnam (Cao Bang, Phu Tho).

\section{Remarks}

Among species of Micronecta occurring in Vietnam, four species, namely M. ornitheia, M. pocsi, M. tuwanoni, and M. clavata sp. nov., are most similar to each other, in having a triangular projection on the margin of the shaft of the left paramere. This structure is also present in the left paramere of M. erythra. However, the right paramere of $M$. erythra is evenly curved throughout the length of its shaft, while that of four species above is nearly straight or only curved near the base of the shaft.

The key structure which can help to reliably separate M. ornitheia, M. pocsi, M. tuwanoni, and M. clavata sp. nov. from each other is the apical part of the right paramere. In M. ornitheia, it is widened, with a small tip making it resemble a bird head. In M. pocsi, it is flap-like, with a small notch on the upper margin before apical part. In M. tuwanoni, the shaft of the right paramere is bent at the distal fourth and the apical part is not widened but tapering towards its tip. In M. clavata sp. nov., it is club-shaped and its tip is more truncate, not modified.

The left paramere of these four species also has diagnostic features. In M. ornitheia, the triangular projection is situated near to the base of the shaft, and there is a distinct notch basally to the projection; and the basal lobe is longer than wide, and sub-trapezoid. In M. pocsi, the triangular projection is also nearer to the base of shaft, but there is no notch on the lateral margin; and the basal lobe is sub-triangular. In M. tuwanoni, the triangular projection arises on the proximal third (thus nearer to the base) of the shaft, and the basal lobe is trapezoid. In M. clavata sp. nov., the triangular projection is near to the middle part of the lateral margin of the shaft, and the basal lobe is sub-rectangular. 
Micronecta (Micronecta) sinuata sp. nov. urn:1sid:zoobank.org:act:78EEDB2B-1576-42AE-95A5-424B0E821218

Figs 13E, 16

\section{Diagnosis}

Body length 2.0-2.2. Pronotum longer than median head length. Dorsum colour brown. Hemelytron punctate, generally brownish.

Males: fore femur with a pair of spines on middle third, one spine in distal third dorsally, and two spines distally; fore tibia without spine; palar claw moderately widened distally, apex rounded (Fig. 16A). Median lobe of sternite VII with angular, acute apex and four long setae (Fig. 16C). Free lobe short, distally widened, both angles nearly square, lateral with ca 25 long setae, mostly on lateral margin (Fig. 16D). Left paramere: shaft broad, flat, tapering towards a slightly swollen, rounded apex, and with a small process near apex; basal lobe longer than wide, sub-rectangular (Fig. 16F). Right paramere: distal part of shaft widened and folded into a gutter-like structure, with a lobe on one side, apex narrowly rounded; base with a distinct hump on mesial side, near base of shaft; pars stridens processus with ca 20 ridges (Fig. 16E).

\section{Etymology}

The species epithet refers to the sinuate and folded tip of the right paramere.

\section{Material examined}

Holotype

VIETNAM • \; Lao Cai Prov., Sa Pa, Ban Den, Ta Van, Muong Hoa stream; 24 Apr. 2011; N.H. Dinh et al. leg.; DNH11.13; ZVNU.

\section{Paratypes}

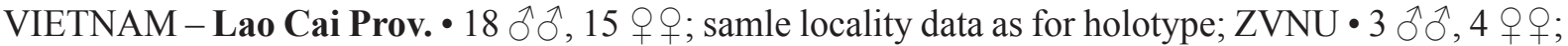
Sa Pa, Hoang Lien N.P., Cat Cat; 1 Jun. 2003; A.D. Tran leg.; TAD0336; ZRC・ 4 ठðð, 8 우우 Sa Pa, Cat Cat, Muong Hoa stream; 22 Apr. 2011; N.H. Dinh et al. leg.; DNH11.01; NHMW • 9 $\widehat{\partial}, 9$ q 0 ; Sa Pa, Su Pan, Cau May, Muong Hoa stream; 24 Apr. 2011; N.H. Dinh et al. leg.; DNH11.12; ZVNU •

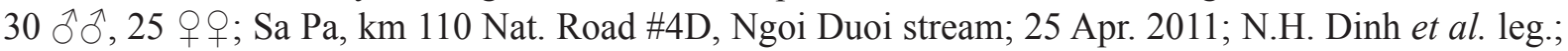
DNH11.14; ZVNU • 1 ô, 1 क; Sa Pa, Nam Sai, Seo Nam Sai stream 1; 24 Oct. 2012; N.H. Dinh et al. leg.; DNH12.09; ZVNU • 1 ô, 2 우; Sa Pa, Sin Chai, Muong Hoa stream (Cat stream); 27 Oct. 2013; A.D. Tran et al. leg.; TAD1365; ZVNU 1 Oे; Sa Pa, Cat Cat, Muong Hoa stream (Cat stream); 27 Oct. 2013; Q.H. Ngo et al. leg.; TAD1367; ZVNU.

\section{Description}

Colour (Fig. 13E). Dorsum generally sordid brown. Frons and vertex light yellowish, eyes dark brown. Pronotum sordid brown, with a yellowish longitudinal stripe on anterior part and two yellowish transverse stripes on posterior part, stripes usually indistinct. Hemelytron generally brownish, embolium hyaline, with brown mark along suture with corium. Membrane translucent. Venter of thorax and abdomen brownish yellow, legs pale greyish yellow.

\section{Structural characteristics}

Macropterous males. Body length 2.06-2.35 (holotype: 2.25), width 0.88-1.1 (holotype: 1.06). Head width $0.72-0.81$ (holotype: 0.76$)$. Pronotum about 2.4 times as wide as long $(0.90: 0.38)$. Pronotum wider than head. Synthlipsis about 1.3 times as wide as posterior width of an eye $(0.4: 0.3)$. Lengths of leg segments: fore leg: femur 0.27 , tibia 0.2 , pala 0.14 ; middle leg: femur 0.67 , tibia 0.25 , tarsus 0.38 , 
claw 0.25; hind leg: femur 0.54, tibia 0.4, tarsus I 0.41 , tarsus II 0.14 , claw 0.08 . Prestrigilar flap on segment V with prolonged apex (Fig. 16B). Strigil present. Median lobe of sternite VII, free lobe, and parameres as in diagnosis.

Macropterous females. Body length 2.1-2.22, width 0.94-1.0. Head width 0.77-0.83. Pronotum about 2.6 times as wide as long $(0.93: 0.36)$. Pronotum wider than head. Synthlipsis about 1.6 times as wide as posterior width of an eye $(0.41: 0.26)$. Lengths of leg segments: fore leg: femur 0.3 , tibiotarsus 0.24 ; middle leg: femur 0.74 , tibia 0.28 , tarsus 0.33 , claw 0.25 ; hind leg: femur 0.56 , tibia 0.37 , tarsus I 0.4 , tarsus II 0.16 , claw 0.05 .

\section{Distribution}

Vietnam: Lao Cai.

\section{Remarks}

This new species appears most similar to M. prashadana Hutchinson, 1940 from Sri Lanka, in the general form of the parameres, the outline of palar claw, and the shape of the free lobe. In both species, the right paramere has a beak-like apical part, and the left paramere has a swollen, rounded apex. However, there are substantial differences between the two species. In M. sinuata sp. nov., the left paramere has its shaft gently tapering towards a slightly swollen, rounded apex; the basal lobe of the left paramere is well developed and sub-rectangular; the right paramere has a pre-apical lobe on the mesial side of the shaft, and the base of the right paramere has a distinct hump on its mesial side, near the base of shaft. In M. prashadana, the shaft of the left paramere is swollen on the basal part, and its apex more swollen and larger; the basal lobe of the left paramere is less developed, much narrower and subovate;
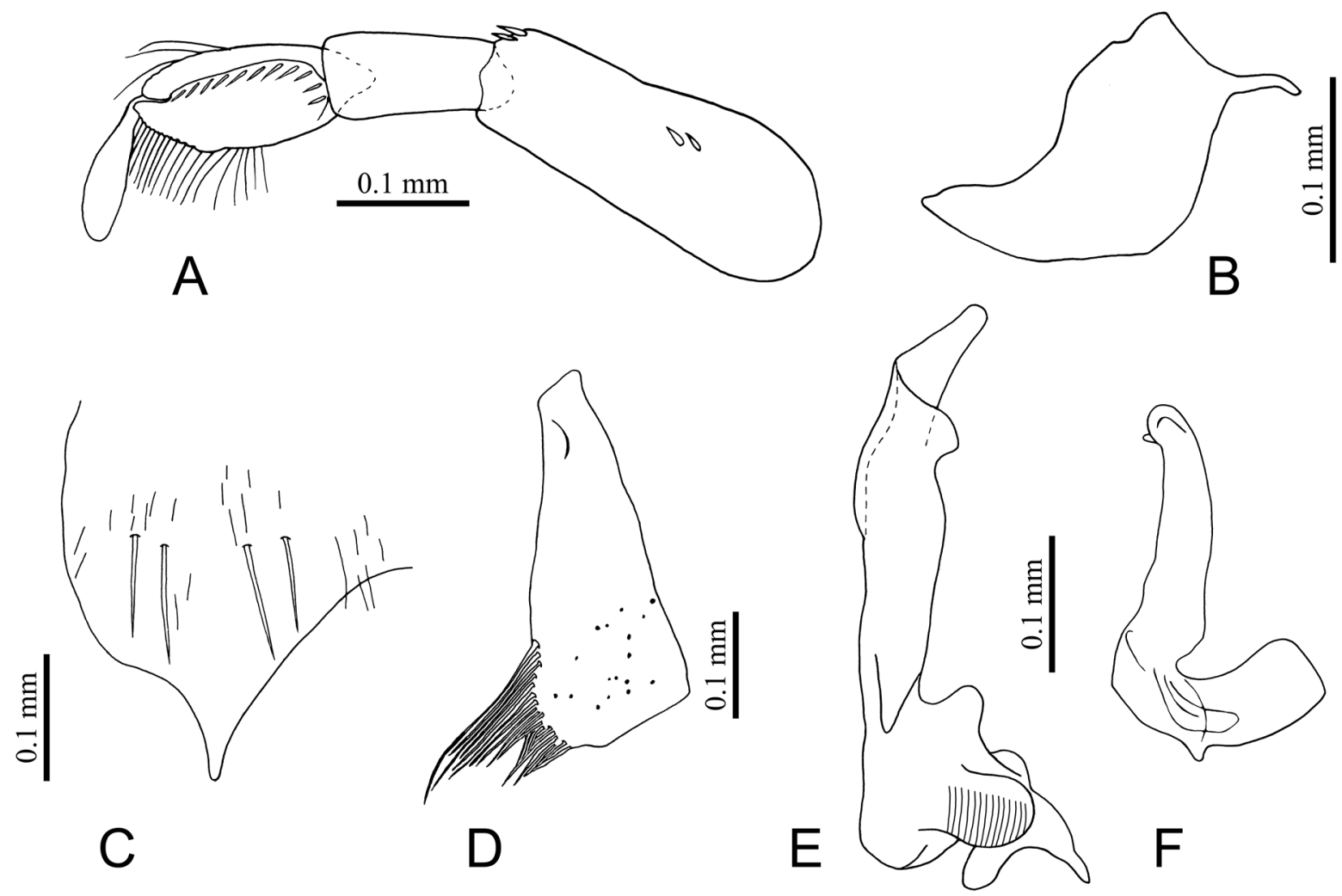

Fig. 16. Morphological features of Micronecta sinuata sp. nov., ô, paratype (ZVNU). A. Fore leg. B. Prestrigilar flap. C. Median lobe of sternite VII. D. Free lobe. E. Right paramere. F. Left paramere. 
the right paramere has a pre-apical lobe on the lateral side of shaft; and the base of the right paramere has no hump.

Among species of Micronecta occurring in Vietnam, M. sinuata sp. nov. has a rather unique structure of both parameres, with no other species having a similar structure.

Micronecta (Micronecta) undulata sp. nov.

urn:1sid:zoobank.org:act:98F8AC39-93D8-4C61-900B-B3BD1F21B676

Figs 13F, 17

\section{Diagnosis}

Body length 1.9-2.2. Pronotum longer than median head length. Hemelytron with a broad, transverse, dark brown mark on greyish background (Fig. 13F).

Males: fore femur with two spines on middle third, one or two spines distally, and no long seta dorsodistally; fore tibia with one small spine on proximal third dorsally, and three spines on distal third; palar claw distally moderately widened, apex rounded (Fig. 17A). Median lobe of sternite VII with narrow, pointed apex and four long setae (Fig. 17C). Free lobe short, distally widened and wavy, both angles nearly square, without long setae; posterior margin strongly sinuate (Fig. 17D). Left paramere: shaft relatively short and broad, apex truncate, with two ridges running to lateral margin, thus forming two triangular projections on lateral margin; basal lobe longer than wide, sub-rectangular (Fig. 17F). Right paramere: shaft parallel sided, slightly curved at proximal part, abruptly constricted at distal third, apical part wavy and lobate; pars stridens processus with 18-27 ridges (Fig. 17E).

\section{Etymology}

The species epithet refers to the wavy, undulating free lobe.

\section{Material examined}

\section{Holotype}

VIETNAM - `’; Phu Tho Prov., Xuan Son N.P., Coi stream, site 1, by the road to Tan Son; $21^{\circ} 09.204^{\prime}$ N, 10456.927' E; 27 Aug. 2015; T.S. Nguyen leg.; TS8517; ZVNU.

\section{Paratypes}

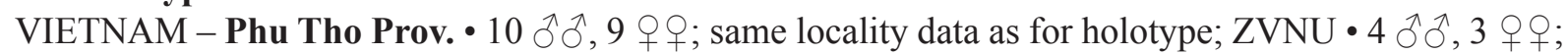
same locality data as for holotype; NHMW • 2 ô, 1 q; Xuan Son N.P., Ban Coi, Coi stream, site 2, near bridge; 7 Jun. 2013; A.D. Tran et al. leg.; TAD1338; ZVNU・ 4 ふ઼, 2 우; Xuan Son N.P., Ban Coi, Coi stream, site 3, by the road to Tan Son; 7 Jun. 2013; A.D. Tran et al. leg.; TAD1339; ZVNU • 1 Ō, 1 q; Xuan Son N.P., Kim Thuong, Xoan stream; 28 Aug. 2013; A.D. Tran et al. leg.; TAD1343;

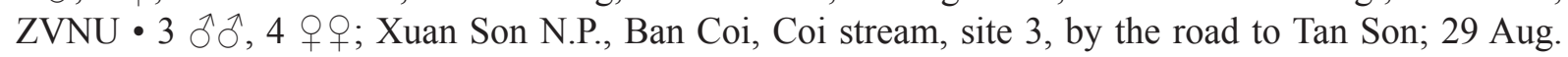

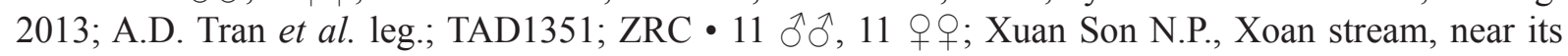
confluence with Ha Bang stream; $21^{\circ} 5.303^{\prime}$ N, 10457.559' E; 27 Aug. 2014; T.S. Nguyen leg.; TS1407; ZVNU • 2 9 ; Xuan Son N.P., Xoan stream, near its confluence with Ha Bang stream; $21^{\circ} 5.303^{\prime}$ N,

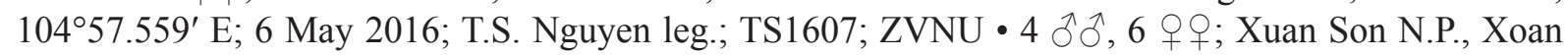
stream, Xoan village area; $21^{\circ} 05.270^{\prime} \mathrm{N}, 1^{\circ} 4^{\circ} 57.591^{\prime}$ E; 23 May 2015; T.S. Nguyen leg.; TS1509; ZVNU • 1 क; Xuan Son N.P., Xoan stream, Xoan village area; $21^{\circ} 05.270^{\prime}$ N, $104^{\circ} 57.591^{\prime}$ E; 7 May 2016; T.S. Nguyen leg.; TS1609; ZVNU • 1 q; Xuan Son N.P., Than stream, site 2; $21^{\circ} 11.257^{\prime}$ N, 10452.382' E; 24 May 2015; T.S. Nguyen leg.; TS1515; ZVNU • 1 गै, 1 o; Xuan Son N.P., Than

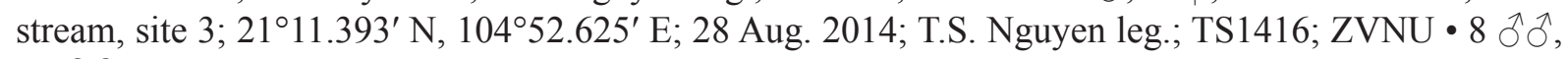

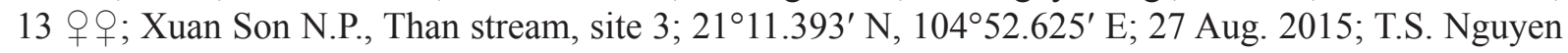

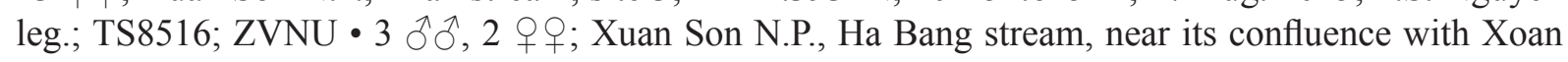




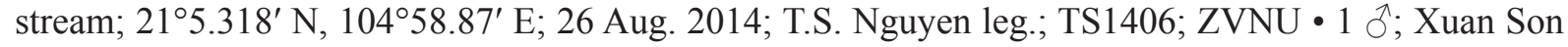
N.P., Ha Bang stream, near its confluence with Xoan stream; 21 ${ }^{\circ} 5.318^{\prime}$ N, $104^{\circ} 58.87^{\prime}$ E; 6 May 2016;

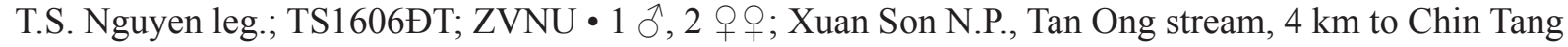

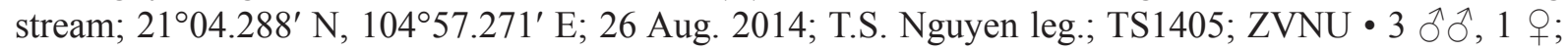
Xuan Son N.P., Tan Ong stream, 4 km to Chin Tang stream; $21^{\circ} 04.288^{\prime}$ N, 104 $57.271^{\prime}$ E; 22 May 2015; T.S. Nguyen leg.; TS1505; ZVNU • 1 ते; Xuan Son N.P., Coi stream, site 1, by the road to Tan Son;

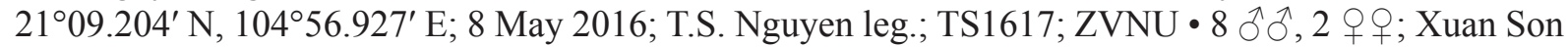
N.P., Coi stream, site 2, near concrete bridge; $21^{\circ} 09.130^{\prime} \mathrm{N}, 104^{\circ} 56.761^{\prime} \mathrm{E} ; 24$ May 2015; T.S. Nguyen leg.; TS1518; ZVNU.

\section{Description}

CoLour (Fig. 13F). Dorsum generally brownish grey. Frons and vertex pale yellowish, eyes blackish brown. Pronotum greyish brown. Hemelytron with greyish background. Clavus with brown punctures near anterior margin. Corium with a broad transverse dark brown mark in the middle. Membrane generally dark brown, more hyaline apically. Venter of thorax and abdomen greyish brown and legs pale yellow or nearly whitish.

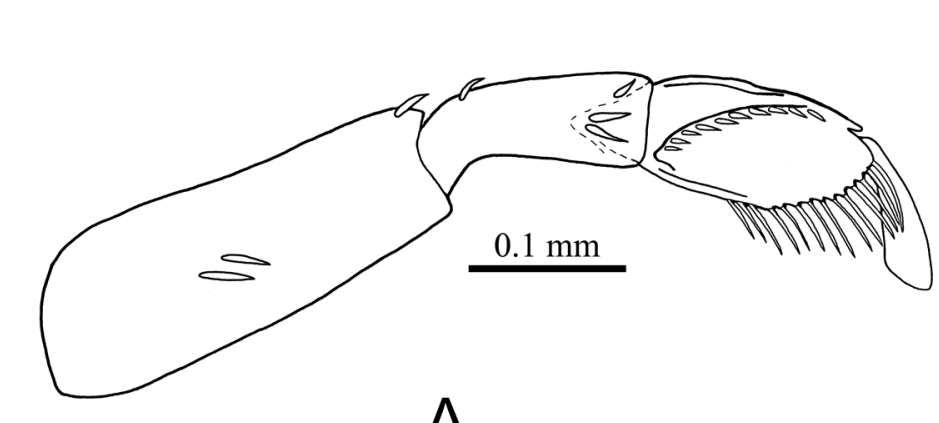

A

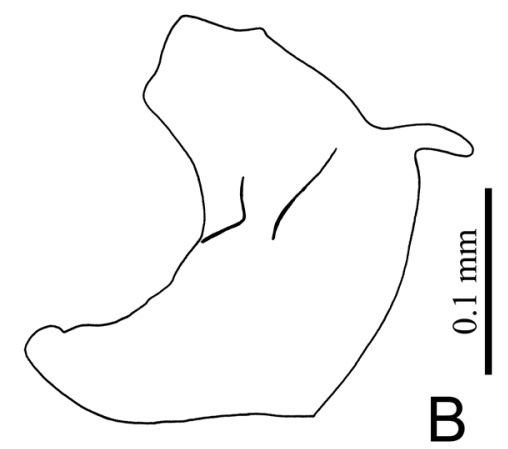

$\mathrm{B}$

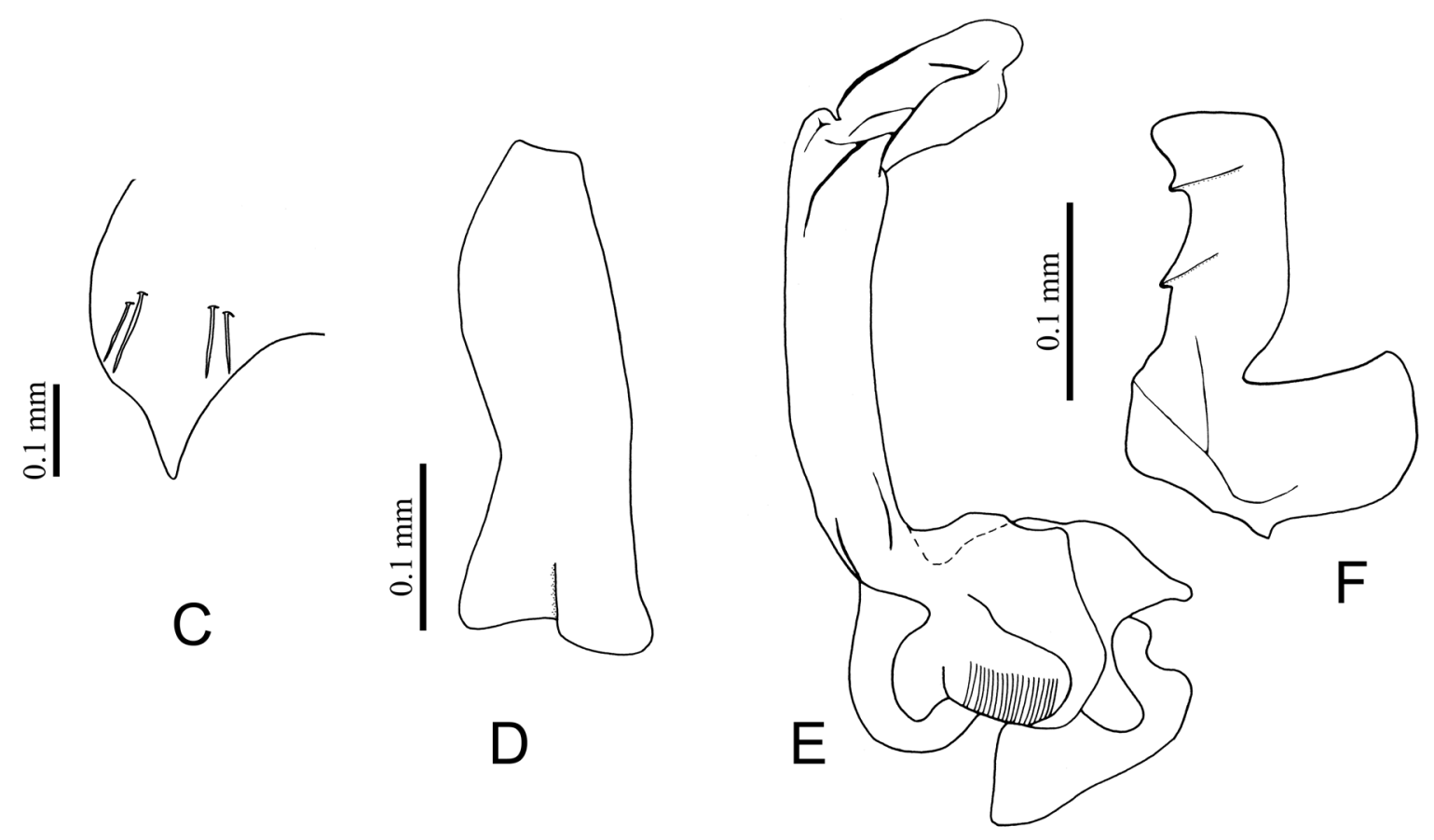

Fig. 17. Morphological features of Micronecta undulata sp. nov., ô, paratype (ZVNU). A. Fore leg. B. Prestrigilar flap. C. Median lobe of sternite VII. D. Free lobe. E. Right paramere. F. Left paramere. 


\title{
Structural characteristics
}

Macropterous males. Body length 1.94-2.19 (holotype: 2.03), width 0.94-1.06 (holotype: 1.00). Head width $0.81-0.83$ (holotype: 0.76 ). Pronotum about 2.4 times as wide as long $(0.87: 0.36)$. Pronotum slightly wider than head. Synthlipsis about 1.3 times as wide as posterior width of an eye $(0.37: 0.29)$. Lengths of leg segments: fore leg: femur 0.32 , tibia 0.14 , pala 0.14 ; middle leg: femur 0.67 , tibia 0.25 , tarsus 0.34 , claw 0.21 ; hind leg: femur 0.56 , tibia 0.40 , tarsus I 0.39 , tarsus II 0.16 , claw 0.16 . Prestrigilar flap on segment V crescent-shaped (Fig. 17B). Strigil present. Median lobe of sternite VII, free lobe, and parameres as in diagnosis.

Macropterous females. Body length 1.94-2.03, width 1.0-1.03. Head width 0.81-0.82. Pronotum about 2.6 times as wide as long $(0.88: 0.34)$. Pronotum slightly wider than head. Synthlipsis about 1.4 times as wide as posterior width of an eye $(0.39: 0.27)$. Lengths of leg segments: fore leg: femur 0.29 , tibiotarsus 0.27 ; middle leg: femur 0.72 , tibia 0.29 , tarsus 0.36 , claw 0.22 ; hind leg: femur 0.52 , tibia 0.36 , tarsus I 0.42 , tarsus II 0.16 , claw 0.16 .

\section{Distribution}

Vietnam: Phu Tho.

\section{Remarks}

See Remarks under M. pingae sp. nov.

\author{
Micronecta (Micronecta) nieseri sp. nov. \\ urn:1sid:zoobank.org:act:1AA8EB22-6D08-4894-81DA-E9CE0D648CFD \\ Figs $13 \mathrm{G}-\mathrm{H}, 18$
}

\section{Diagnosis}

Body length 1.8-2.4. Pronotum longer than median head length. With dark and pale colour forms (Fig. 13G-H).

Males: fore femur with one pair of spines on proximal third ventrally, one longer spine on distal third dorsally, two spines distally, and one long seta dorsodistally; fore tibia with two long spines on distal third ventrally; palar claw distally moderately widened, apex rounded (Fig. 18A). Median lobe of sternite VII with three or four long setae and an angular apex (Fig. 18C). Free lobe short, distally strongly widened, posterior margin straight, lateral corner broadly notched, with a row of uniformly short, dark coloured setae restricted to lateral angle (Fig. 18D). Left paramere: shaft relatively short and broad, with two ridges running to lateral margin, with the proximal ridge forming a triangular projection on lateral margin; mesial margin sinuate distally; apex tongue-shaped; basal lobe sub-triangular, directed towards paramere's apex (Fig. 18F). Right paramere: shaft with sinuate sides, abruptly constricted and bent at the middle part, apical part wavy and lobate (Fig. 18E); pars stridens processus with ca 25 ridges.

\section{Etymology}

This species is named after Dr Nico Nieser in honour of his great contributions to the taxonomy and our knowledge of Micronectidae.

\section{Material examined}

Holotype

VIETNAM - ơ; Lao Cai Prov., Sa Pa, Thanh Phu, Nam Cang stream; 26 Oct. 2013; A.D. Tran et al. leg.; TAD1359; ZVNU. 


\section{Paratypes}

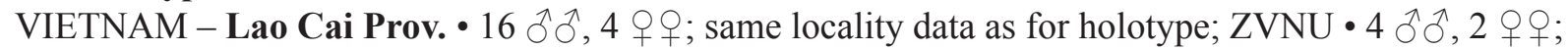
same locality data as for holotype; NHMW • $7 \widehat{\jmath} \widehat{\jmath}, 11$ 우; Sa Pa, Hoang Lien N.P., Cat Cat; 1 Jun.

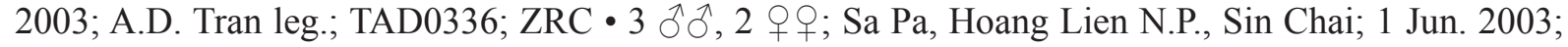
A.D. Tran leg.; TAD0337; ZRC • 1 ठ̊; Sa Pa Ban Den, Ta Van, Muong Hoa stream; 24 Apr. 2011; N.H.

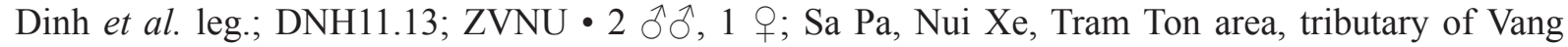
stream; 23 Apr. 2011; N.H. Dinh et al. leg.; DNH11.07; ZVNU • 2 ồ ; Sa Pa, Ban Ho, Nam Pu stream

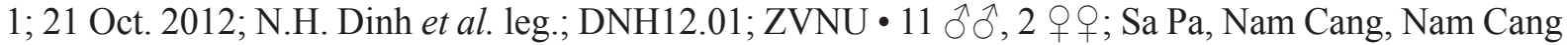
stream; 23 Oct. 2012; N.H. Dinh et al. leg.; DNH12.08; ZVNU • 1 o; Sa Pa, Nam Sai, Seo Nam Sai

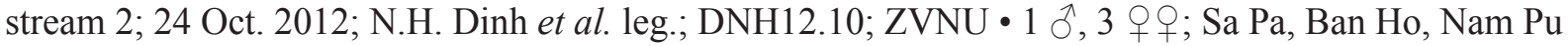
stream (tributary of Muong Hoa stream), site 1, at lower section; 26 Oct. 2013; A.D. Tran et al. leg.;

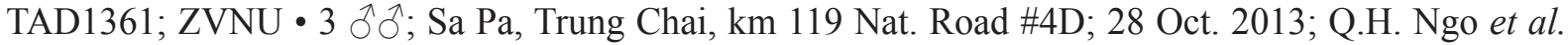
leg.; TAD1370; ZVNU.

\section{Description}

Colour (Fig. 13G-H). With variations in colour of dorsum pattern of hemelytra, a dark form and a pale form. Most specimens with dark dorsum, generally darker in males (Fig. 13G): frons and vertex brownish, eyes dark reddish brown. Pronotum dark brown (males) or light brownish yellow (females). Hemelytron generally light brownish, with ill-defined dark marks; in some specimens with minute
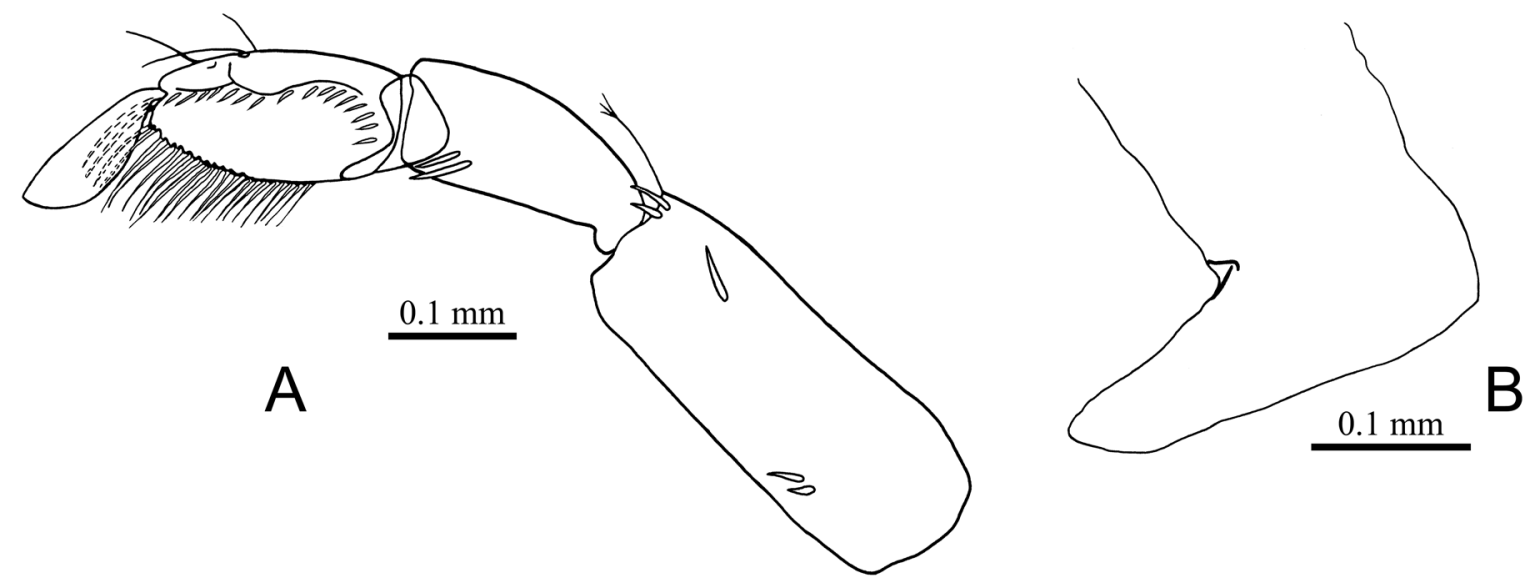
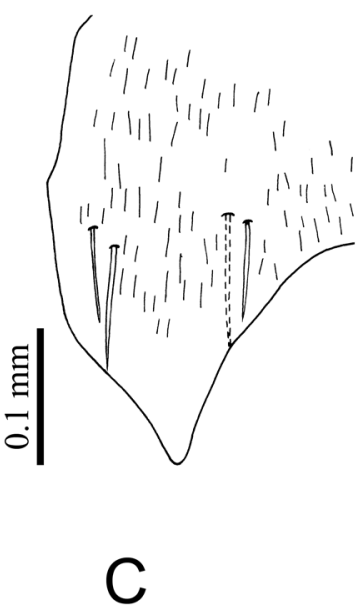

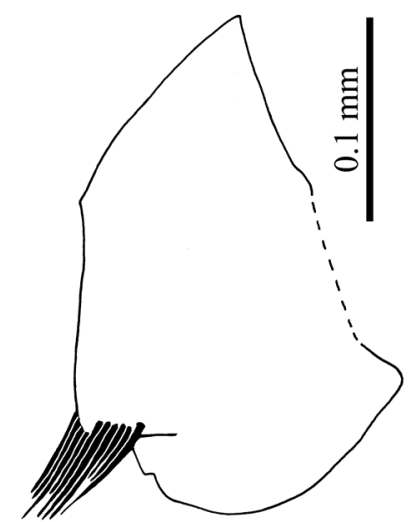

D
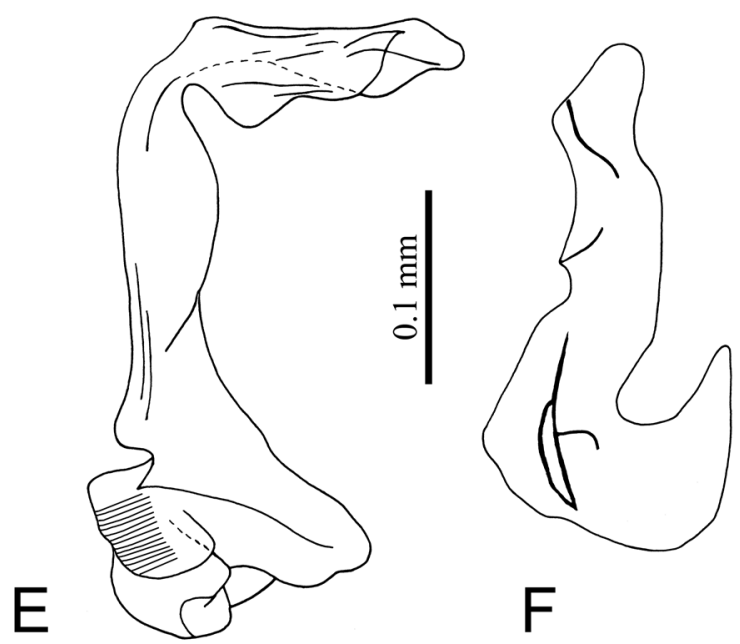

F

Fig. 18. Morphological features of Micronecta nieseri sp. nov., ô, paratype (ZVNU). A. Fore leg. B. Prestrigilar flap. C. Median lobe of sternite VII. D. Free lobe. E. Right paramere. F. Left paramere. 
reddish dots. Membrane translucent and generally brown. Venter of thorax and abdomen yellowish brown (males) or light yellow (females), legs pale yellow. Some specimens with pale, bright dorsum (Fig. 13H): frons and vertex pale, eyes reddish brown. Pronotum sordid yellow but a little bit darker than vertex. Hemelytron without dark marks. Right membrane with similar colour and texture to corium. Left membrane generally hyaline. Venter pale yellow and legs very pale yellow or nearly whitish. Sample at locality TAD1359 with both colour forms.

\section{Structural characteristics}

Macropterous males. Body length 2.13-2.44 (holotype: 2.31), width 1.0-1.30 (holotype: 1.25). Head width 0.82-1.01 (holotype: 0.95). Pronotum well developed, about 2.4 times as wide as long (0.94:0.40). Pronotum slightly wider than head. Synthlipsis 1.2 times as wide as posterior width of an eye $(0.36: 0.29)$. Lengths of leg segments: fore leg: femur 0.38 , tibia 0.20 , pala 0.23 ; middle leg: femur 0.85 , tibia 0.30 , tarsus 0.36 , claw 0.20 ; hind leg: femur 0.50 , tibia 0.41 , tarsus I 0.41 , tarsus II 0.18 , claw 0.07. Prestrigilar flap on segment V prolonged, with weakly acute apex (Fig. 18B). Strigil present. Median lobe of sternite VII, free lobe, and parameres as in diagnosis.

Macropterous females. Body length 1.84-2.3, width 0.8-1.0. Head width 0.88-0.9. Pronotum well developed, about 2.5 times as wide as long $(0.94: 0.37)$. Pronotum slightly wider than head. Synthlipsis 1.5 times as wide as posterior width of an eye $(0.41: 0.27)$. Lengths of leg segments: fore leg: femur 0.32 , tibiotarsus 0.3 ; middle leg: femur 0.81 , tibia 0.38 , tarsus 0.35 , claw 0.25 ; hind leg: femur 0.59 , tibia 0.32 , tarsus I 0.4 , tarsus II 0.2 , claw 0.09 .

\section{Distribution}

Vietnam: Lao Cai.

\section{Remarks}

See Remarks under M. pingae sp. nov.

Micronecta (Micronecta) pingae sp. nov. urn:lsid:zoobank.org:act:1B2C7138-D9CD-4B1C-B894-C256CCA5B05A

Figs 13I-J, 19

\section{Diagnosis}

Body length 2.1-2.6. Pronotum longer than median head length. With dark and pale colour forms (Fig. 13I-J).

Males: fore femur with two spines on proximal third ventrally, one large spine on middle third, one longer spine in distal third dorsally, one pair of spines distally, and one long seta dorsodistally; fore tibia with a pair of long spines on distal third ventrally; palar claw moderately widened distally, apex rounded (Fig. 19A). Median lobe of sternite VII with three or four long setae and a narrowly rounded apex (Fig. 19C). Free lobe short, strongly widened distally, posterior margin convex medianly and both corners broadly notched, with a row of uniformly short, dark coloured setae restricted to lateral notch (Fig. 19D). Left paramere: shaft relatively short and broad, with a pre-apical ridge running to lateral margin, forming a large triangular projection on lateral margin; lateral margin notched on proximal part; mesial margin sinuate distally; apex truncate; basal lobe tongue-shaped, directed towards paramere's apex (Fig. 19F). Right paramere: shaft broad, abruptly constricted and bent at middle part, mesial margin of proximal part convex, apical part strongly wavy and lobate, apex narrowly rounded; pars stridens processus with ca 30 ridges (Fig. 19E).

\section{Etymology}

This species is dedicated to Dr Chen Ping-ping, for her significant contributions to the taxonomy and our knowledge of Micronectidae. 


\section{Material examined}

\section{Holotype}

VIETNAM • ग’; Nghe An Prov., Ky Son, Nat' road 7, Ta Ca commune, Loi stream; 16 Apr. 2013; A.D. Tran et al. leg.; TAD1301; ZVNU.

\section{Paratypes}

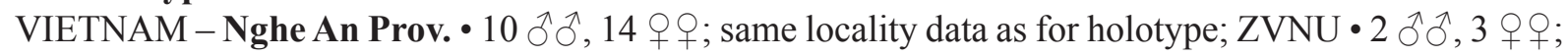
same locality data as for holotype; NHMW $\bullet 5$ o $\widehat{\delta}$; Con Cuong, Lien Huong Village, Khe Thoi stream; 21 Dec. 2012; Q.H. Ngo leg.; NQH1209; ZVNU・ 4 $\widehat{\jmath}, 3$ 우; Con Cuong, Tung Huong Village, Khe Thoi stream; 21 Dec. 2012; Q.H. Ngo leg.; NQH1210; ZRC • 1 q; Pu Mat N.P., Khe Kem waterfall and stream, site \#2, ca $300 \mathrm{~m}$ downstream from waterfall; A.D. Tran et al. leg.; 18 Apr. 2013; TAD1311; ZVNU. - Cao Bang Prov. • 1 ภ, 2 $q$ + ; Bao Lac, Hung Dao commune, Nhi Ao River, near Nam Xui bridge; 20 Dec. 2013; A.D. Tran et al. leg.; TAD1380; ZVNU.
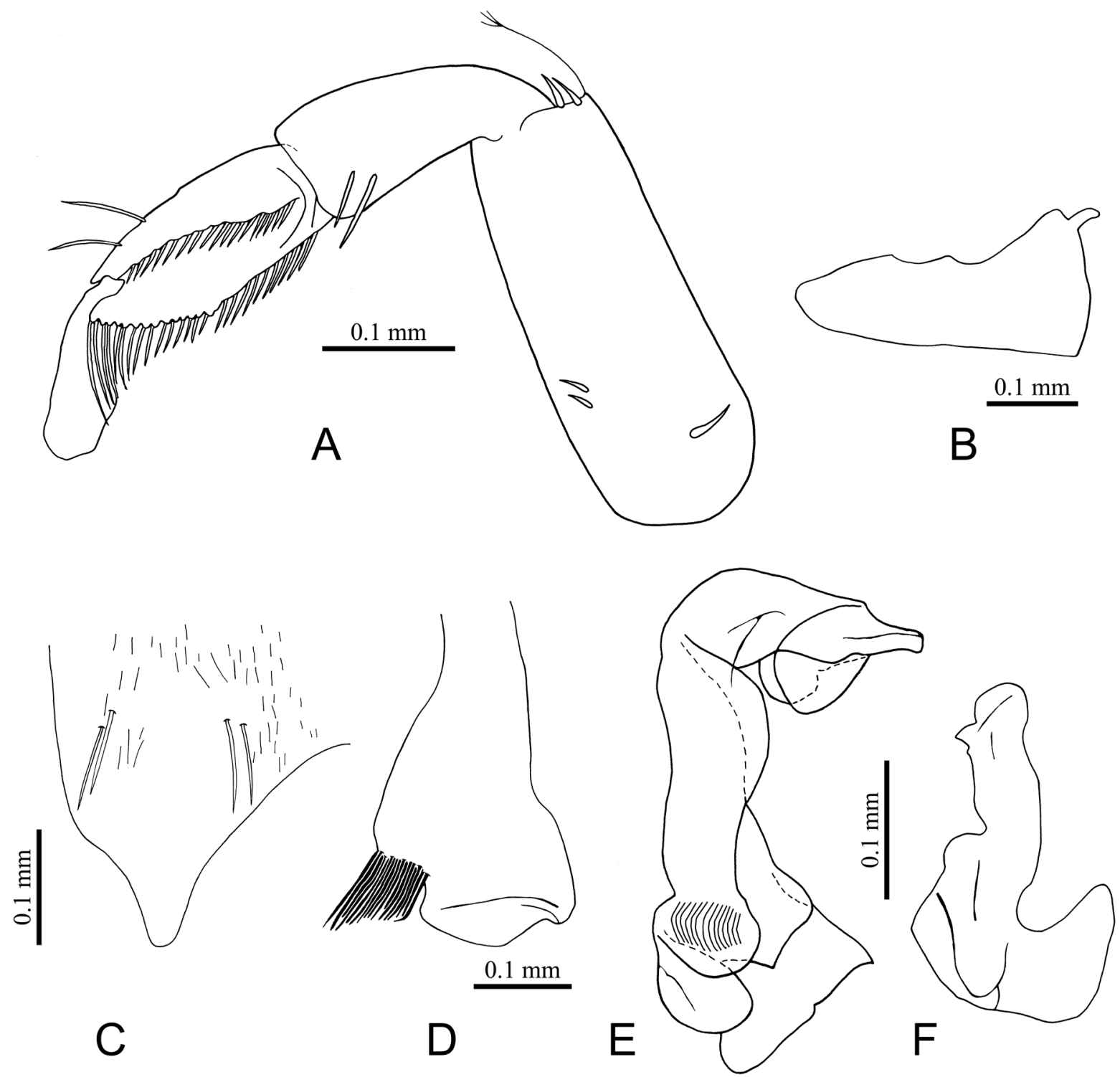

Fig. 19. Morphological features of Micronecta pingae sp. nov., §̂, paratype (ZVNU). A. Fore leg. B. Prestrigilar flap. C. Median lobe of sternite VII. D. Free lobe. E. Right paramere. F. Left paramere. 


\section{Description}

CoLour (Fig. 13I-J). With variations in colour of dorsum and pattern of hemelytra (a dark form and a pale form). Dark form (specimens from site TAD1380, Cao Bang Prov. and TAD1301, Nghe An Prov.) with dorsum generally light brown (Fig. 13I): frons and vertex brownish yellow to brown; eyes reddish brown. Pronotum pale yellowish brown. Hemelytron with minute red dots scattered especially on orangish band along anterior margin of clavus, and on boundary between corium and embolium. Corium with three brown marks in middle part, usually fused into one irregular-shaped mark. Right membrane with similar colour and texture to corium, more translucent apically. Left membrane translucent and brown. Venter of thorax and abdomen pale yellow to yellowish brown, and legs very light pale yellow or nearly whitish. Pale form (specimens at site TAD1301, Nghe An Prov.) (Fig. 13J): frons, vertex, and pronotum pale yellowish. Hemelytron with indistinct marks, more like scattered small orangish dots. Membrane with similar colour and texture to corium, more translucent apically. Venter of thorax and abdomen pale yellow, and legs very light pale yellow or nearly whitish.

\section{Structural characteristics}

Macropterous males. Body length 2.19-2.63 (holotype: 2.38), width 1.0-1.25 (holotype: 1.23). Head width $0.84-0.87$ (holotype: 0.85$)$. Pronotum 2.75 times as wide as long $(0.99: 0.36)$. Pronotum wider than head. Synthlipsis about 1.6 times as wide as posterior width of an eye $(0.41: 0.26)$. Lengths of leg segments: fore leg: femur 0.30 , tibia 0.18 , pala 0.20 ; middle leg: femur 0.77 , tibia 0.34 , tarsus 0.43 , claw 0.25 ; hind leg: femur 0.49 , tibia 0.41 , tarsus I 0.41 , tarsus II 0.22 , claw 0.05 . Prestrigilar flap on segment V with prolonged apex (Fig. 19B). Strigil present. Median lobe of sternite VII, free lobe, and parameres as in diagnosis.

Macropterous females. Body length 2.13-2.5, width 1.0-1.28. Head width 0.81-0.85. Pronotum 2.5 times as wide as long $(0.90: 0.36)$. Pronotum wider than head. Synthlipsis 1.6 times as wide as posterior width of an eye $(0.40: 0.25)$. Lengths of leg segments: fore leg: femur 0.27 , tibiotarsus 0.29 ; middle leg: femur 0.72 , tibia 0.29 , tarsus 0.38 , claw 0.2 ; hind leg: femur 0.5 , tibia 0.36 , tarsus I 0.33 , tarsus II 0.16 , claw 0.05 .

\section{Distribution}

Vietnam: Cao Bang, Nghe An.

\section{Remarks}

Three new species, $M$. undulata sp. nov., $M$. nieseri sp. nov., and $M$. pingae sp. nov., are apparently related to each other and to M. janssoni Nieser, Chen \& Yang, 2005 from Yunnan (China) by having the left paramere with transverse ridge(s) or grooves on its shaft, a strongly modified apical part of the right paramere, and by the outline of the palar claw.

Among these four species, M. undulata sp. nov. is most similar to M. janssoni in the general outline of the prestrigilar flap on segment V, the shape of the median lobe of sternite VII, the broad truncate apex of the left paramere, and the shape of the basal lobe of the left paramere. The characteristics which separate these two species include the structure of the free lobe, the ridges on the left paramere, and the shape of the apical part of the right paramere. In M. undulata sp. nov., the free lobe is wavy distally, and without long setae, while in $M$. janssoni, it is only slightly sinuate at the apical margin and with long setae on the lateral angle. The left paramere of $M$. undulata sp. nov. has two transverse ridges on its shaft, one near the base, and one near the apex, while that of M. janssoni has one transverse ridge near the base of shaft and three less distinct grooves on the distal third of the shaft. The apical part of the right paramere is also differently modified in these two species (compare Fig. 17E with Nieser et al. 2005: fig. 16). 
In a parallel manner, $M$. nieseri sp. nov. is most similar to $M$. pingae sp. nov. in the general outline of the prestrigilar flap on segment $\mathrm{V}$, the shape of the basal lobe of the left paramere, the notch on the lateral margin near the base of the left paramere shaft, and the sinuate mesial margin of the left paramere. They can easily be separated from each other by the following characteristics. In M. nieseri sp. nov., the median lobe of sternite VII has an angular apex; the free lobe has a broadly notched lateral corner; and the left paramere has two transverse ridges, one near the basal notch and one near to the tounge-like apex. In M. pingae sp. nov., the median lobe of sternite VII is narrowly rounded; the free lobe has both lateral and mesial corners broadly notched; and the left paramere has only one transverse ridge pre-apically which runs into a triangular projection and has a truncate apex. The apical part of the right paramere of $M$. nieseri sp. nov. and M. pingae sp. nov. are both strongly modified, but differently, with that of M. nieseri sp. nov. being more elongate, and that of $M$. pingae sp. nov., by contrast, being shorter and broader, with a more acuminate tip. Both M. nieseri sp. nov. and M. pingae sp. nov. have various colour forms, with both having a paler form in which the hemelytra generally are pale yellow and without distinct markings.

\section{Micronecta (Pardanecta) haliploides Horváth, 1904}

Figs 13K, 20

Sigara punctata Fieber, 1844: 15, pl. 1 fig. 26 (type locality uncertain; junior homonym of Sigara punctata Illiger, 1807).

Micronecta haliploides Horváth, 1904: 594-595 (type locality: Colombo, Sri Lanka).

Micronecta inflatula Breddin, 1905a: 57 (type locality: Java, Indonesia).

Micronecta pardalina Breddin, 1905a: 57 (type locality: Java, Indonesia).

Micronecta merope Distant, 1910: 351, 352 (type locality: Bengal, Canning, Rajshai).

Micronecta haliploides - Kirkaldy 1908: 209 (checklist). — Distant 1906: 50-51 (diagnosis). Lundblad 1933b: 104-109, 113, fig. 35, pl. IV, pl. XVIII fig. 3 (rediscription, key). — Nieser 2002b: 265, 267, fig. 5 (key, notes). - Buzzetti et al. 2006: 34 (nomenclatural notes).

Micronecta punctata - Chen 1960: 117 (synonymised Micronecta haliploides Horváth, 1904 with M. punctata (Fieber, 1844); synonymised M. inflatula and M. merope with M. punctata). Wróblewski 1962: 177-178 (redescription, assigned to subgenus Pardanecta); 1967: 239-240 (additional habitat notes); 1968: 776 (synonymy list). - Fernando 1964: 609, figs 16, 26, 38 (diagnosis). — Leong 1966: 85, 88. (notes, key).

Micronecta inflatula - Breddin 1905b: 156, 159 (key, additonal notes).

Micronecta pardalina - Breddin 1905b: 156, 158-159 (description).

\section{Diagnosis}

Body length 2.4-3.3. Pronotum slightly shorter than median head length. Dorsum generally greyish. Pronotum with a transverse brown stripe, sometimes broken in the middle. Hemelytron with numerous dark brown spots; embolium with three dark spots.

Males: Fore femur, palar claw (Fig. 20A), median lobe of sternite VII, and free lobe (Fig. 20B) as in diagnosis of subgenus. Fore tibia with two spines ventrodistally. Left paramere: shaft stout, with knoblike apex; basal lobe tongue-shaped, directed towards apex of paramere (Fig. 20D). Right paramere: shaft relatively slender, curved at distal third, slightly widened, then tapering towards a narrowly rounded apex (Fig. 20C). 


\section{Material examined}

VIETNAM - Ninh Binh Prov. • 1 ô, 4 우; Gia Vien, Van Long Wetland Nature Reserve; 25 Aug.

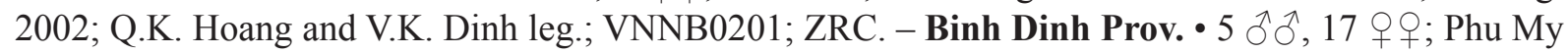
District, Tra O Lagoon; 10 May 2012; A.D. Tran leg.; TAD1216; ZVNU. - Dong Nai Prov.・1 1 ; Cat Tien N.P., Bau Sau (Crocodile Lake); 13 Nov. 2009; A.D. Tran leg.; TAD0910; ZVNU • 3 ô ô, 1 क; Vinh Cuu, Ma Da, Bo Hao lotus pond; 15 Apr. 2010; T.D. Pham leg.; PTD1010; ZVNU. - Ba Ria-Vung Tau Prov. 4 $\widehat{\jmath}, 5$ 우; Con Dao, Dam Trau area, Ong Ta stream; 13 Apr. 2010; A.D. Tran et al. leg.; TAD1009; ZVNU. - Ca Mau Prov. • 1 \&; U Minh District, Khanh An commune, 14 hamlet; 17 Apr. 2018; T.A.N. Nguyen leg.; CM1819; ZVNU.

\section{Distribution}

Vietnam: Hanoi, Quang Ninh, Ha Tinh (Wróblewski 1962, 1967, as M. punctata); first records for Ninh Binh and southern provinces of Vietnam. Other countries: widespread from India and Sri Lanka through Southeast Asian mainland to Sumatra, Java, and Bali (Nieser 2002b).

\section{Remarks}

Micronecta haliploides can immediately be recognised by the distinct dark spots scattered on the hemelytra. In this species the knob-like apex of the left paramere is also unique within Micronecta.

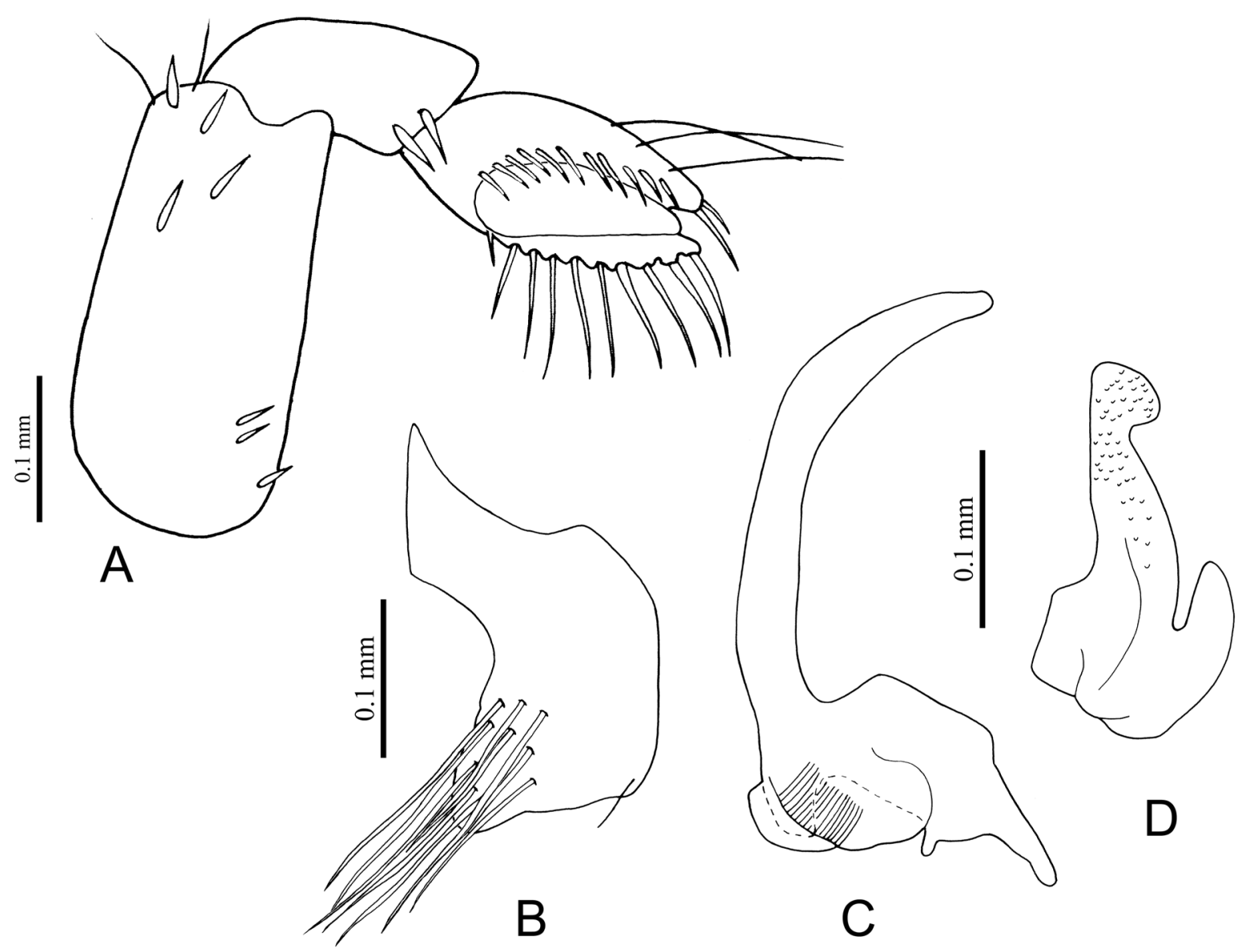

Fig. 20. Morphological features of Micronecta haliploides Horváth, 1904, đ̊ (ZVNU). A. Fore leg. B. Free lobe. C. Right paramere. D. Left paramere. 
Micronecta (Sigmonecta) quadristrigata Breddin, 1905

Figs $21 \mathrm{~A}, 22 \mathrm{~A}-\mathrm{C}$

? Sigara lineata Fieber 1844: 15, pl. 1 fig. 25 (junior secondary homonym of Notonecta lineata Forster, 1771; primary junior homonym of Sigara lineata Fabricius, 1787; junior secondary homonym of Corixa lineata Rambur, 1840) (suspected synonymy Wróblewski 1968: 776).

? Sigara m-notata Kirkaldy, 1897a: 240 (replacement name for Sigara lineata Fieber) (nomen oblitum). Micronecta quadristrigata Breddin, 1905a: 57 (type locality: Buitenzorg (Bogor), Indonesia).

Micronecta minthe Distant, 1910: 347 (type locality: Kolkata, India).

Micronecta quadristrigata - Breddin 1905b: 155-157, fig. 19. — Lundblad 1933b: 87-91, figs 2627, pl. XIX fig. 1 (redescription). - Wróblewski 1962: 176 (assigned to subgenus Sigmonecta); 1968: 771, 776 (synonymy list); 1972a: 29-31 (description, distribution). — Jansson 1995: 34 (catalogue, nomenclatural notes). - Tinerella 2008: 28, 39-45, figs 16e-f, $23-25$ (nomen protectum; redescription, distribution); 2013: 33, 102-108, figs 57-60 (redescription). - Chen et al. 2015: 34, 52-58, figs 9, 21, 23, 29, 42, 50, 57, 65, 73, 88-89, 97 (resdescription, record for Borneo). — Zettel et al. 2017: 41 (record Cambodia).

Micronecta minthe - Lundblad 1933b: 87-90 (synonymised with M. quadristrigata).

Micronecta quadristrigata f. minthe - Wróblewski 1972a: 32-33 (lectotype designation).

(For an extensive synonymy list and nomenclatural discussion, see Tinerella 2008.)

\section{Diagnosis}

Body length 2.2-2.9. Pronotum longer than median head length. Dorsum generally yellowish brown. Hemelytron with four interrupted, longitudinal, brown stripes; embolium with four black spots (Fig. 21A).

Males: fore femur with a pair of spines on proximal third ventrally, four spines on distal third; fore tibia with two spines on distal third ventrally; palar claw widened distally, apex rounded. Median lobe of sternite VII and free lobe (Fig. 22A) as in diagnosis of subgenus. Left paramere: shaft relatively thick, with sickle-shaped apex, mesial side before apical part covered with small scales (Fig. 22C). Right paramere: shaft long and slender, gently curved at distal third and tapering from there towards a narrowly rounded apex (Fig. 22B).

\section{Material examined}

VIETNAM - Quang Nam Prov. 1 § , 1 q; Duy Xuyen District, My Son temple complex; $15^{\circ} 45.439^{\prime}$ N,

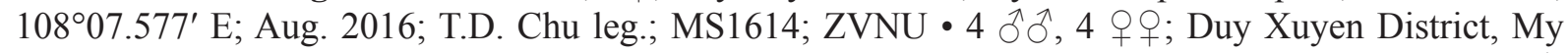
Son temple complex; $15^{\circ} 46.308^{\prime}$ N, 108 06.621' E; Aug. 2016; T.D. Chu leg.; MS1629; ZVNU • 1 万'; Duy Xuyen District, My Son temple complex; $15^{\circ} 44.865^{\prime}$ N, 10807.81' E; Apr. 2017; T.D. Chu leg.; MS1701; ZVNU • 1 क; Duy Xuyen District, My Son temple complex; $15^{\circ} 45.312^{\prime}$ N, $108^{\circ} 07.377^{\prime}$ E; Apr. 2017; T.D. Chu leg.; MS1707; ZVNU • 2 q ; Duy Xuyen District, My Son temple complex;

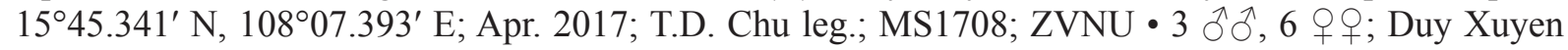
District, My Son temple complex; $15^{\circ} 46.355^{\prime}$ N, 108 ${ }^{\circ} 07.079^{\prime}$ E; Apr. 2017; T.D. Chu leg.; MS1725; ZVNU. - Dong Nai Prov. 5 ổ, 3 q $ᄋ$; Vinh Cuu, Ma Da, Bo Hao Lake, west side; 10 Apr. 2009; A.D. Tran leg.; TAD0905; ZVNU • 1 q; Cat Tien N.P., Bau Sau (Crocodile Lake); 6 Nov. 2009; A.D. Tran leg.; TAD0929; ZVNU • 1 q; Vinh Cuu, Ma Da, Bo Hao Lake, east side, near forest ranger station; 10 Apr. 2009; A.D. Tran leg.; TAD0906; ZVNU.

\section{Distribution}

Vietnam: Quang Ninh, Hanoi, Ninh Binh, Nghe An, Ha Tinh, Quang Tri (Wróblewski 1962, 1967); first records for Quang Nam, Dong Nai. Other countries: widespread from the Middle East, through southern 
Asia, southeastern Asia, to eastern Asia and to Australia (Wróblewski 1972b; Nieser \& Chen 1999; Tinerella 2008, 2013; Zettel et al. 2017; Polhemus 2017).

\section{Remarks}

See Remarks under M. altera.

Micronecta (Sigmonecta) altera Wróblewski, 1972

Figs 21B, 22D-H

Micronecta quadristrigata Breddin, 1905a: 57 (partim).

Micronecta altera Wróblewski, 1972a: 33-37, 50, figs 21-24, 44, 51, 74 (type locality: Sri Lanka; also included specimens from India, Pakistan, Thailand, Hong Kong, Vietnam).

Micronecta quadristrigata - Hutchinson 1940: 376-377. — Wróblewski 1960: 301-304 (partim); 1967: 237-238 (partim).

\section{Diagnosis}

Body length 2.4-3.1. Pronotum longer than median head length. Dorsum generally yellowish brown. Hemelytron with four interrupted, longitudinal, brown stripes; embolium with four black spots (Fig. 21B).

Males: fore femur with a pair of spines on proximal third, two spines on middle third; fore tibia with two large spines on distal third; palar claw widened distally, with a small notch in the middle, apex rounded (Fig. 22D). Median lobe of sternite VII and free lobe (Fig. 22E) as in diagnosis of subgenus. Left paramere: shaft relatively thick, with sickle-shaped apex, mesial side before apical part covered with small scales; basal lobe subovate (Fig. $22 \mathrm{G}-\mathrm{H}$ ). Right paramere: shaft long and slender, clearly thickened at proximal half, then curved and tapering towards narrowly rounded apex (Fig. 22F).

\section{Material examined}

VIETNAM - Lang Son Prov.• 1 o, 1 ; Loc Binh, Mau Son, Khuoi Tang stream; 590 m a.s.1.; 6 Nov. 2020; A.D. Tran et al. leg.; TAD20-34; ZVNU. - Phu Tho Prov. • 1 \&; Xuan Son N.P., Kim Thuong, Chieng stream, near ranger station; 28 Aug. 2013; A.D. Tran et al. leg.; TAD1345; ZVNU • 1 \%; Xuan Son N.P., Chieng stream, near ranger station; $21^{\circ} 06.072^{\prime} \mathrm{N}, 1^{\circ} 4^{\circ} 59.433^{\prime} \mathrm{E}$; 22 May 2015; T.S. Nguyen leg.; TS1508; ZVNU • 1 ; Xuan Son N.P., Ban Coi, Coi stream, site 2, near bridge; 7 Jun. 2013; A.D. Tran

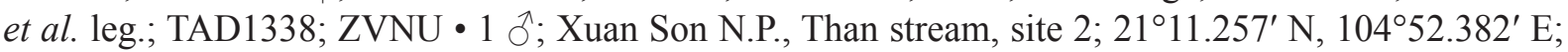
24 May 2015; T.S. Nguyen leg.; TS1515; ZVNU. - Hanoi • 8 $\widehat{\jmath}, 9$ 9 우 Nhue River, Noi bridge; 25 Mar. 2010; T.M. Pham leg.; ZVNU・3 $\widehat{\jmath}, 2$ q $\propto$; Thanh Huong Lake (used for recreational fishing), near Khuat Duy Tien Road (Thanh Xuan District); 29 Mar. 2010; T.M. Pham leg.; HN04; ZVNU • 1 ठิ, 4 q $९$; paddy-field near Noi Bridge of Nhue River; 4 May 2010; T.M. Pham leg.; HN15; ZVNU • 7 $\widehat{\jmath}$, 10 Q 9 ; Lotus pond 2 near West Lake Water Park (right); 30 Mar. 2010; T.M. Pham leg.; HN02; ZVNU •

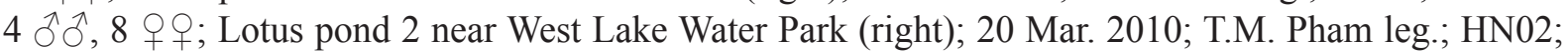

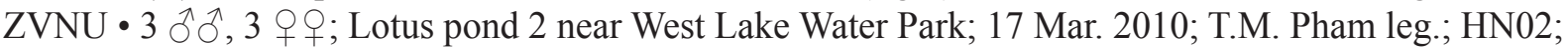

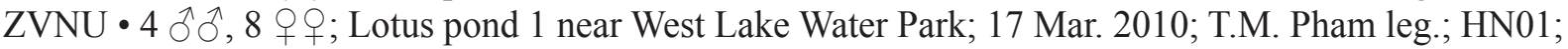

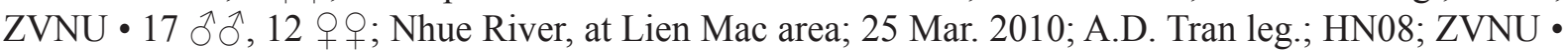
2 ふึ, 2 o 9 ; paddy-field at Thuan Village, Phu Lam ward (Ha Dong District); 31 Mar. 2010; T.M. Pham leg.; HN11; ZVNU • 8 $\widehat{\partial}, 1$ 1 ; Nhue River; 18 Aug. 2010; A.D. Tran leg.; TAD1017; ZVNU • $11 \hat{\jmath} \widehat{\jmath}, 30$ 우; Nhue River; 18 Aug. 2010; A.D. Tran leg.; TAD1018; ZVNU・ $1 \hat{\jmath}, 2$ 우; paddy-field

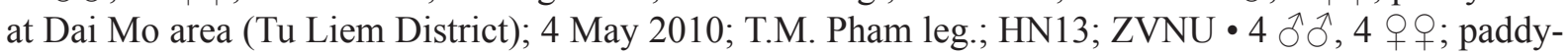
field at Ngoc Truc area (Tu Liem District); 4 May 2010; T.M. Pham leg.; HN14; ZVNU • 1 §; West

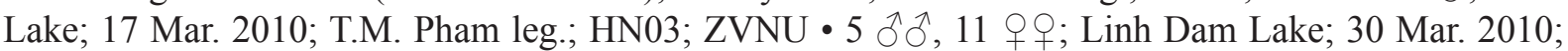

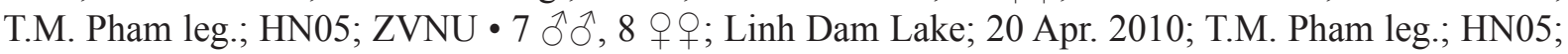


ZVNU • $3 \widehat{\partial} \widehat{\partial}, 5$ 우; Day River, at Mai Linh Bridge (Ha Dong District); 21 Apr. 2010; T.M. Pham leg.; HN12; ZVNU • 1 O̊, 3 qo; Thanh Xuan District; 7 Aug. 2019; V.P. Nguyen leg.; NVP1901; ZVNU • 1 गे, 1 क; Ba Vi N.P., Khoang Xanh, Tien stream; 95 m a.s.l.; 17 Dec. 2011; Q.H. Ngo and A.D. Tran leg.; TAD1127; ZVNU • 5 q o ; Ba Vi N.P., Minh Quang, Cai stream; 65 m a.s.1.; 26 Apr. 2012; Q.H. Ngo

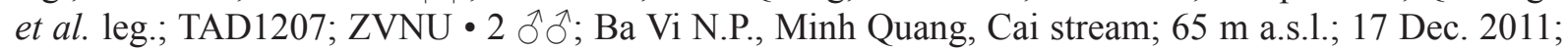
Q.H. Ngo et al. leg.; TAD1126; ZVNU・1 O’; Ba Vi N.P., Khanh Thuong, Mit stream, open area near Village; 40 m a.s.l.; 26 Apr. 2012; Q.H. Ngo and A.D. Tran leg.; TAD1205; ZVNU • 1 ô, 2 o $\circ$; Ba Vi N.P., Ba Trai, Ri stream; 67 m a.s.1.; 27 Apr. 2012; Q.H. Ngo leg.; TAD1209; ZVNU. - Thanh Hoa Prov. 1 đ̊; Pu Luong Nature Reserve, Ba Thuoc, Co Lung, Ban Khuyn, Khuyn stream; 18 Mar.

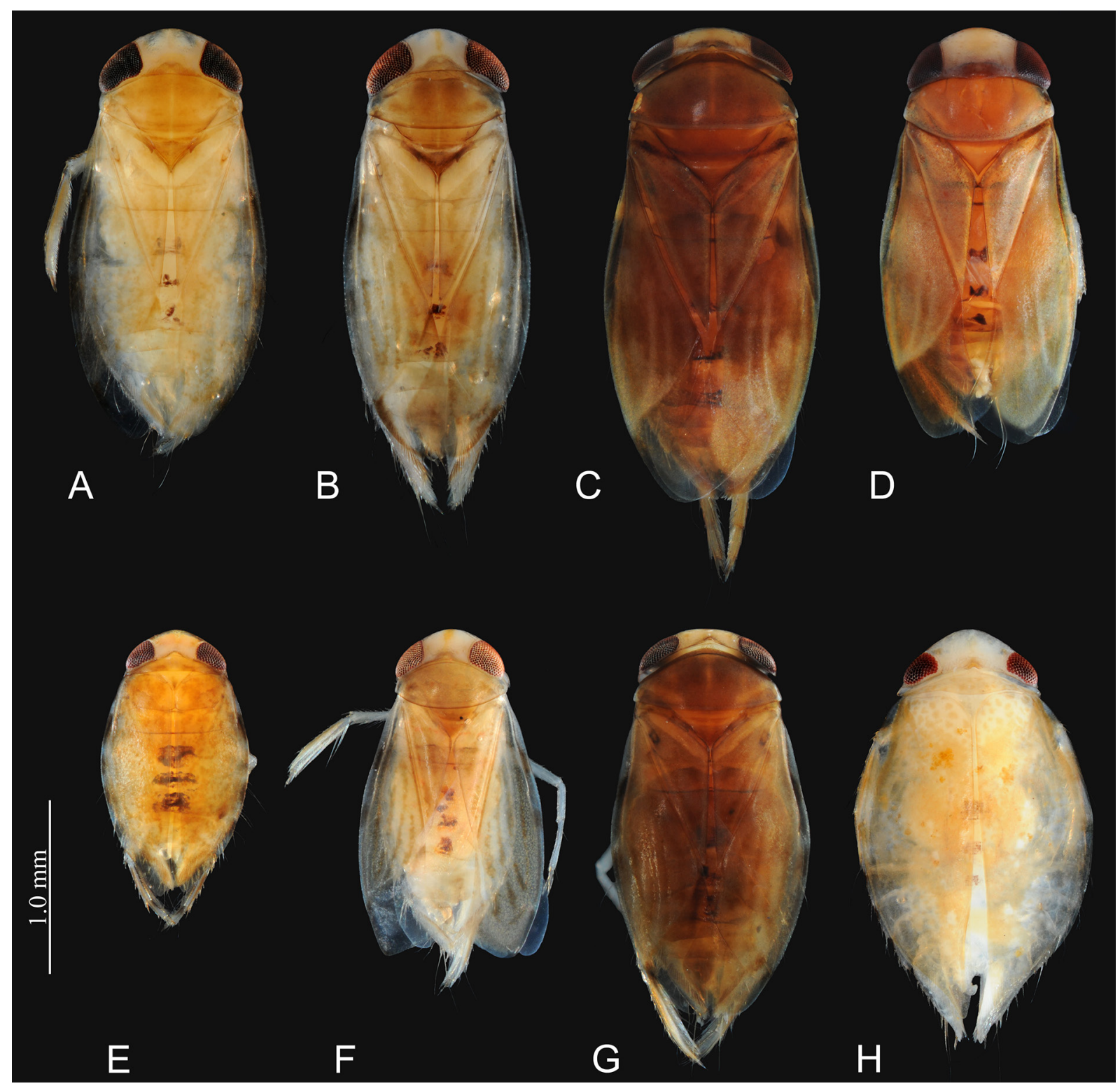

Fig. 21. Habitus photos of species of Micronecta Kirkaldy, 1897 and Synaptonecta Lundblad, 1933, §ðð. A. M. quadristrigata Breddin, 1905 (ZVNU). B. M. altera Wróblewski, 1972 (ZVNU). C. M. polhemusi Nieser, 2000 (ZRC). D. M. melanochroa Nieser, Chen \& Yang, 2005 (ZVNU). E. M. caperata sp. nov., holotype (ZVNU). F. M. fugitans Breddin, 1905 (ZVNU). G. M. tarsalis Chen, 1960 (ZVNU). H. S. issa (Distant, 1910) (ZVNU). All to the same scale. 
2013; T.D. Pham leg.; PL1303; ZVNU. - Quang Nam Prov. • 1 đ̂, 4 qq ; Duy Xuyen District, My

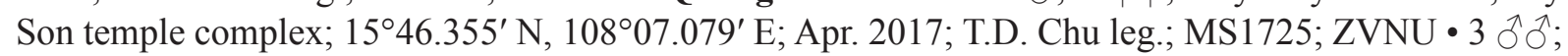
Duy Xuyen District, My Son temple complex; $15^{\circ} 46.978^{\prime}$ N, $108^{\circ} 07.334^{\prime}$ E; Apr. 2017; T.D. Chu leg.; MS1724; ZVNU. - Binh Dinh Prov. • 2 ô $\partial^{\lambda}$; Phu My District, Tra O lagoon; 10 May 2012; A.D. Tran leg.; TAD1216; ZVNU. - Binh Thuan Prov. • 2 ồ; Phan Thiet City, Huynh Thuc Khang road, Tien stream; 11 May 2019; T.N. Ha leg.; NHPT19.01; ZVNU. - Dong Nai Prov. $\bullet 2 \lambda \hat{\jmath}, 1$ + ; Vinh Cuu, Ma Da stream, near Rang Rang Forest station (near bridge); 9 Apr. 2009; A.D. Tran leg.; TAD0902; ZVNU.
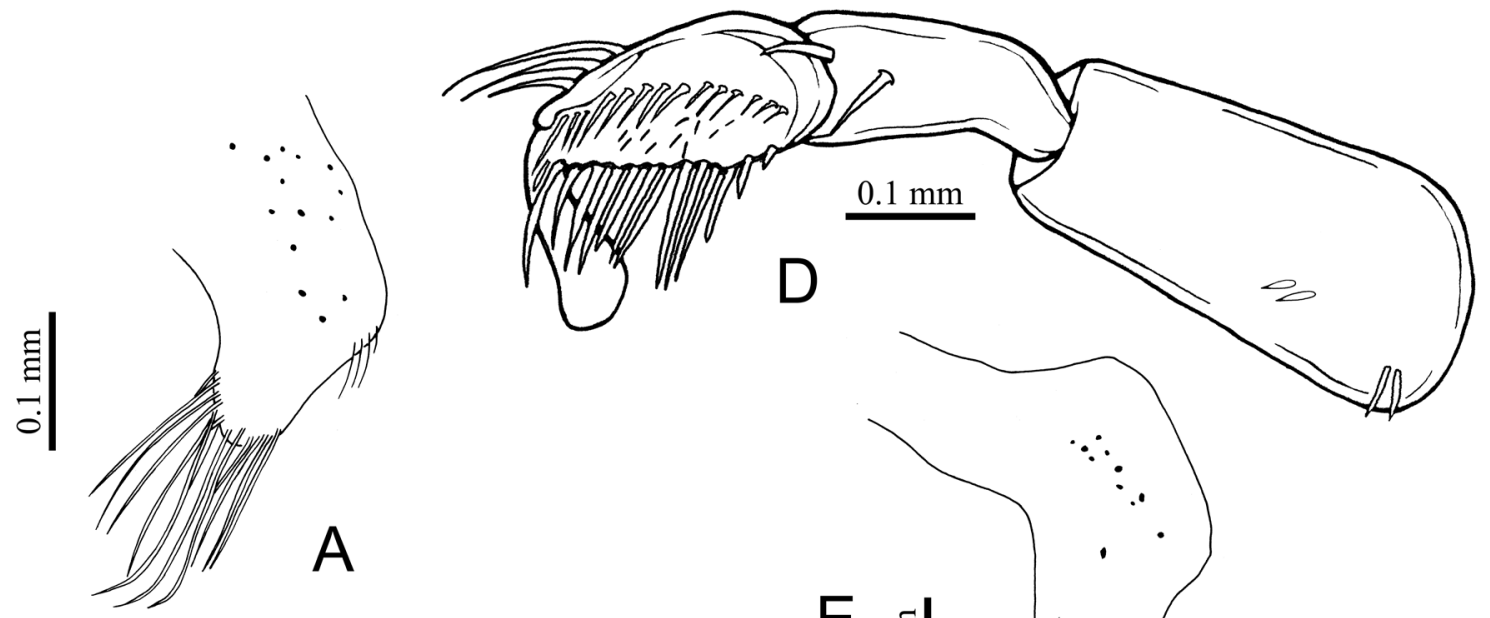

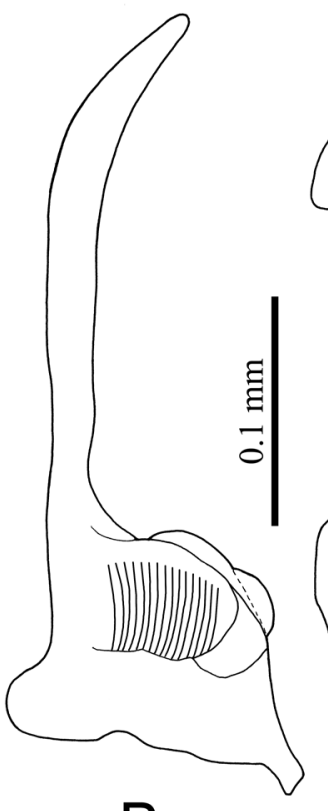

B

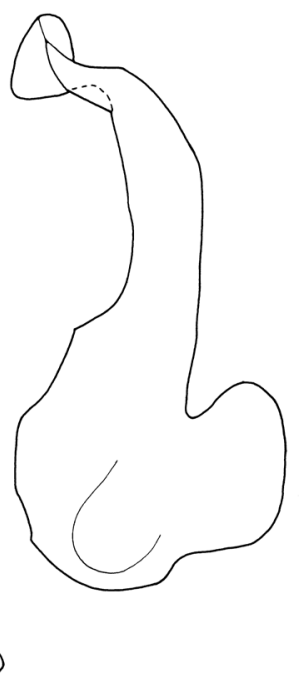

C

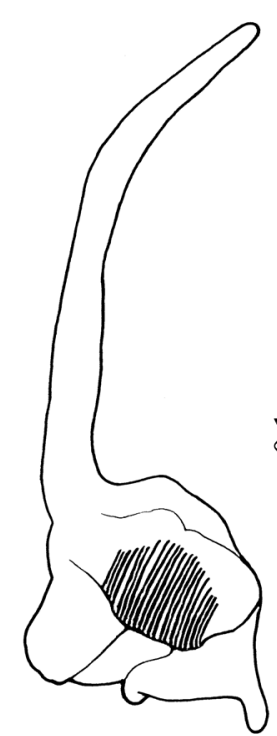

$\mathrm{F}$

$\mathrm{E}$ 斯

Fig. 22. Morphological features of species of Micronecta Kirkaldy, 1897, ठð. A-C. M. quadristrigata Breddin, 1905 (ZVNU). D-H. M. altera Wróblewski, 1972 (ZVNU). A, E = free lobe; B, F = right paramere; $\mathrm{C}, \mathrm{G}=$ left paramere; $\mathrm{D}=$ fore leg; $\mathrm{H}$ = apical part of left paramere. 


\section{Distribution}

Sri Lanka, India, East Pakistan, Thailand, Hong Kong, Vietnam (Wróblewski 1972a).

\section{Remarks}

Wróblewski (1972a) clearly indicated that the holotype and paratypes of M. altera were all from Sri Lanka, and noted that he had seen examples of this species from India, Pakistan, Thailand, Hong Kong, and Vietnam, but without providing specific locality data. However, subsequent studies by various heteropterists did not provide any additional reports of this species from Southeast Asia again. Nieser (2000), when producing his key to Southeast Asian Micronecta, apparently overlooked M. altera and did not include it. Based on numerous samples as above, we now confirm the occurrence of this species in Vietnam. Among subsequent studies dealing with M. quadistrigata and another closely related species, M. kymatista Nieser \& Chen, 1999, only Nieser \& Chen (1999) made a brief comparative reference to $M$. altera. Tinerella $(2008,2013)$ also commented on this species, questioning the potential conspecificity between M. quadristrigata, M. altera, and M. kymatista.

As Wróblewski (1972a) previously noted, there are a few differences between M. quadristrigata and $M$. altera, including the body length (M. altera is slightly larger than M. quadristrigta), the fore tibia and pala (M. altera has larger ones), the shape of the palar claw (M. altera has a small notch in the middle), the shaft of the right paramere (that of M. altera is longer, clearly thicker on the basal half, then gradually tapering on the apical half, while that of M. quadristrigata is mostly parallel sided and only tapering on the apical fifth), and the curvature between the base and the shaft of the left paramere, opposite the basal lobe (which is about $90^{\circ}$ in M. altera, and is clearly greater than $90^{\circ}$ in M. quadristrigata) (compare Fig. 22B, F). Our samples help to confirm the observation by Wróblewski (1972a) that M. quadristrigata and M. altera are separate species, and that the detailed structures of the parameres provide reliable characters. It is notable that the body lengths of M. quadristrigata and M. altera, as provided by Wróblewski (1972a: table 1), had overlapping ranges, although that of M. altera fell into the larger range. Based on such comparative morphological features, it seems that illustrations of specimens of M. quadristrigata in Chen et al. (2015) belong to M. altera instead. However, we do not have access to these specimens to confirm this speculation. Among three species of the subgenus Sigmonecta, M. kymatista Nieser \& Chen, 1999 is most similar to M. quadristrigata in the appearance of parameres. For comparison between these two species, see Nieser \& Chen (1999: 83).

\section{Micronecta (Unguinecta) khasiensis Hutchinson, 1940}

Micronecta khasiensis Hutchinson, 1940: 396-398, figs 178-186 (type locality: Assam, India; assigned to subgenus Mesonecta).

Micronecta khasiensis - Wróblewski 1962: 176-177 (descriptive notes; first record in Vietnam); 1967: 235 (descriptive notes; further records in Vietnam); 1968: 775 (checklist). — Nieser et al. 2005: 200 (assigned to subgenus Unguinecta).

\section{Diagnosis}

Body length 2.1-2.3. Pronotum longer than median head length. Dorsum generally dark brown or greyish brown. Hemelytron greyish brown with indistinct dark brown stripes.

Males: pala with a secondary claw; primary palar claw parallel sided, apex truncate. Median lobe of sternite VII short, with an angular apex. Free lobe with lateral angle produced, posterior margin nearly straight, mesial angle rounded. Left paramere: shaft styliform, slightly expanded before narrowly rounded apex; basal lobe broad, subovate. Right paramere: shaft evenly curved and tapering towards pointed apex (based on description by Hutchinson 1940: figs 178-186).

\section{Material examined}

No material available. 


\section{Distribution}

Vietnam: Lao Cai (Sa Pa), Hanoi (Wróblewski 1962, 1967). Other country: India (Assam) (Wróblewski 1968).

\section{Remarks}

See further Remarks under M. polhemusi.

\section{Micronecta (Unguinecta) melanochroa Nieser, Chen \& Yang, 2005}

Figs 21D, 23A-D

Micronecta melanochroa Nieser, Chen \& Yang, 2005: 202-203, figs 42-50 (type locality: Yunnan, China; assigned to subgenus Unguinecta).

\section{Diagnosis}

Body length 2.3-2.4. Pronotum longer than median head length. Dorsum generally dark brown. Hemelytron greyish brown without darker brown patches; embolium yellowish or light brown, with a thin dark stripe near mesial margin (Fig. 21D).

Males: pala with a secondary claw; primary palar claw sub-triangular, strongly widened distally (Fig. 23A). Median lobe of sternite VII narrow and long, with a narrowly rounded apex. Free lobe with mesial angle rounded, posterior margin nearly straight, lateral angle well-produced, ca 20 long setae on lateral side of free lobe (Fig. 23B). Left paramere: shaft styliform, tapering towards narrowly rounded apex, apical part slightly twisted; basal lobe relatively short and broadly rounded (Fig. 23D). Right paramere: shaft with mesial side nearly straight proximally, lateral side evenly curved, slightly thickened in the middle, then tapering towards blunt apex (Fig. 23C).

\section{Material examined}

VIETNAM - Phu Tho Prov. 1 ふै; Xuan Son N.P., Ban Coi, Coi stream, site 1, water from underground; 7 Jun. 2013; A.D. Tran et al. leg.; TAD1337; ZVNU • 1 §’; Xuan Son N.P., Kim Thuong, Xoan stream; 28 Aug. 2013; A.D. Tran et al. leg.; TAD1343; ZVNU • 14 §ิ ô, 19 우; Xuan Son N.P., Dong Son,

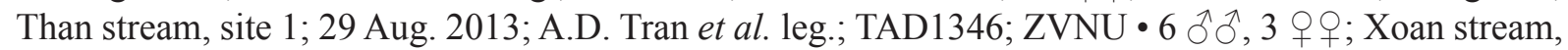
near its confluence with Ha Bang stream; $21^{\circ} 05.303^{\prime}$ N, 104 $57.559^{\prime}$ E; 27 Aug. 2014; T.S. Nguyen leg.; TS1407; ZVNU • 1 §, 1 क; Lap stream, the first concrete bridge from Ngoc waterfall; $21^{\circ} 08.398^{\prime} \mathrm{N}$, $104^{\circ} 56.303^{\prime}$ E; 28 Aug. 2014; T.S. Nguyen leg.; TS1412; ZVNU • 2 ô $^{\lambda}$; Lap stream, the second concrete bridge from Ngoc waterfall; $21^{\circ} 08.322^{\prime} \mathrm{N}, 1^{\circ} 4^{\circ} 56.256^{\prime} \mathrm{E}$; 28 Aug. 2014; T.S. Nguyen leg.; TS1413; ZVNU. - Nghe An Prov. 12 $\lesssim \AA$, 5 우; Con Cuong, Lien Huong Village, Khe Thoi stream; 21 Dec. 2012; Q.H. Ngo leg.; NQH1209; ZVNU.

\section{Distribution}

First record for Vietnam. Other country: China (Yunnan).

\section{Remarks}

See Remarks under M. polhemusi.

Micronecta (Unguinecta) polhemusi Nieser, 2000

Figs $21 \mathrm{C}, 23 \mathrm{E}-\mathrm{G}$

Micronecta polhemusi Nieser, 2000: 283-286, figs 18-27 (type locality: Phitsanulok, Thailand; also paratypes from southern Vietnam). 
Micronecta polhemusi - Nieser 2002b: 265, 269, fig. 11 (diagnosis; record Singapore). - Nieser et al. 2005: 200 (assigned to subgenus Unguinecta). — Polhemus 2017: 127 (record Cambodia).

\section{Diagnosis}

Body length 2.4-2.8. Pronotum longer than median head length. Dorsum generally dark grey. Hemelytron: corium with hyaline lines; embolium dark brown with dark pattern (Fig. 21C).

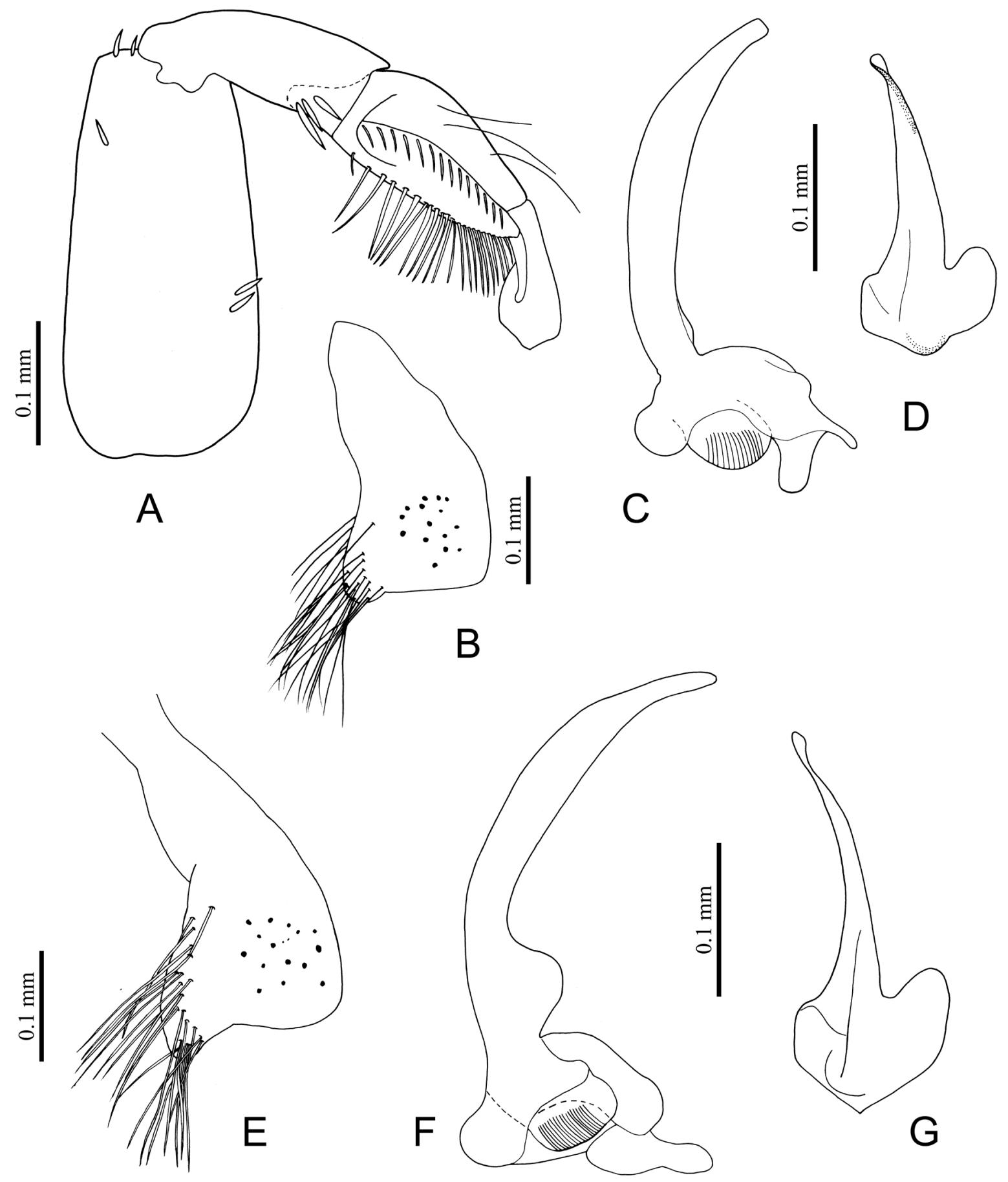

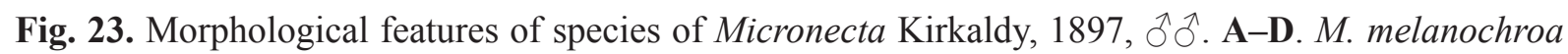
Nieser, Chen \& Yang, 2005 (ZVNU). E-G. M. polhemusi Nieser, 2000 (ZVNU). A = fore leg; B, E = free lobe; $\mathrm{C}, \mathrm{F}=$ right paramere; $\mathrm{D}, \mathrm{G}=$ left paramere. 
Males: pala with a secondary claw; primary palar claw widened distally, apex rounded. Median lobe of sternite VII short and broad, with an angular apex. Free lobe subparallel sided, with mesial angle rounded, posterior margin nearly straight, lateral angle well-produced, ca 16-23 long setae on lateral side of free lobe (Fig. 23E). Left paramere: shaft styliform, tapering towards narrowly rounded apex, apical part slightly twisted; basal lobe relatively short and broad (Fig. 23G). Right paramere: base of shaft with a distinct swelling, proximal part subparallel sided, from distal fourth tapering towards narrowly rounded apex (Fig. 23F).

\section{Material examined}

VIETNAM - Lao Cai Prov. 1 đ̇; Sa Pa, Nui Xe area, Vang stream and its tributaries ; 25 Oct. 2020; A.D. Tran et al. leg.; TAD20-19; ZVNU. - Quang Ninh Prov.• 1 q; Dong Rui (in bonsai pot); 13 Sep.

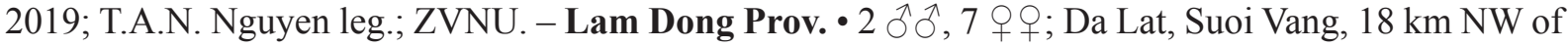
Da Lat; 21 May 2003; A.D. Tran leg.; TAD0331; ZRC.

\section{Distribution}

Vietnam: Dong Nai (Cat Tien) (Nieser 2000). The records by Tran et al. (2014) from Phu Tho Prov. were a misidentification. After a re-examination, we determine them as M. melanochroa. Other countries: Thailand, Singapore (Nieser 2000, 2002b), and Cambodia (Polhemus 2017).

\section{Remarks}

Three species, M. polhemusi, M. khasiensis, and M. melanochroa, may easily be confused because of their dark dorsum and their similar parameres. Detailed structures of the parameres and primary palar claw, however, provide reliable characters for separating them. The base of right paramere shaft of M. polhemusi has a large swelling, which is indistinct or absent in the other two species. Micronecta khasiensis can be separated from M. melanochroa by the male primary palar claw and detailed structures of the parameres. The primary palar claw of $M$. khasiensis is narrow and parallel sided, while that of M. melanochroa is broader and strongly widened apically. The primary palar claw of M. pohemusi is club-shaped, and moderately widened apically. The left paramere of $M$. khasiensis is slightly expanded before the narrowly rounded apex, while that of $M$. melanochroa has a slightly twisted apical part. The right paramere of $M$. khasiensis has a pointed apex, while that of $M$. melanochroa has a blunt apex.

\section{Incertae sedis}

Micronecta caperata sp. nov.

urn:1sid:zoobank.org:act:826E598E-CEF2-4A77-AA7B-6403633B323C

Figs 21E, 24

\section{Diagnosis}

Body length 1.5-1.9. Pronotum distinctly shorter than median head length; lateral margin of pronotum very short. Dorsum colour yellowish brown. Hemelytron punctate, with scattered small light brownish spots; suture between clavus, corium, and membrane indistinct (Fig. 21E).

Males: fore femur with two spines in distal third dorsally; fore tibia without spine; palar claw narrow, evenly curved (Fig. 24A). Median lobe of sternite VII with angular apex and four long setae (Fig. 24B). Free lobe absent. Left paramere: shaft broad and flat, distal part with ca five transverse wrinkles, apex rounded; basal lobe longer than wide, sub-trapezoid (Fig. 24D). Right paramere: shaft relatively slender, tapering towards apex, gently curved at distal third, apex narrowly rounded (Fig. 24C); pars stridens processus with ca 30 ridges. 


\section{Etymology}

The species epithet refers to the wrinkles on the left paramere.

\section{Material examined}

All are hindwing-brachypterous.

\section{Holotype}

VIETNAM - ^’; Nghe An Prov., Pu Mat N.P., Khe Kem stream, site \#3; 20 Dec. 2012; Q.H. Ngo leg.; NQH1205; ZVNU.

\section{Paratypes}

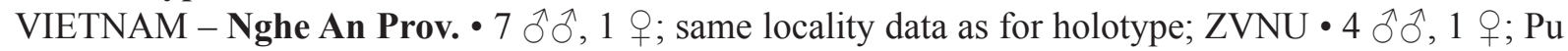
Mat N.P., Khe Kem stream, site \#4; 20 Dec. 2012; Q.H. Ngo leg.; NQH1206; ZVNU • 2 ôे, 1 q; Pu

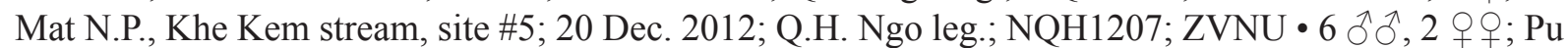
Mat N.P., Khe Kem stream, site \#6; 20 Dec. 2012; Q.H. Ngo leg.; NQH1208; ZVNU • 3 ô ô; Pu Mat

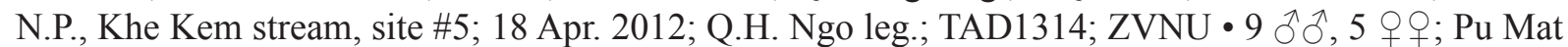
N.P., Chat stream, tributary of Choang stream; 1 Sep. 2020; A.D. Tran et al. leg.; TAD20-14; ZVNU •

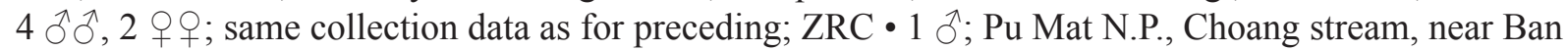
Bu; 1 Sep. 2020; A.D. Tran and T.C. Nguyen leg.; TAD20-17; NHMW. - Cao Bang Prov. • 1 đૈ; Hoa An, stream at Ban Say bridge; 17 Dec. 2013; A.D. Tran et al. leg.; TAD1372; ZVNU • 2 ô; Quang Uyen, road 207, Doc Lap commune, stream \#2; 18 Dec. 2013; A.D. Tran et al. leg.; TAD1374; ZVNU. - Phu Tho Prov. 1 đ̊; Xuan Son N.P., Ban Coi, Coi stream, site 3, by the road to Tan Son; 7 Jun. 2013; A.D. Tran et al. leg.; TAD1339; ZVNU・ $1 \partial^{\lambda}$; Xuan Son N.P., Xoan stream, near its confluence with Ha Bang stream; $2^{\circ} 5.303^{\prime} \mathrm{N}, 104^{\circ} 57.559^{\prime}$ E; 22 May 2015; T.S. Nguyen leg.; TS1507; ZVNU • 1 q ; Xuan Son N.P., Xoan stream, near its confluence with Ha Bang stream; 21 ${ }^{\circ} 5.303^{\prime}$ N, $104^{\circ} 57.559^{\prime}$ E; 6 May

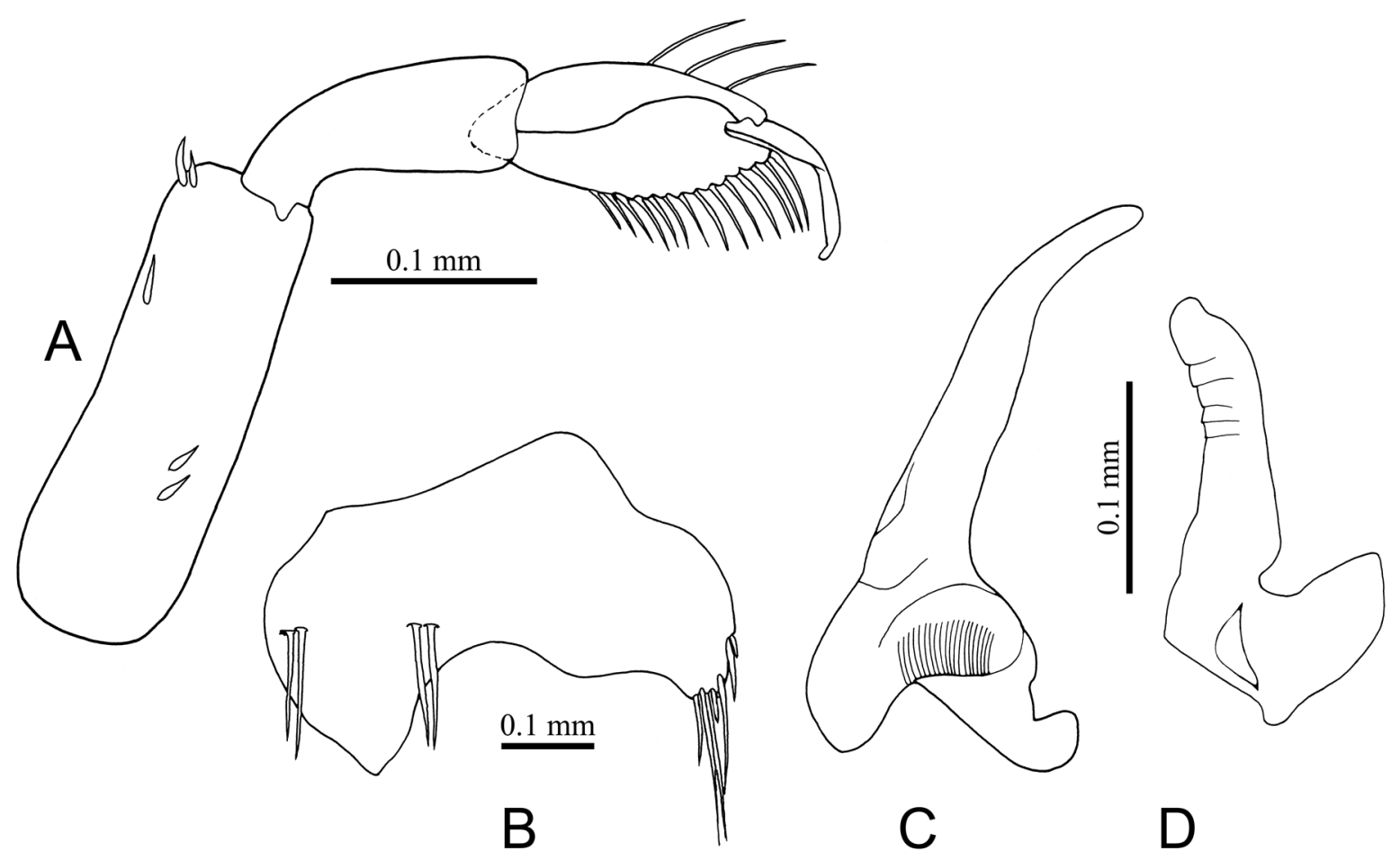

Fig. 24. Morphological features of Micronecta caperata sp. nov., §̂, paratype (ZVNU). A. Fore leg. B. sternite VII and median lobe. C. Right paramere. D. Left paramere. 
2016; T.S. Nguyen leg.; TS1607; ZVNU • 2 우; Xuan Son N.P., Ha Bang stream, near its confluence

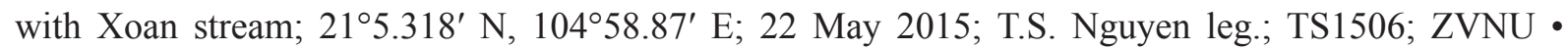
2 ô $^{\top}$; Xuan Son N.P., Coi stream, site 1, by the road to Tan Son; $21^{\circ} 09.204^{\prime}$ N, $104^{\circ} 56.927^{\prime}$ E; 8 May 2016; T.S. Nguyen leg.; TS1617; ZVNU • 2 우; Ha Bang stream, Ha Bang village area; $21^{\circ} 04.343^{\prime}$ N,

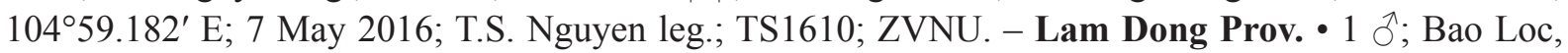
Damb'ri waterfall; 19 May 2003; A.D. Tran leg.; TAD0326; ZRC.

\section{Description}

Colour (Fig. 21E). Frons and vertex light yellowish, eyes reddish. Pronotum light brownish yellow. Hemelytron light yellow with scattered small light brownish spots. Membrane with similar colour to corium, but more translucent. Hindwings absent. Venter of thorax and abdomen, and legs pale yellow.

\section{Structural characteristics}

Hindwing-BRachypterous MaLes. Body length 1.57-1.88 (holotype: 1.75), width 0.81-1.03 (holotype: 1.00). Head width $0.6-0.72$ (holotype: 0.68 ). Head slightly wider than pronotum. Pronotum very short, mostly covered by head, about 7.2 times as wide as long $(0.65: 0.09)$. Synthlips about 1.35 times as wide as posterior width of an eye $(0.27: 0.20)$. Lengths of leg segments: fore leg: femur 0.24 , tibia 0.13 , pala 0.12 ; middle leg: femur 0.58 , tibia 0.2 , tarsus 0.29 , claw 0.2 ; hind leg: femur 0.42 , tibia 0.3 , tarsus I 0.3 , tarsus II 0.16, claw 0.05. Prestrigilar flap on segment V absent. Strigil present. Median lobe of sternite VII, and parameres as in diagnosis.

Hindwing-BRachypterous Females. Body length 1.56-1.9, width 0.86-1.03. Head width 0.6-0.74. Head slightly wider than pronotum. Pronotum very short, mostly covered by head, about 7 times as wide as long $(0.67: 0.10)$. Synthlips about 1.4 times as wide as posterior width of an eye $(0.29: 0.21)$. Lengths of leg segments: fore leg: femur 0.23 , tibiotarsus 0.2 ; middle leg: femur 0.59 , tibia 0.22 , tarsus 0.26 , claw 0.18 ; hind leg: femur 0.38 , tibia 0.3 , tarsus I 0.32 , tarsus II 0.17 , claw 0.05 .

\section{Distribution}

Vietnam: Cao Bang, Phu Tho, Nghe An, Lam Dong.

\section{Remarks}

Micronecta caperata sp. nov. has a mixed set of characteristics that does not allow its placement in any of the currently recognised subgenera of Micronecta. It is probably the only species of Micronecta that has no free lobe of tergite VIII. Its palar claw is very narrow and constricted pre-apically, which is similar to that of the subgenus Indonectella (resepresented by only one species, M. grisea). However, M. caperata sp. nov. has a strigil on segment VI, while the strigil is absent in Indonectella. The very short pronotum of this species is similar to that of M. johorensis Fernando, 1964, M. dentifera Nieser, 2002, and M. eucosmeta Hutchinson, 1940, but the parameres of M. caperata sp. nov. are completely different from those of these three species. The left paramere is broad and flat, which is a characteristic of the nominate subgenus Micronecta.

The outline of the right paramere of $M$. caperata sp. nov. is relatively similar to that of $M$. ceylonica Wrósblewski, 1968, but its left paramere is distinctly different from that of the latter. The left paramere, with wrinkles on distal part of shaft, is unique for M. caperata sp. nov.

Although this new species does not fit into any of the recognised subgenus, we refrain from establishing a new subgenus for a single species, until an intrageneric phylogenetic analysis of Micronecta becomes available. We thus temporarily do not assign this species to any of the current subgenera. 
Micronecta fugitans Breddin, 1905

Figs 21F, 25A-D

Micronecta fugitans Breddin, 1905a: 57 (type locality: Buitenzorg (Bogor), Indonesia).

Micronecta fugitans - Breddin 1905b: 157, fig. 20 (description). — Lundblad 1933b: 91-93, fig. 28, pl. XIX fig. 4 (redescription, record Java, Sumatra). - Wróblewski 1960: 304-306 (descriptive notes); 1968: 761-762, 775, figs 21-22 (descriptive notes, checklist). - Nieser 2002b: 267 (diagnosis, distribution).

\section{Diagnosis}

Body length 1.8-2.2. Pronotum longer than median head length. Dorsum generally light brown. Hemelytron with four broken longitudinal stripes, usually confluent posteriorly; embolium with three brown patches, usually fused into a longitudinal stripe (Fig. 21F).

Males: palar claw parallel sided, broadly curved, with a notch before apex; apex pointed (Fig. 25A). Median lobe of sternite VII triangular with rounded apex and one long setae. Free lobe widened distally, mesial angle obtuse, posterior margin convex, lateral angle nearly square, with ca 10 long setae on lateral side (Fig. 25B). Left paramere: shaft styliform, relatively stout, with distal part dark brown, apex blunt; basal lobe short and subovate (Fig. 25D). Right paramere: shaft with proximal part parallel sided and nearly straight, distal third evenly curved and tapering towards pointed apex (Fig. 25C).

\section{Material examined}

VIETNAM - Binh Thuan Prov. 14 $\widehat{\partial}, 11$ q $q$; Phan Thiet City, Huynh Thuc Khang street, Suoi Tien

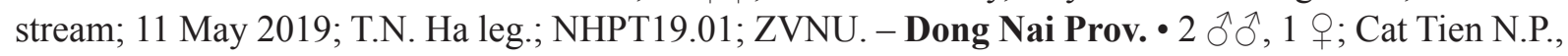
Dak-Lua stream (near Dak-Lua station); 9 Apr. 2010; A.D. Tran and T.D. Pham leg.; PTD1001; ZVNU.

\section{Distribution}

First records for Vietnam (Binh Thuan, Dong Nai). Other countries: Thailand, Peninsular Malaysia, Sumatra, Java, Sulawesi (Nieser 2002b).

\section{Remarks}

The illustration of the parameres of M. fugitans from Peninsular Malaysia by Wróblewski (1968) appears different from those of M. fugitans illustrated by Lundblad (1933b). Wróblewski (1968) also noted these differences. We think that the specimens studied by Wróblewski (1968) may belong to another species, not $M$. fugitans. Our samples from Vietnam perfectly match the illustration of $M$. fugitans by Lundblad (1933b). The dark distal part of the shaft of the left paramere, and the shape of the palar claw are important diagnostic characterstics for determining this species. Note that the shape of its right paramere is very similar to that of $M$. tarsalis, but this is the only similarity between the two species.

\section{Micronecta tarsalis Chen, 1960}

Figs $21 \mathrm{G}, 25 \mathrm{E}-\mathrm{H}$

Micronecta tarsalis Chen, 1960: 114, figs 1-5, 12-13 (type locality: Sri Lanka).

Micronecta tarsalis - Fernando 1964: 608-609, figs 28, 43 (diagnosis). - Wróblewski 1967: 231, 238-239 (record Vietnam); 1968: 776 (checklist); 1972a: 40, 50, figs 46, 53 (descriptive notes, key). — Nieser \& Chen 1999: 79, 81-82, fig. 16 (remarks, distribution). — Nieser 2000: 287, fig. 43 (key); 2002b: 266, 270, fig. 15 (key, diagnosis). 

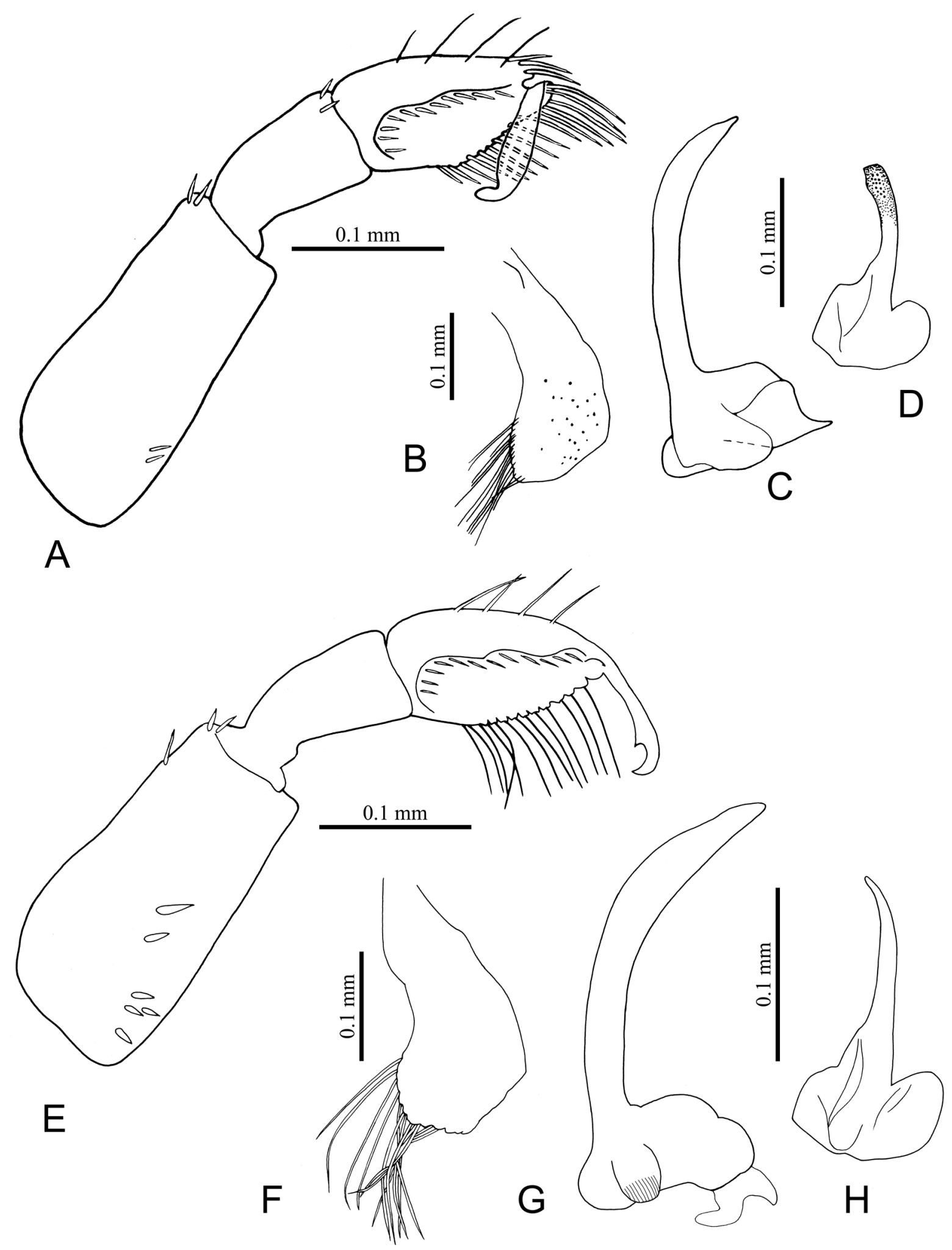

Fig. 25. Morphological features of species of Micronecta Kirkaldy, 1897, §ิð. A-D. M. fugitans Breddin, 1905 (ZVNU). E-H. M. tarsalis Chen, 1960 (ZVNU). A, E = fore leg; B, F = free lobe; C, G = right paramere; $\mathrm{D}, \mathrm{H}=$ left paramere. 


\section{Diagnosis}

Body length 1.8-2.1. Pronotum longer than median head length. Dorsum generally yellowish brown. Pronotum with an indistinct dark brown stripe. Hemelytron with four broken longitudinal brown stripes, sometimes indistinct; embolium with four dark spots (Fig. 21G).

Males: palar claw parallel sided, proximally straight, with a pointed pre-apical tooth, apex hooked (Fig. 25E). Median lobe of sternite VII with short, angular apex and two long setae. Free lobe: both angles angularly obtuse, posterior margin straight, lateral side strongly expanded, convex with ca 14 long setae (Fig. 25F). Left paramere: shaft slender, pre-apically curved and slightly twisted, apex narrowly rounded; basal lobe short and subovate (Fig. $25 \mathrm{H}$ ). Right paramere: shaft evenly curved, distal fourth tapering towards pointed apex (Fig. 25G).

\section{Material examined}

VIETNAM - Quang Nam Prov. 1 ô; Duy Xuyen District, My Son temple complex; $15^{\circ} 44.885^{\prime}$ N,

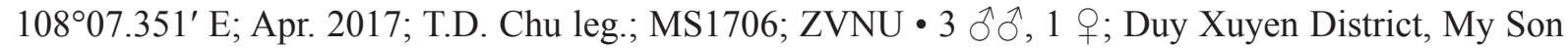
temple complex; $15^{\circ} 46.228^{\prime}$ N, 10807.155’ E; Apr. 2017; T.D. Chu leg.; MS1723; ZVNU.

\section{Distribution}

Vietnam: Ninh Binh, Ha Tinh (Wróblewski 1967); first record for Quang Nam. The record by Tran et al. (2011) from Hanoi was a misidentification, those specimens belong to M. jaczewskii. Other countries: Sri Lanka, southern India, Sulawesi (Nieser 2002b).

\section{Remarks}

Micronecta tarsalis is the only species in this genus that has the palar claw modified with a distinct apical hook and a pointed pre-apical tooth. This character state in this species does not match that in any known subgenus of Micronecta. The shape of the free lobe is also unique for this species. The left paramere of M. tarsalis is somewhat similar to that of M. polhemusi. The right paramere of this species is similar to that of $M$. fugitans.

Genus Synaptoneta Lundblad, 1933

Synaptonecta Lundblad 1933b: 109 (type species: Synaptonecta breddini Lundblad, 1933 by monotypy).

Synaptonecta - Wróblewski 1967: 2; 1968: 775 (recognised as subgenus of Micronecta); 1972a: 4-7 (re-instated generic rank; comparative notes).

\section{Remarks}

The genus Synaptoneta was established by Lundblad (1933b) to include a single species, Synaptonecta breddini. In the same publication, Lundblad (1933b) recognised Micronecta issa Distant, 1910 as a separate species, probably due to the fact that he studied specimens of different sexes and wing morphs, a macropterous female specimen as $M$. issa and a brachypterous male specimen (holotype) as S. breddini. This problem was pointed out by Hutchinson (1940) when he synonymised $S$. breddini with $M$. issa, thus also placing M. issa in Synaptonecta. Even after Hutchinson's (1940) revision, Synaptonecta was sometimes not recognised as a separate genus, e.g., by Leong (1966), Wróblewski $(1967,1968)$. Only after the careful comparative study by Wróblewski (1972a) has the generic rank of Synaptonecta been applied consistently. Also see Comparative notes under the genus Micronecta.

There are currently two species of Synaptonecta, the widespread S. issa (Distant, 1910) and S. capillata Wróblewski, 1972, which seems to be restricted to Sri Lanka and is only known from female specimens. 
Synaptonecta issa (Distant, 1910)

Figs $21 \mathrm{H}, 26$

Micronecta issa Distant, 1910: 350 (type locality: Calcutta (Kolkata), India).

Synaptonecta breddini Lundblad, 1933b: 109-111, fig. 36 (type locality: Java, Indonesia).

Micronecta issa - Hutchinson 1933: 398. — Lundblad 1933b: 100-101 (descriptive notes). — Leong 1966: 84, 88 (synonymy, notes, key).

Synaptonecta breddini - Hutchinson 1940: 398-399, figs 107-112 (symnonymised with Synaptonecta issa).

Micronecta (Synaptonecta) issa - Wróblewski 1967: 243-244 (descriptive notes).

Synaptonecta issa (Distant) - Wróblewski 1972b: 7-9, 48, figs 27, 31 (redescription). - Nieser \& Chen 1999: 78 (key, distribution). — Nieser 2002b: 265-266 (key, diagnosis). — Polhemus 2017: 127 (record Cambodia).

\section{Diagnosis}

Body length: brachypterous form 1.8-2.0, macropterous form 1.9-2.4. Brachypterous form with ovate body outline. Pronotum very short. Hemelytron covered with minute scales and dark spots; no suture between corium and clavus; embolium with seven dark patches distributed (Fig. 21H).

Males: Palar claw very narrowed, apex pointed (Fig. 26A). Strigil present. Free lobe very narrow. Median lobe of sternite VII narrow, sub-triangular, with six long setae (Fig. 26B). Left paramere: shaft constricted in the middle then widened apically (Fig. 26D). Right paramere broad, with small barbs on mesial side and apical part (Fig. 26C).

Other characteristics as in Remarks for the genus above.
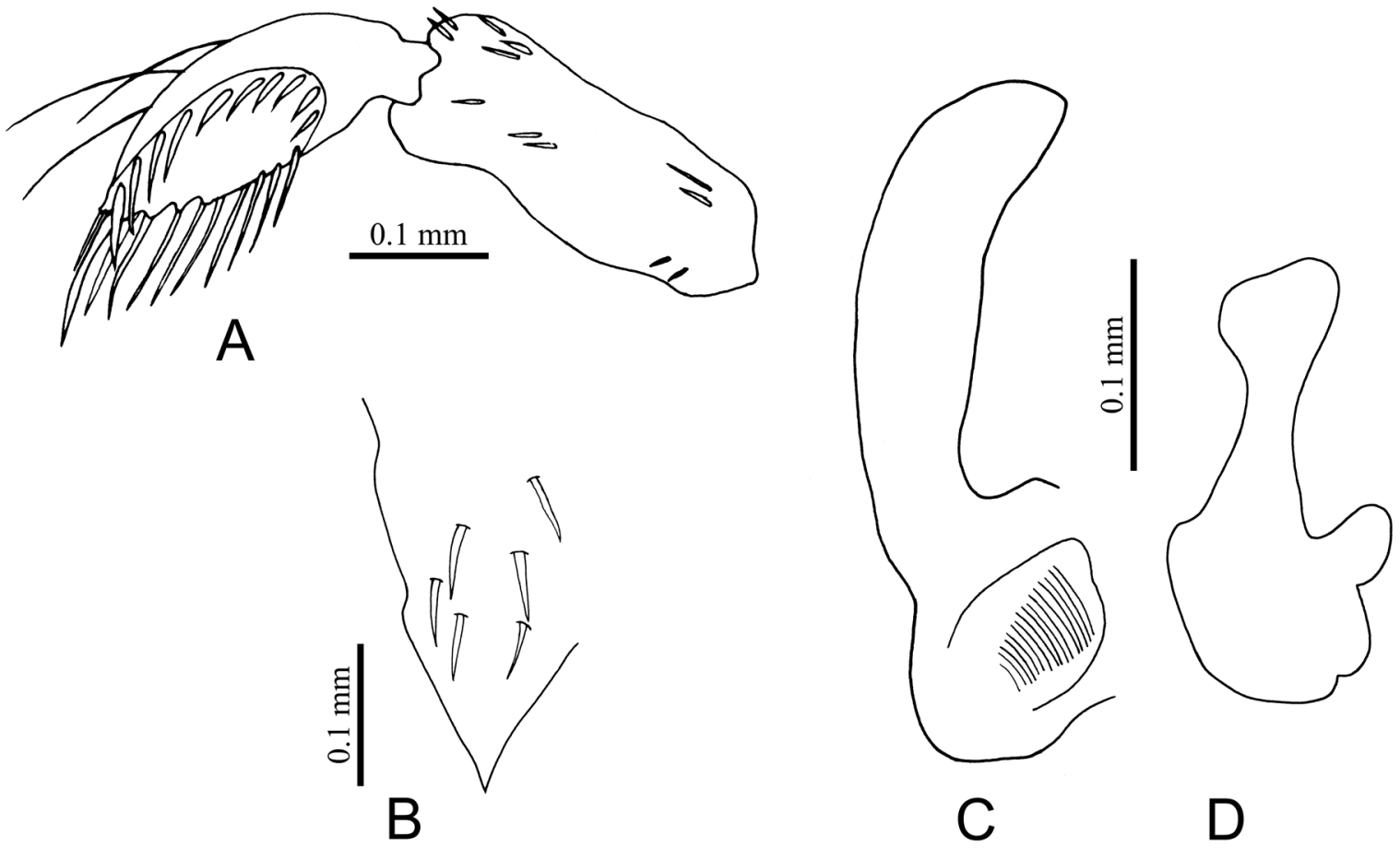

Fig. 26. Morphological features of Synaptonecta issa (Distant, 1910), §̋ (ZVNU). A. Fore leg. B. Median lobe of sternite VII. C. Right paramere. D. Left paramere. 


\section{Material examined}

VIETNAM - Dong Nai Prov. 1 ô, 1 q; Vinh Cuu, Ma Da, Bo Hao lotus lake; 18 Apr. 2009; A.D. Tran leg.; TAD0911; ZVNU • 1 §̇; Cat Tien N.P., Dak-Lua stream (near Dak-Lua station); 9 Apr. 2010; A.D. Tran and T.D. Pham leg.; PTD1001; ZVNU • 1 ô, 1 q; Vinh Cuu, Ma Da, Bo Hao lotus pond; 15 Apr. 2010; T.D. Pham leg.; PTD1010; ZVNU.

\section{Distribution}

Vietnam: Hanoi, Ninh Binh (Wróblewski 1967), first records for Dong Nai Other countries: widespread from South Asia (India, Sri Lanka) to Southeast Asia, including Peninsular Malaysia, Singapore, Java (Nieser 2002b), and Cambodia (Polhemus 2017).

\section{Remarks}

This species can be easily separated from other micronectids in Vietnam and surrounding regions by the characterstics in the Diagnosis above.

\section{Checklist of Vietnamese Micronectidae}

Micronecta Kirkaldy, 1897

M. (Basileonecta) scutellaris (Stål, 1858)

M. (Basileonecta) sedula Horváth, 1905

M. (Basileonecta) siva (Kirkaldy, 1897a)

M. (Ctenonecta) jaczewskii Wróblewski, 1962

M. (Dichaetonecta) decorata Lundblad, 1933

M. (Dichaetonecta) desertana Distant, 1920

M. (Dichaetonecta) johorensis Fernando, 1964

M. (Dichaetonecta) ludibunda Breddin, 1905

M. (Dichaetonecta) sahlbergi (Jakovlev, 1881)

M. (Indonectella) grisea (Fieber, 1844)

M. (Lundbladella) guttatostriata Lundblad, 1933

M. (Micronecta) drepani Nieser, 2000

M. (Micronecta) erythra Nieser, Chen \& Yang, 2005

M. (Micronecta) cultellata sp. nov.

M. (Micronecta) anatolica Lindberg, 1922

M. (Micronecta) arcuata sp. nov.

M. (Micronecta) fulvopicta sp. nov.

M. (Micronecta) acuminata sp. nov.

M. (Micronecta) vietnamica sp. nov.

M. (Micronecta) ornitheia Nieser, Chen \& Yang, 2005

M. (Micronecta) pocsi Wróblewski, 1967

M. (Micronecta) tuwanoni Nieser, Chen, Leksawasdi, Thanyakam \& Duangsupa, 2004

M. (Micronecta) clavata sp. nov.

M. (Micronecta) sinuata sp. nov.

M. (Micronecta) undulata sp. nov.

M. (Micronecta) nieseri sp. nov.

M. (Micronecta) pingae sp. nov.

M. (Pardanecta) haliploides Horváth, 1904

M. (Sigmonecta) quadristrigata Breddin, 1905

M. (Sigmonecta) altera Wróblewski, 1972 
M. (Unguinecta) khasiensis Hutchinson, 1940

M. (Unguinecta) melanochroa Nieser, Chen \& Yang, 2005

M. (Unguinecta) polhemusi Nieser, 2000

$M$. caperata sp. nov. [not assigned to any subgenus]

M. fugitans Breddin, 1905a [not assigned to any subgenus]

M. tarsalis Chen, 1960 [not assigned to any subgenus]

Synaptonecta Lundblad 1933

Synaptonecta issa (Distant, 1910)

\section{Discussion}

With regard to our knowledge of the Asian fauna of Micronectidae, recent regional taxonomic reviews have covered only some parts, e.g., southwestern China (Yunnan), Borneo, New Guinea (Nieser et al. 2005; Tinerella 2008; Chen et al. 2015). The fauna of Southeast Asian mainland remains poorly studied, and there is still a big gap in our knowledge. Nieser (2000) provided a key to 24 species of Micronectidae from Southeast Asia, but his study emphasised the Thai fauna. Subsequently, Nieser et al. (2004) described two more species of Micronecta from Thailand. Nieser (2002b) reviewed the Micronectidae from Peninsular Malaysia and Singapore, reporting 20 species, of which 19 belong to Micronecta. However, there is a lack of comprehensive data from the remaining Southeast Asian countries, e.g., Laos, Cambodia, and Myanmar. Very little is known about the micronectid fauna in these countries. Concerning the micronectid fauna of Vietnam, prior to the present study, 16 species, including 15 species of Micronecta and one of Synaptonecta, were reported, largely thanks to the works by Wróblewski from 1962 to 1972 . However, the studies by Wróblewski during that period were based on sporadic samples.

The present study has significantly raised the number of micronectid species known from Vietnam to 37, by reporting eleven species as new to science and nine as first records for the country, all of Micronecta. Thus, the results from the present study have partially filled in the gap of knowledge of the regional micronectid fauna. Although the discoveries of new species or new records are normal for insects, such a high number of new species found from Vietnam is rather surprising. This is probably due to the cumulative collections of Micronectidae made throughout Vietnam over the past 20 years. Micronectid species are known to have strong flying ability, meaning they possess a high dispersal capability, and many micronectid species are known to have wide ranges of distribution. Thus, the eleven new species reported here probably occur not only in Vietnam, but also in surrounding areas. The nine species reported as first records for Vietnam support this hypothesis. Therefore, the findings also suggest that a more comprehensive study based on extensive collections throughout the Southeast Asian mainland is required for a better understanding of the regional fauna and overall diversity of Micronectidae.

Another point to consider for future studies is the subgeneric classification of Micronecta, which remains a challenging task (see also Remarks section on Micronecta). This is due to the incomplete knowledge of the species diversity of Micronecta and the lack of intrageneric phylogenetic analyses. Recent regional taxonomic reviews of Micronectidae, and Micronecta in particular (Nieser 2000, 2002b; Nieser et al. 2005; Tinerella 2008, 2013; Chen et al. 2015), have made some contributions towards this task. Tinerella $(2008,2013)$ attempted to reconstruct phylogenetic relationships among Australasian micronectid genera based on morphological data, but the intrageneric relationship of Micronecta was not a focus in his studies. Therefore, a taxonomic review that covers major geographic areas of distribution of Micronecta and comprehensive phylogenetic analyses with an adequate taxon sampling and relevant morphological and DNA evidence are still much needed. 


\section{Acknowledgements}

We would like to express our sincere gratitude to Assoc. Prof. Nguyen Lai Thanh for granting access to high magnification microscopic equipment in his laboratory (at the Center for Life Science Research, VNU University of Science, Hanoi) and also for his enthusiastic help; and Dr Nguyen Thanh Son for guiding us through the techniques of photographing habitus of small-sized insects like Micronectidae. Our sincere thanks also extend to Assoc. Prof. Nguyen Van Vinh (VNU University of Science, Hanoi) for facilitating some fieldtrips and Dr Hwang Wei Song (Lee Kong Chian Natural History Museum, National University of Singapore) for the loan of micronectid specimens. This study is supported by the Vietnam Ministry of Science and Technology, under project number ĐTĐL.CN-65/19. The first author thanks the Nagao Natural Environment Foundation Scholarship Programmes for funding her MSc study and field trip to southern Vietnam in 2019. We are grateful to Dr Herbert Zettel (Natural History Museum Vienna, Austria) and an anonymous reviewer for their critical reviews of the manuscript.

\section{References}

Breddin G. 1905a. Übersicht der javanischen Micronecta-Arten (Rhynchota). Societas Entomologica 20: 57 .

Breddin G. 1905b. Rhynchota Heteroptera aus Java, gesammelt von Prof. K. Kraepelin 1904. Mitteilungen aus dem Naturhistorischen Museum in Hamburg 22: 111-159.

Brown E.S. 1951. Aquatic and semiaquatic insects. In: Expedition to S.W. Arabia, 1937-1938 1: 221273. British Museum (Natural History), London.

Buzzetti F.M., Nieser N. \& Damgaard J. 2006. Notes on water bugs from South East Asia and Australia (Heteroptera: Nepomorpha \& Gerromorpha). Atti dell'Accademia roveretana degli Agiati A 256, Ser. VIII, Vol. VI, B: 31-45.

Chen L.C. 1960. A study of the genus Micronecta of India, Japan, Taiwan, and adjacent regions (Heteroptera: Corixidae). Journal of the Kansas Entomological Society 33: 99-118.

Chen P.P., Nieser N. \& Zettel H. 2005. The Aquatic and Semi-aquatic Bugs (Heteroptera: Nepomorpha \& Gerromorpha) of Malesia. Fauna Malesia Handbook 5. Brill Publishing, Leiden, The Netherlands.

Chen P.P., Nieser N. \& Sangpradub N. 2006. Records of aquatic bugs (Heteroptera, Gerromorpha, Nepomorpha) mainly from Northeast Thailand, with descriptions of four new species. Denisia 19: 775794.

Chen P.P., Nieser N. \& Lapidin J. 2015. A review of Bornean Micronectidae (Hemiptera, Heteroptera, Nepomorpha) with descriptions of two new species from Sabah, Malaysia. ZooKeys 501: 27-62. https://doi.org/10.3897/zookeys.501.9416

Cheng L. (ed.) 1976. Marine Insects. Library - Scripps Digital Collection, UC San Diego. Available from https://escholarship.org/uc/item/1pm1485b [accessed 31 May 2021].

Distant W.L. 1906. The Fauna of British India, Rhynchota III. Taylor \& Francis, London.

Distant W.L. 1910. The Fauna of British India, Rhynchota V. Taylor \& Francis, London.

Distant W.L. 1920. The Rhynchota Heteroptera (Notonectidae and Corixidae) of Seistan. Records of the Indian Museum 18: 205-207.

Fernando C.H. 1964. A preliminary account of the water bugs of the family Corixidae in Ceylon. Journal of the Bombay Natural History Society 61: 603-613.

Fernando C.H. \& Cheng L. 1974. A preliminary study on the fauna and distribution of aquatic Hemiptera in Malaya and Singapore. Federation Museums Journal 19: 21-46. 
Fieber F.X. 1844. Monographie der Gattung Sigara. Entomologische Monographien, Leipzig: 11-15 (preprint of Abhandlungen der königlichen Böhmischen Gesellschaft der Wissenschaften (5) 3 (1845): 289-293. Available from https://www.biodiversitylibrary.org/page/45616748 [accessed 9 Jun. 2021].

Horváth G. 1899. Synopsis des Micronecta Paleaerctiques. Revue d'Entomologie 18: 101-104.

Horváth G. 1904. Hydrocorisae tres novae. Annales Historico-Naturales Musei Nationalis Hungarici 2: 594-595.

Horváth G. 1905. Hémiptères nouveaux de Japon. Annales Historico-Naturales Musei Nationalis Hungarici 3: 413-423.

Hutchinson G.E. 1933. A revision of the Distantian and Paivaian types of Notonectidae and Corixidae in the Indian Museum. Records of the Indian Museum 35: 393-408.

Hutchinson G.E. 1940. A revision of the Corixidae of India and adjacent regions. Transactions of the Connecticut Academy of Arts and Sciences 33: 399-476.

Jaczewski T. 1924. Revision of the Polish Corixidae. Annales Zoologici Musei Polonici Historiae Naturalis 3: 1-98.

Jakovlev V.E. 1881. Contributions to the Hemipteran fauna of Russia and adjacent regions. V-VIII. Bulletin de la Société impériale des Naturalistes de Moscou 56: 194-214. [Title in Russian, text in Russian and German.]

Jansson A. 1995. Family Corixidae Leach, 1815. Water boatmen. In: Aukema B. \& Rieger C. (eds) Catalogue of the Heteroptera of the Palearctic Region. Vol. 1: 26-56. Netherlands Entomological Society, Leiden.

Kirkaldy G.W. 1897a. Notes on the genus Sigara, Fabr. (Rhynchota). Entomologist 30: 238-240. https://doi.org/10.5962/bhl.part.7490

Kirkaldy G.W. 1897b. Synonymic notes on aquatic Rhynchota. Entomologist 30: 258-260. https://doi.org/10.5962/bhl.part.7490

Kirkaldy G.W. 1898. Notes on aquatic Rhynchota. No. 1. Entomologist 31: 2-4.

Kirkaldy G.W. 1905. Five new species of Micronecta Kirkaldy. Entomological News, and Proceedings of the Entomological Section of the Academy of Natural Sciences of Philadelphia 16: 260-263.

Kirkaldy G.W. 1908. A note on the species of Micronecta occurring in India and Ceylon (Hemiptera). Canadian Entomologist 40: 209. https://doi.org/10.4039/Ent40209-6

Leong C.Y. 1966. A taxonomic study of the Malayan Corixidae (Hemiptera- Heteroptera) with the description of Micronecta malayana sp. nov. Bulletin of the National Museum of Singapore 33: 83-90.

Lindberg H. 1922. Neu Micronecta-Arten (Hem. Het). Notulae Entomologicae 2: 114-117.

Lundblad O.M. 1933a. Some new or little-known Rhynchota from China. Annals and Magazine of Natural History, Series 1012 (70): 70, 449-464. https://doi.org/10.1080/00222933308673709

Lundblad O.M. 1933b. Zur Kenntnis der aquatilen und semi-aquatilen Hemipteren von Sumatra, Java und Bali. Archiv für Hydrobiologie 12, Supplement. Tropische Binnengewässer 4: 76-114.

Matsumura S. 1905. Die Wasser-Hemipteren Japans. Journal of the Sapporo Agricultural College 2 (2): 53-66.

Matsumura S. 1915. Uebersicht der Wasser-Hemipteren von Japan und Formosa. Entomological Magazine, Kyoto 1: 103-119.

Nieser N. 2000. Three new species of Micronecta from Thailand with a key to SE Asian species (Heteroptera: Corixidae). Journal of the New York Entomological Society 107 (1999): 277-288. 
Nieser N. 2002a. Four new species of Micronecta (Insecta: Heteroptera: Micronectidae) from the Malay Peninsula. The Raffles Bulletin of Zoology 50 (1): 9-16.

Nieser N. 2002b. Guide to aquatic Heteroptera of Singapore and Peninsular Malaysia IV. Corixoidea. The Raffles Bulletin of Zoology 50 (1): 263-274.

Nieser N. \& Chen P.P. 1999. Sixteen new species of Nepomorpha (Heteroptera) mainly from Sulawesi (Indonesia). Tijdschrift voor Entomologie 142: 77-123. https://doi.org/10.1163/22119434-99900023

Nieser N. \& Chen P.P. 2006. Two new genera and a new subfamily of Micronectidae (Heteroptera, Nepomorpha) from Brazil. Denisia 19: 523-534.

Nieser N., Chen P.P., Leksawasdi P., Thanyakam A. \& Duagsupa C. 2004. Five new species of Nepomorpha (Heteroptera) from Southeast Asia. Tijdschrift voor Entomologie 147: 29-40.

https://doi.org/10.1163/22119434-900000134

Nieser N., Chen P.P. \& Yang C.M. 2005. A new subgenus and six new species of Nepomorpha (Insecta: Heteroptera) from Yunnan, China. The Raffles Bulletin of Zoology 53 (2): 189-209.

Poisson R. 1938. Les Hémiptères aquatiques Sandaliorhyncha de la faune française. II Micronectinae. Étude systématique et biologique; principales espèces paléarctiques. Annales de la Société entomologique de France 107: 81-120.

Polhemus D.A. 2017. An initial survey of aquatic and semi-aquatic Heteroptera (Insecta) from the Cardamom Mountains and adjacent uplands of southwestern Cambodia, with descriptions of four new species. Tijdschrift voor Entomologie 160: 89-138. https://doi.org/10.1163/22119434-00002068

Popov Y.A. 2014. 3.2. Heteroptera. In: Ponomarenko A.G., Aristov D.S., Bashkuev A.S., Gubin Y.M., Khramov A.V., Lukashevich E.D., Popov Y.A., Pritykina L.N., Sinitsa S.M., Sinitshenkova N.D., Sukatsheva I.D., Vassilenko D.V. \& Yan E.V. (eds) Upper Jurassic Lagerstätte Shar Teg, southwestern Mongolia. Paleontological Journal 48 (14): 1573-1682. https://doi.org/10.1134/S0031030114140160

Stål C. 1858. Orthoptera och Hemiptera från södra-Afrika. Öfversigt af Kunglia Vetenskapsakademiens Förhandlingar 15 (6): 307-320.

Štys P. \& Jansson A. 1988. Check-list of recent family group and genus-group names of Nepomorpha (Heteroptera) of the world. Acta entomologica Fennica 50: 1-44.

Tinerella P.P. 2008. Taxonomic revision and systematics of New Guinea and Oceania pygmy water boatmen (Hemiptera: Heteroptera: Corixoidea: Micronectidae). Zootaxa 1797: 1-66.

https://doi.org/10.11646/zootaxa.1797.1.1

Tinerella P.P. 2013. Taxonomic revision and systematics of continental Australian pygmy water boatmen (Hemiptera: Heteroptera: Corixoidea: Micronectidae). Zootaxa 3623: 1-121.

https://doi.org/10.11646/zootaxa.3623.1.1

Tran A.D., Pham T.M., Nguyen X.Q., Ngo X.N., Nguyen Q.H. 2011. Notes on the water bugs (Hemiptera: Heteroptera) in urban areas of Hanoi. VNU Journal of Science: Natural Sciences and Technology 27 (1): $9-13$.

Tran A.D., Phan Q.L. \& Nguyen X.Q. 2014. Preliminary data on water bugs (Insecta: Hemiptera) in Xuân Sơn National Park, Phú Thọ Province. VNU Journal of Science: Natural Sciences and Technology 30 (3S): 21-27.

Wang Y., Moreira F.F.F., Rédei D., Chen P.P., Kuechler S.M., Luo J., Men Y., Wu H. \& Xie Q. 2020. Diversification of true water bugs revealed by transcriptome-based phylogenomics. Systematic Entomology 46 (2): 339-356. https://doi.org/10.1111/syen.12465 
Wróblewski A. 1960. Notes on some Asiatic species of the genus Micronecta Kirk. Heteroptera: Corixidae). Annales Zoologici 18: 301-331.

Wróblewski A. 1962. Notes on Micronectinae from Viêt-nam (Heteroptera, Corixidae). Bulletin de l'Académie polonaise des Sciences 10 (5) 175-180.

Wróblewski A. 1963. Notes on Micronectinae from the U.S.S.R. (Heteroptera, Corixidae). Annales Zoologici Warszawa 21: 463-484.

Wróblewski A. 1964. Notes on Micronectinae from Ceylon (Heteroptera, Corixidae). Bulletin de l'Académie polonaise des Sciences 12: 165-170.

Wróblewski A. 1967. Further notes on Micronectinae from Viêt-nam (Heteroptera, Corixidae). Polskie pismo entomologiczne 37: 229-251.

Wróblewski A. 1968. Notes on Oriental Micronectinae. Polskie Pismo Entomologiczne 30 (XII): 753779 .

Wróblewski A. 1970. Notes on Australian Micronectinae (Heteroptera: Corixidae). Bulletin de l'Académie polonaise des Sciences 40: 681-703.

Wróblewski A. 1972a. Further notes on Micronectinae from Ceylon (Heteroptera, Corixidae). Bulletin de l'Académie polonaise des Sciences 42: 3-55.

Wróblewski A. 1972b. Supplementary notes on Australian Micronectinae (Heteroptera, Corixidae). Bulletin de l'Académie polonaise des Sciences 42: 517-526.

Yang C.T. 1967. A new and an unrecorded species of Micronecta with a key to Taiwanese species (Hemiptera, Corixidae). Bulletin of the Institute of Zoology, Academia Sinica 6: 43-46.

Ye Z., Damgaard J., Yang H., Hebsgaard M.B., Weir T. \& Bu W. 2019. Phylogeny and diversification of the true water bugs (Insecta: Hemiptera: Heteroptera: Nepomorpha). Cladisitics 36 (1): 72-87. https://doi.org/10.1111/cla.12383

Zettel H., Sophany P., Sokha K. \& Freitag H. 2017. Checklist of the aquatic Hemiptera (Heteroptera: Gerromorpha and Nepomorpha) of Cambodia, with descriptions of new species of Microvelia Westwood, 1834 and Ranatra Fabricius, 1790. Aquatic Insects 38 (1-2): 21-48.

https://doi.org/10.1080/01650424.2017.1332372

Manuscript received: 22 December 2020

Manuscript accepted: 13 April 2021

Published on: 24 June 2021

Topic editor: Nesrine Akkari

Desk editor: Kristiaan Hoedemakers

Printed versions of all papers are also deposited in the libraries of the institutes that are members of the EJT consortium: Muséum national d'histoire naturelle, Paris, France; Meise Botanic Garden, Belgium; Royal Museum for Central Africa, Tervuren, Belgium; Royal Belgian Institute of Natural Sciences, Brussels, Belgium; Natural History Museum of Denmark, Copenhagen, Denmark; Naturalis Biodiversity Center, Leiden, the Netherlands; Museo Nacional de Ciencias Naturales-CSIC, Madrid, Spain; Real Jardín Botánico de Madrid CSIC, Spain; Zoological Research Museum Alexander Koenig, Bonn, Germany; National Museum, Prague, Czech Republic. 